\title{
Understanding the effect of canopy design on crop evapotranspiration for Scilate apple and Syrah grape in Hawke's Bay, New Zealand
}

\author{
Michelle Clare Schurmann
}

2020

A thesis submitted to Victoria University of Wellington in partial fulfilment of requirements for the degree of Master of Science

School of Geography, Environment and Earth Sciences Victoria University of Wellington 



\section{Abstract}

Efficient and effective irrigation scheduling is strongly dependent upon accurate estimation of crop evapotranspiration (ETc), this requires understanding and incorporation of the effects that different soil conditions, orchard designs and trellis systems have on ETc. Orchard designs and trellis systems are designed to harness $\geq 85 \%$ light interception when fully grown, which is expected to lead to high yield and fruit quality. To investigate the effectiveness of such designs, an experiment in Hawke's Bay, New Zealand, was carried out. Scilate apple trees of fifth-leaf vee and tall spindle, fourth-leaf planar, and Syrah grapes that were seven-years-old grown on silt-loam soil, and fourteen-years-old grown on stoney soil were used to investigate how light interception (LI), leaf area index (LAI), yield and fruit quality differed amoung these orchard designs, and ultimately affected evapotranspiration during the $2019 / 20$ season.

Frequency domain reflectometers measuring soil water content (SWC), and tensiometers (matric potential) were used to continuously measure the soil water balance and estimate crop evapotranspiration. Light interception (LI-COR, Lincoln, Nebraska, USA) and manual LAI readings were taken over four periods from budburst to full canopy. Fresh weight yield was extrapolated from a sample per tree/vine $(n=30)$, maturity was measured by starch pattern index in apples, and quality was estimated from dry matter content (DMC\%), and soluble solids content. Hourly ETo was computed using the FAO standardised PenmanMonteith equation, and data collected by an automated on-site weather station. ETc was estimated for 'well-watered' conditions using extrapolated daily light interception measurements, and compared with measured changes in SWC.

The apple trellis systems showed variation in LI (vee: $56 \%$, tall spindle: $50 \%$, planar: $36 \%$ ), and LAI (vee: 3.2, tall spindle: 1.6, planar: 1.3). The vee system had the largest fresh weight yield in tonnes per hectare (vee: 141, tall spindle: 108, planar: 54). The different aged vines and soil type also showed variability in LI (young Syrah: 36\%, old Syrah: 22\%) and LAl (young Syrah: 1.3, old Syrah: $0.7)$. This variability was particularly obvious in the SWC results, where tall spindle showed the highest ETC and change in SWC, whereas planar and vee 
the lowest which was attributed to an 'over-irrigated' environment causing waterlogging, and ultimately decreasing transpiration, despite vee having the highest LI and LAI. Differences in orchard design and trellis system caused changes in ETc and soil water content which can be illustrated by light interception and LAI. However, this thesis demonstrated that soil and groundwater heterogeneity can cause significant variability in results which needs to be accounted for when modelling, irrigating and growing. Future work suggestions are the inclusion of transpiration measurements using sap flow meters to differentiate drainage and groundwater effects from ETc, and to further clarify when the trees/vines are being over-watered.

Keywords: evapotranspiration, canopy systems, light interception, leaf area, Malus $\times$ domestica Borkh., Vitis vinifera L. 


\section{Acknowledgements}

The completion of this thesis would not have been possible without the support and encouragement from the many friends, colleagues, and family throughout the course of my studies.

Firstly, I would like to thank my supervisors Dr. Bethanna Jackson (Victoria University of Wellington) and Dr. Ken Breen (Plant and Food Research Ltd) for your wealth of scientific knowledge, guidance, and nurturing support in both my studies and career. Thank you.

Thank you to those that helped with the technical side of the experiment. The team at Plant and Food Research, Hawke's Bay: Murrary Oliver and Jess Byrne, and Dez Tessler (Victoria University of Wellington).

A big thank you to the orchard management team at T\&G Global, Hawke's Bay, Shane Lagas and Andy Jones, and at Villa Maria Te Awa, Paul Robinson for catering to my requirements throughout the season. To Gary Wellwood for allowing me carry out research at T\&G Global at their trial block, and to Chris Fitzgerald (T\&G Global) for answering all of my questions regarding the insand-outs of the site. Jonathan Hamlet (Villa Maria) for helping with vine selections and project set-up.

To my colleagues at Plant and Food Research Clyde, thank you for your encouragement, help, and laughter throughout. To my Hawke's Bay family - the Pryce's, thank you for a taking me in during my visits.

Finally, to those close, Claudia, Sky, and Michael, thank you for your ongoing support and love. And to my family, thank you for being the motivation and enthusiasm I always needed. 


\section{Contents}

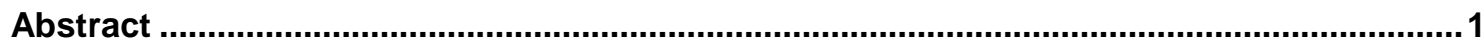

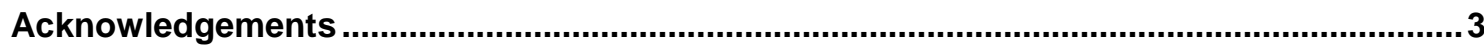

List of Figures

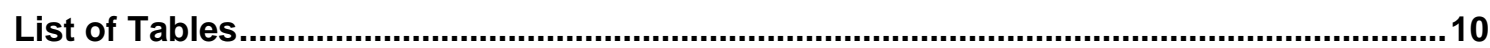

1 Chapter 1: Introducing crop evapotranspiration and Hawke's Bay region ..............11

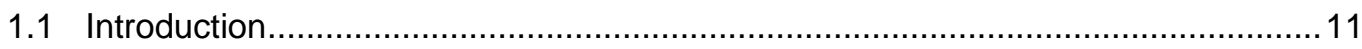

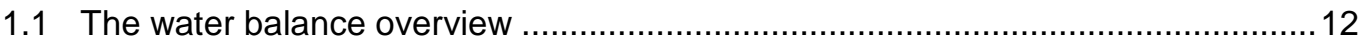

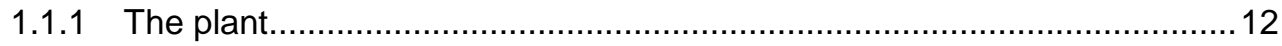

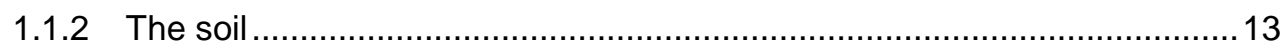

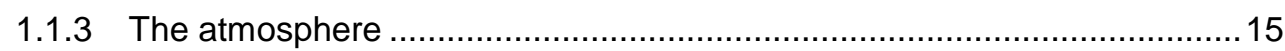

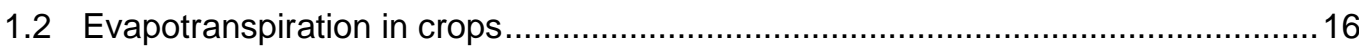

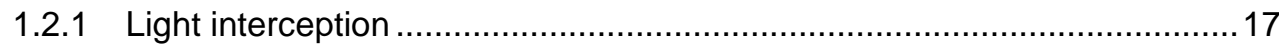

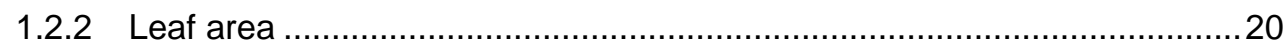

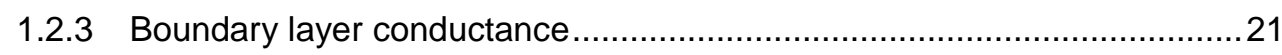

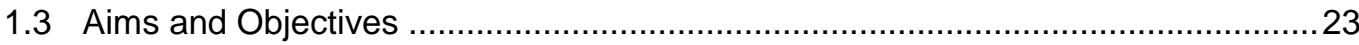

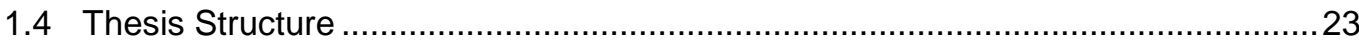

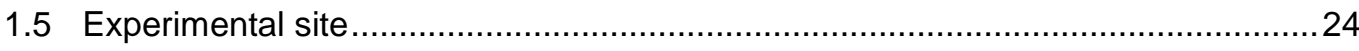

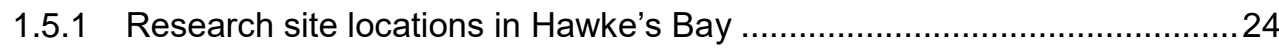

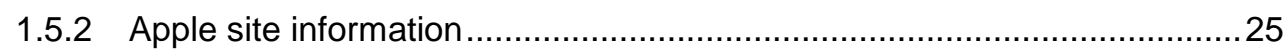

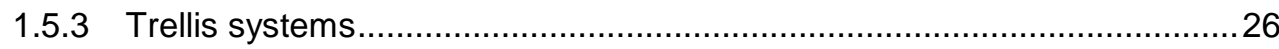

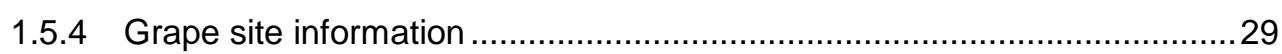

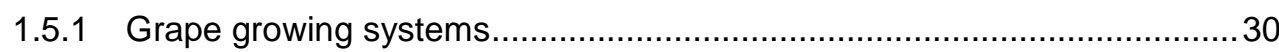

2 Chapter 2: Dynamics of the soil water balance and crop evapotranspiration........34

2.1 Quantification of soil water content and soil matric potential .................................34

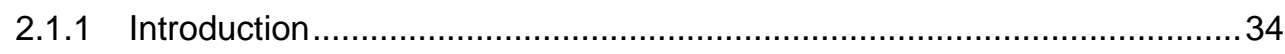

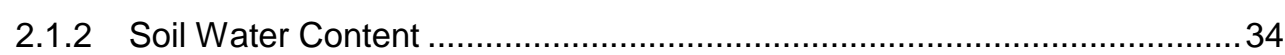

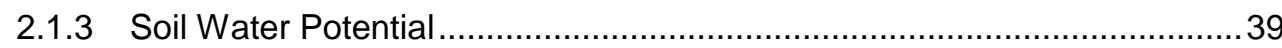

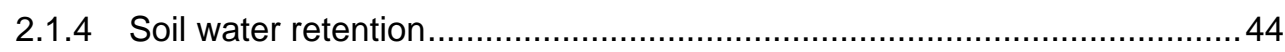

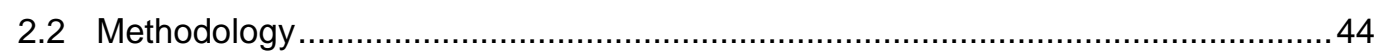

2.2.1 Installation of frequency domain probes ................................................. 44

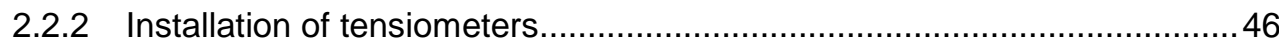

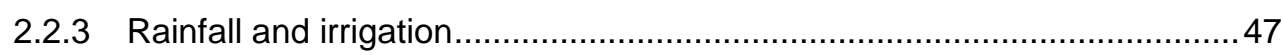

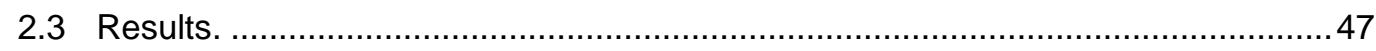

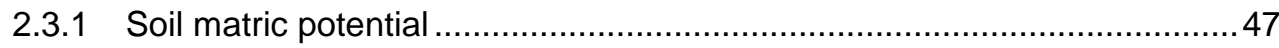


2.3.2 Volumetric soil moisture content..................................................... 52

2.3.3 Changes in soil water content............................................................ 55

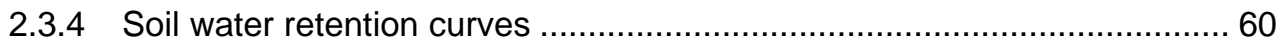

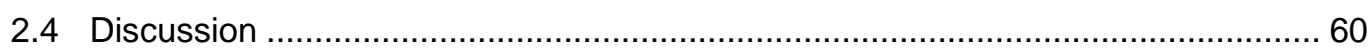

2.4.1 Effects of trellis system and vine age-soil type on soil water balance.......60 60

3 Chapter 3: Understanding the effect of canopy architecture and orchard designs

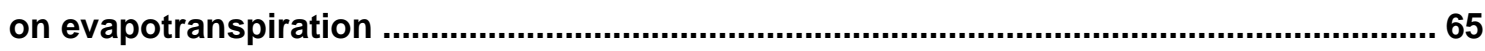

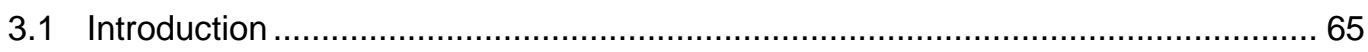

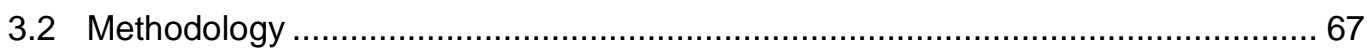

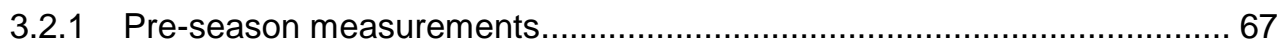

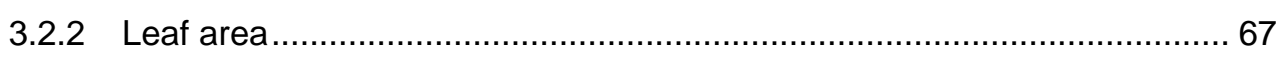

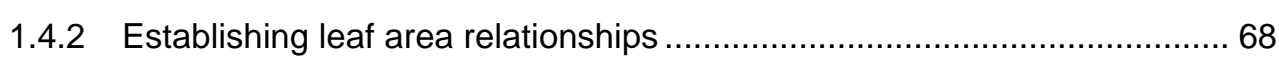

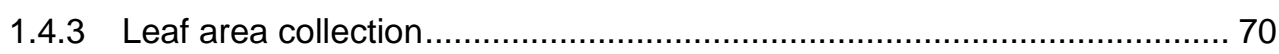

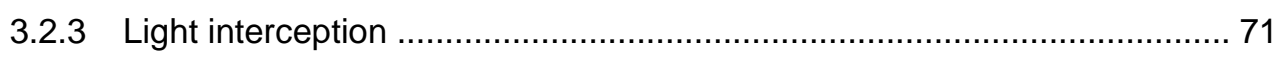

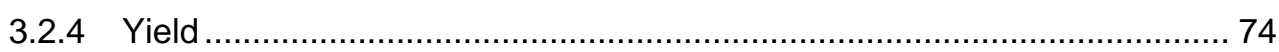

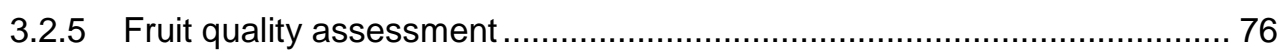

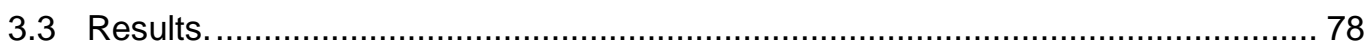

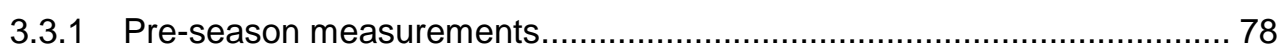

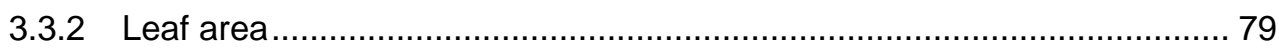

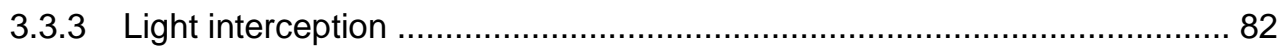

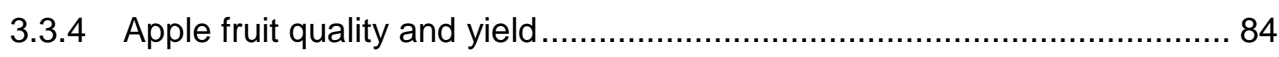

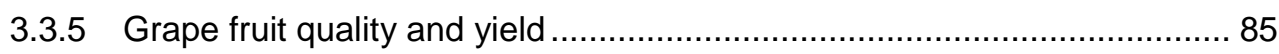

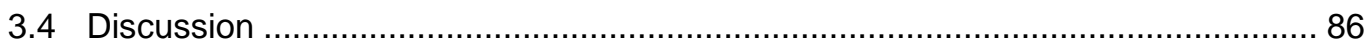

3.4.1 Effect of orchard design and trellis systems on the light environment and

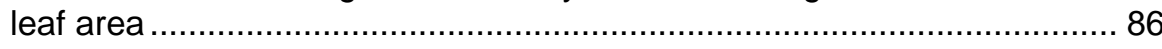

3.4.2 Understanding changes in soil water content in relation to light interception

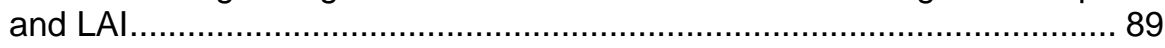

3.4.3 Conclusion and future research suggestions ..................................... 90

4 Chapter 4: Water balance modelling and estimation of crop evapotranspiration . 92

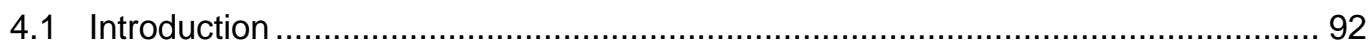

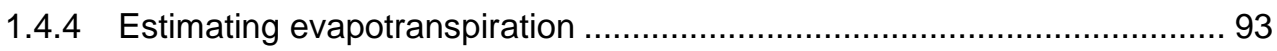

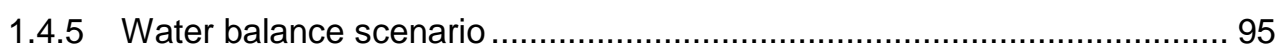

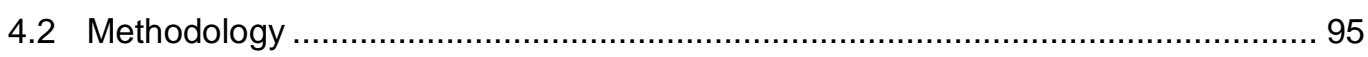

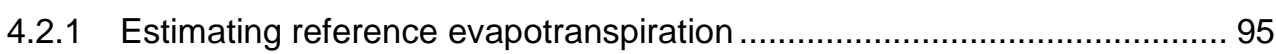

4.2.2 Estimating crop evapotranspiration .................................................... 96

4.2.3 Methods for a simple water balance ................................................ 97

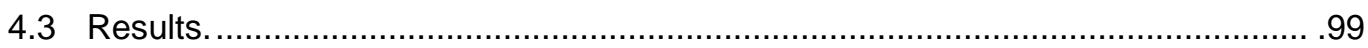

4.3.1 Estimated crop evapotranspiration (ETc) adjusted by light interception

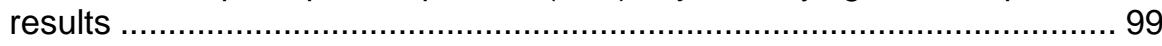

4.3.2 Cumulative seasonal relationships ................................................ 100 
4.3.3 Estimated drainage in a well-watered scenario. 100

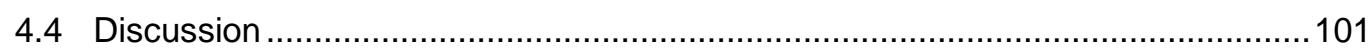

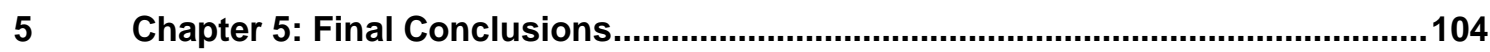

5.1 Future directions and recommendations.......................................................107

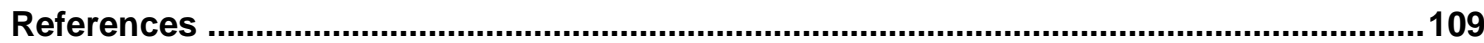




\section{List of Figures}

Figure 1: Illustration showing the difference between soil saturation, field capacity and the permanent wilting point (Derived from Sumon Datta, Saleh Taghvaeian, 2017)... 15 Figure 2: Map showing both apple and grape site locations within the Hastings region.

Figure 3: identifying the three different Scilate apple trellis sites at Evenden orchard; vee, planar and tall spindle. All planted within the same block.

Figure 4: Images showing the vee trellis system at Evenden orchard. Each individual tree is growing at an alternating angle, spaced 0.5 meters apart.

Figure 5: Image showing the planar trellis system, where there is two horizontal cordons with six uprights each side.

Figure 6: Photos taken from the Evenden orchard on 18th October after a large rainfall event which resulted in a large amount of water logging. Photos taken at the vee system plot.

Figure 7: Map identifying the two Syrah grape plots at Te Awa vineyard; young Syrah and old Syrah.

Figure 8: Diagram showing the Vertical Shoot Positioning system at both a side view (left) and an end view (right). Derived from Dami et al. (2005).

Figure 9: Images showing the VSP system pre-winter prune with all the vertically trained shoots, and post-winter prune where only the two cordon vines are left.

Figure 10: Diagram illustrating the differences in soil matric potential between the atmosphere, tree and soil. Image derived from: www.metergroup.com

Figure 11: Soil column with the water table at $80 \mathrm{~cm}$ depth in the profile. The diagram illustrates the relationships between the soil potential components. Modified from Tindall et al. (1998).

Figure 12: Photos showing the soil water probe position in grapes plot (left), and tensiometer in apples plot (right).

Figure 13: Suction matric potential recorded with tensiometers at $10 \mathrm{~cm}$ soil depth (top figure), and $30 \mathrm{~cm}$ (bottom figure) in three 'Scilate' apple canopy types over the 2019/2020 growing season. Note the difference in y-axis scale for the $10 \mathrm{~cm}$ and $30 \mathrm{~cm}$ tensiometer

Figure 14: Diurnal trends of matric potential at both $10 \mathrm{~cm}$ depth (top figure), and $30 \mathrm{~cm}$ depth (bottom figure) for three Scilate apple trellis systems for a two day period.

Vertical black-dashed line indicate the rainfall event, and the grey vertical-dashed line in.

Figure 15: Tensiometer results for the young Syrah site showing changes in the matric potential at $10 \mathrm{~cm}$ depth and $30 \mathrm{~cm}$ depth. Rainfall event illustrated by the grey line.... 52 
Figure 16: Volumetric soil water content $(\mathrm{cm})$ recorded using frequency domain reflectometry in the top $30 \mathrm{~cm}$ soil depth in three Scilate' apple canopy types over the 2019/2020 growing season. Each trace represents the mean of three FDR sensors. .53 Figure 17: Average soil water content for the young Syrah plot for the month of October.

Figure 18: Temporal changes in soil water content of the old Syrah grape over the 2019/20 season. Rainfall showed by grey lines

Figure 19: Changes in soil water content over time for all three apple trellis system sites.

Figure 20: Changes in soil water content for all three apple trellis systems. Rainfall and irrigation shown on top axis. 56

Figure 21: Changes in soil water content for the two grape sites over the season. The young Syrah results are only for October due to instrument recording problems.

Figure 22: Cumulative change in soil water content ( $L$ per tree) for the three apple trellis systems. Irrigation and rainfall shown on the top axis.

Figure 23: Cumulative changes in SWC for both grape sites for October, when the young Syrah instrument was working. 59

Figure 24: Cumulative changes in soil water content for both grape plots over the season. Note the young Syrah ends at the start of November due to instrument recording issues.

Figure 25: Annotated images of an Scilate apple leaf (left) and Syrah grape leaf (right) showing the positions at which leaf length and leaf width were measured for regression against leaf area. 69

Figure 26: Quantm sensors were positioned at equal spacings on a horizontal bar situated below the canopy on a trolley. Above-canopy (incoming) PAR was recorded by a sensor placed on the top of a pole attached to the trolley (right). .72

Figure 27: Image showing the monitored centre leader tree (orange), and the arrow represents the area measured by the light meter during one reading.

Figure 28: Image showing starch pattern index stages SPI 1,4 and 7 and the iodine patterns associated. Where SPI shows immaturity (no starch clearance) compared with SPI 7 (full clearance) which is tree ripe.

Figure 29: Mean leaf area per tree for three Scilate apple trellis systems over the 201920 growing season. Error bars represent standard errors ( $n=3$, in Vee $n=6)$. 80

Figure 30: Mean Leaf Area Index for three Scilate apple trellis systems over the 201920 growing season. Error bars represent standard errors $(n=3$, in Vee $n=6)$. 80

Figure 31: Mean leaf area per vine for two Syrah vineyards of different ages over the 2019-20 growing season. Error bars represent standard errors $(n=3)$. 
Figure 32: Mean leaf area index for Syrah grape vines of two ages over the 2019/2020 season. Error bars represent standard errors $(n=3)$.

Figure 33; Mean whole-canopy light interception of three Scilate apple trellis systems through the 2019-20 growing season. Figure also shows 'Royal Gala' fourth leaf planar system light interception from Breen et al. (2002) illustrating the potential light interception that the planar system could reach if it was the same age as the Vee and Tall Spindle systems (fourth leaf). Error bars represent standard errors ( $n=3$, in vee $\mathrm{n}=6)$

Figure 34; Mean Whole-canopy Light interception in Syrah grape vines of two ages in the 2019-20 season. Error bars represent standard errors $(n=3)$

Figure 35; Effective area of shade (EAS) adjusted evapotranspiration for the three apple trellis systems over the season.

Figure 36; Accumulative crop evapotranspiration for the 2019/2020 season for the three different apple trellis systems 100

Figure 37: Estimated drainage for three different apple trellis systems based on a water balance scenario 101 


\section{List of Tables}

Table 1: Orchard design characteristics between the three different trellis systems. ... 26

Table 2; Orchard design characteristics of the two Syrah grape plots. 30

Table 3; R-squared values for relationships between leaf area and leaf width, length or length $\mathrm{x}$ width calculated for Scilate apple and Syrah grape 70

Table 4; R-squared values for leaf area relationships between leaf area and leaf width or length for the three different leaf types in Scilate apple trees 70 Table 5; Linear regression equations for lines of best fit for Scilate apple and Syrah leaves to allow calculation of leaf area $(y)$ from leaf length $(x)$ in apple and leaf width $(x)$ in grape. 70

Table 6: Numbers of fruit per tree recorded pre-harvest in February 2020 for all apple trellis systems.

Table 7; Showing mean TCA at the start of the season, mean TCA at the end, and the change in TCA for the $2019 / 2020$ season. Standard error \pm are shown in brackets .... 79 Table 8; Mean fruit yield and weight of Scilate trees grown on three trellis systems during the 2019-20 season. Standard errors for each variable \pm are shown in brackets $(n=3)$.

Table 9; Mean starch pattern index, dry matter content and dry matter yield of Scilate trees grown on three trellis systems during the 2019-20 season. Standard errors for each variable \pm are shown in brackets $(n=3)$

Table 10; Mean fruit yield and fruit quality characteristics of Syrah grape vines of two ages at harvest at the end of the $2019-20$ season. Standard errors for each variable \pm are shown in brackets $(n=3)$.

Table 11; Regression relationships to calculate daily effective area of shade (y) from light interception $(\mathrm{x})$ measurements taken throughout the season. The regression equation and $r$-squared values are shown

Table 12; Showing the number of emitters per plot, and emitter rates for the three different apple trellis systems. 


\section{Chapter 1: Introducing crop evapotranspiration and Hawke's Bay region}

\subsection{Introduction}

Limited water resources and shifting climates are challenging modern fruit production. More sustainably managing the demand and usage of water resources is the way forward for the future. Competition between agricultural expansion and urban expansion for an environment with a finite water resource brings about changes in the legal framework around which water may be used, for example TANK (Hawke's Bay Regional Council, 2019). TANK is a policy plan change proposed by the Hawke's Bay Regional Council to ensure that environmental resources are used sustainably by setting rules such as establishing limits for water extraction (Hawke's Bay Regional Council, 2019).

By 2050, the global population is predicted to increase to more than nine billion people (Aitken, 2020; Vollset et al. 2020). The horticultural produce demand to feed this predicted peak population will be almost double today's, in a world of increasing environmental stress and decreasing land availability (Aitken 2020). In New Zealand, horticulture made up more than $10 \%$ of New Zealand's total merchandise exports and contributed NZ $\$ 6.2$ billion to the economy annually in 2019 (Stats NZ 2020). The produce demand, coupled with increasing uncertainty about future availability of water as a result of climate change is a pressing concern. Changes in rainfall and evaporation patterns, as well as increased seasonal demand of water are already causing groundwater depletion, drought, and water restrictions in the Hawke's Bay region (Rakowski and Knowling 2018). These problems are likely to be exacerbated in the future (Rakowski and Knowling 2018). To respond to these pressures, efficient irrigation and innovative orchard designs are required, particularly in fruit crops where the correct water supply is crucial for maintaining fruit quality and yield (Green et al., 2006). In many cases, improving crop water use efficiency also has indirect benefits such as restoration of connected ecosystem services such as water quality, soil health and agricultural production, among others.

Irrigation plays a significant role in global horticultural production. In droughtprone regions such as Hawke's Bay (New Zealand), irrigation can be a 
significant factor in depletion of natural water resources. Harper (2015) has shown that in some areas of the Heretaunga aquifer (Hawke's Bays main aquifer system), the maximum groundwater decline is approximately -0.1 meters per year, which equates to a decline of 2 meters every 20 years. This is the result of groundwater pumping for domestic, industrial, and irrigation use (Harper 2015). Hence the urgency for more efficient, and sustainable water use practices.

Models are an increasingly crucial tool in both short term and long term planning for management of irrigation. There are numerous models designed to consider the impacts of land use and water use on various ecosystem services such as horticultural production. However, the models do not currently consider how canopy morphology and differences in orchard/vineyard layout affect crop water use, and how this, among other factors affects the amount of irrigation water needed to be applied to meet demand. To calculate the crop water demand, an understanding of the whole soil-plant-atmospheric continuum is needed, which can be described as the crop water balance.

\subsection{The water balance overview}

A crop water balance can be considered over three main domains that influence the water flux: the plant, the soil, and the atmosphere.

\subsubsection{The plant}

Plants depend on water. Approximately $95 \%$ of the water plants take up is lost to the atmosphere via transpiration, and only $5 \%$ is used within the plant for structure and function. However, this transpiration stream is critical for regulation of plant temperature through evaporative cooling, as well as transporting nutrients (Evert and Eichhorn 2013). Understanding how water moves from the soil, through the plant, and out into the atmosphere is essential for understanding an orchard settings water balance.

Water and nutrient uptake occurs from the soil solution through root hairs on the growing root tips. Water diffuses into the root where it makes its way into the xylem vessels via various pathways (Evert and Eichhorn 2013). These vessels provide the main water and nutrient transport pathway from the roots to the 
leaves (Evert and Eichhorn 2013). When the water reaches the exposed leaf cell surfaces inside the substomatal chamber, liquid water converts into a gas through the process of evaporation, and is then released into the atmosphere through the stomatal aperture (if it is open). The transpiration flow is regulated by the loss of water from cell surfaces in the substomatal chamber according to the vapour pressure deficit in the chamber, and in healthy plants, this is actively regulated by the stomata.

The primary function of stomata is to regulate gas exchange, which includes, but is not limited to: entry of carbon dioxide into plants to facilitate photosynthesis, and removal of water vapour for evaporative cooling (Evert and Eichhorn 2013; Reece et al. 2010). The size and density of stomata on leaf surface of fruit trees differ with environmental conditions, such as water stress (Elias 1995), season, varieties, leaf position and leaf age (Jones et al., 2011). Stomata are sensitive to environmental cues that cause them to open or close in response. For example, the environmental signal of sunlight causes the stomata to open by starting a series of reactions that cause the guard cells to fill with water, becoming turgid, and therefore holding the stomatal pores open. In C3 plants, such as grape and apple, stomata typically open in the day and close at night. However, they can also close during the day if the temperature is too hot, there is limited water, or carbon dioxide accumulates in the leaf (Evert and Eichhorn 2013). In CAM plants, stomata close during the day where they use crassulacean acid as a carbon dioxide source, and then open during the night. High air temperatures can cause the guard cells to become flaccid and close because of increases in water loss from the plant, and insufficient water being supplied from the soil to support the guard cell pressure to remain open (Reece et al. 2010). If there is a higher carbon dioxide concentration inside the leaf, then the stomata are signalled to close as respiration is releasing more carbon dioxide than photosynthesis is using. If photosynthesis is not functioning, then there is no need to keep the stomata open and lose water to the atmosphere.

\subsubsection{The soil}

The amount of water present in the soil is another factor that influences the response of a plant's stomata. Therefore, understanding the soil water status is essential for calculating a crops water demand. Initial conditions of the soil 
profile, such as groundwater table level, how close it is to key thresholds such as saturation, field capacity or permanent wilting point, as well as plant characteristics, such as stomata number, density and state, are important to account for when describing the water balance as these influence the movement of water throughout the system.

The depth of the groundwater table plays a significant role in the amount of water readily available to the plant without water inputs from rainfall or irrigation. The depth of a water table can differ with topography and area. Groundwater affects the direction and rate of water movement in the soil profile, and this movement is affected by soil texture (Allen et al. 1998).

The root function of a plant is dependent on soil oxygen, which means that the plant's functionality is dependent on the soil moisture content being the right balance of oxygen: water for plant water uptake (Ritchie 1998). Field capacity describes the amount of soil water that is held in the soil after excess water has drained away, and contains all the water it can hold against gravity, which is considered to be optimum growing conditions (Allen et al. 1998; Lopez and Barclay 2017) (Figure 1). Soil saturation describes the state when all pore spaces are filled with water, and there is no air left in the soil. Prolonged periods at saturation (anaerobic conditions) can cause reduced plant water uptake and harm to the plant as both grape and apple crops cannot withstand anaerobic environments (Allen et al. 1998). Species with a waterlogged root system, vary in their response. For example, plants can respond by increasing the biomass of the shoot in relation to the roots (Barrett-Lennard et al., 1988), reduce its photosynthetic activity due to lower water potential and stomatal conductance, to plant death (de Sousa et al., 2002).

When the soil moisture content has decreased to a point where any water leftover is held so tightly to the soil matrix that the roots can't extract it, causing them to wilt, this is known as the permanent wilting point (Allen et al. 1998; Kirkham 2014). Every individual crop has a permanent wilting point that differs. Water stress to the plant first results in stomatal closure, which prevents further water loss from transpiration pathways. Stomatal closure is more strongly related to soil water content than leaf water status. This is because closure is 
mainly controlled by chemical signals such as abscisic acid (ABA) that occur in dehydrating roots (Reece et al., 2010).
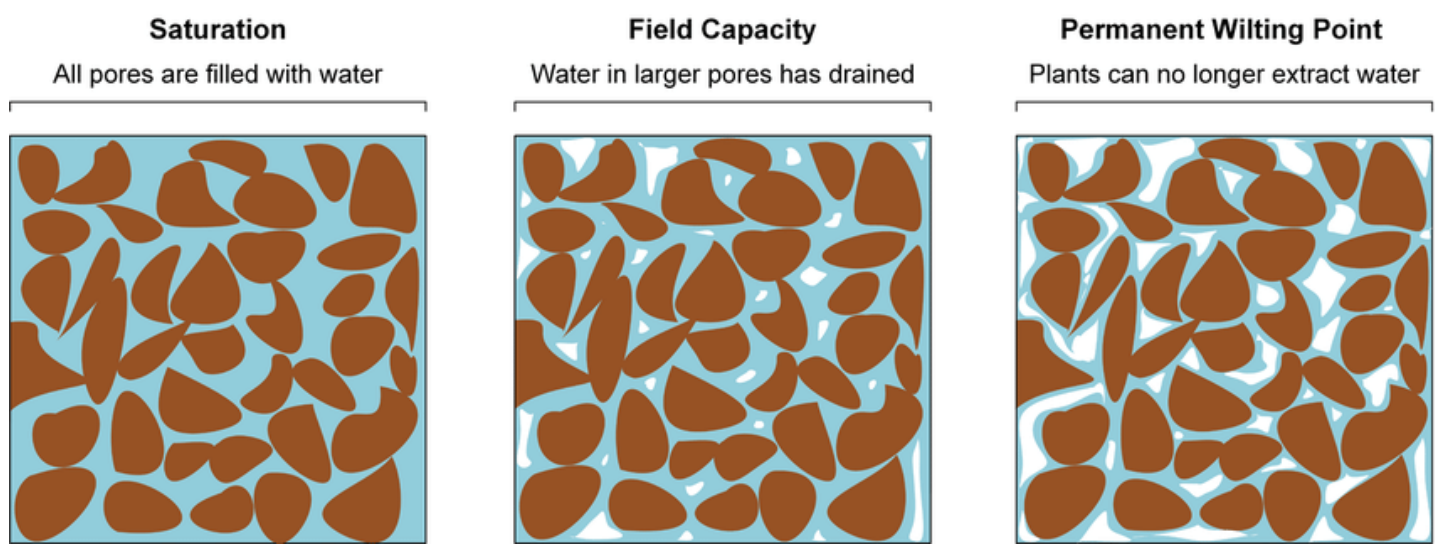

Figure 1: Illustration showing the difference between soil saturation, field capacity and the permanent wilting point (Derived from Datta and Taghvaeian, 2017).

Excess water entering the balance causes drainage and redistribution of water throughout the soil profile. Drainage only occurs when there is excess water to soil saturation (Zhang et al., 2002). Overland flow can occur during significant water input events (most commonly a large rainfall event), where inputs exceeds the soils maximum infiltration rate, causing surface runoff (Zhang et al. 2002).

\subsubsection{The atmosphere}

The majority of water that falls on an orchard/vineyard ground as either rainfall or irrigation typically infiltrates to the soil profile below (Philip 1969). However, in some parts of the world, such as in arid or semi-arid climates, almost all rainfall is lost to evaporation. These are the main water inputs into the water balance. When water inputs equal, or exceed the field capacity, the soil water deficit is assumed to be zero, otherwise known as soil saturation (Zhang et al. 2002). Atmospheric conditions are one of the main controllers that drive water movement through a plant, known as evapotranspiration. Evapotranspiration is an integral part of the water cycle, and a crucial part of an orchards water balance (Allen et al. 1998; Kirkham 2014; Zhang et al. 2002). This will be explained more in depth below. 


\subsection{Evapotranspiration in crops}

In a horticultural setting, there are two main processes where water is lost to the atmosphere in the form of water vapour. Evaporation occurs directly from a wetted surface of the crop, or the inter-row (typically grass with herbicide strip), and transpiration from the crop itself, including inter-row grass transpiration. Evapotranspiration is a term used in this thesis that describes both evaporation and transpiration. Apart from topsoil water availability, evaporation in a horticulture setting is primarily determined by the fraction of solar radiation reaching the soil surface (Allen et al. 1998). As the crop canopy develops throughout the season, canopy shading of the ground increases and less solar radiation reaches the ground because it is intercepted by the canopy (Allen et al. 1998). During the beginning of a growing season, post-bud-burst when the canopy has not developed yet, water is primarily lost through soil evaporation. However, as the leaf canopy develops, transpiration becomes the main process through which water is lost to the atmosphere.

Transpiration is the removal of water (in the form of vapour) in plant tissues into the atmosphere (Allen et al. 1998; Evert and Eichhorn 2013; Reece et al. 2010). Stomata present on the plants leaves regulate the release of gases and water into the atmosphere (Evert and Eichhorn 2013; Reece et al. 2010). The plant roots uptake nutrients and water, which are transported through the plant (Reece et al. 2010). The vaporisation of water occurs within the intercellular spaces in the leaf, where stomatal aperture controls the vapour exchange with the atmosphere. When the atmospheric humidity is lower than the intercellular spaces, water vapour diffuses outwards of the stomata and into the atmosphere (Allen et al. 1998). The rate of diffusion is controlled by the degree and number of opening stomata and the humidity gradient. For transpiration to occur, three main physical conditions are required (Allen et al. 1998). Firstly, solar radiation is needed to provide the latent heat energy source required for vaporisation of the water. Secondly, a water vapour pressure gradient to drive vapour diffusion out of the stomata and into the atmosphere. And lastly, a water supply is needed to meet the vaporisation demand.

Transpiration is the response to the water potential gradient between the roots and leaves, which is caused by stomatal water loss (Allen et al. 1998). The 
potential gradient between the leaves and soil drive root water absorption, and the movement of water through the plant (sap flow). Since stomatal control is influenced largely by solar radiation and the VPD, the atmospheric environment is a large controller of the transpiration rate. Therefore, water loss through transpiration is affected by the whole soil-plant-atmospheric continuum (Kramer \& Boyer, 1995; Allen et al., 1998).

During warm sunny days, transpiration causes leaf water deficits almost daily (Allen et al., 1998). When drying soil causes root water absorption to lag behind water loss by transpiration, permanent water deficits occur (permanent wilting point), which result in stomatal closure response and potential death by dehydration (Allen et al. 1998). Different types of plants have different transpiration rates due to different crop phenology, physiology, morphology, environment and crop management.

The major factors influencing evapotranspiration, and therefore crop water use are the radiation absorbed by the leaves, which is closely related to light interception of the canopy, stomatal conductance, which is controlled by stomata and VPD, and lastly stomata number which is primarily controlled by leaf area (Behboudian and Mills 2010; Jackson 2011; Palmer and Jackson 1977). Assuming that water availability is not limited for the plant, crop evapotranspiration and crop water use is primarily controlled by stomata in daily response to weather variables. These factors will be discussed in detail separately below.

Within the apple and grape sites in this study, the plants were genetically identical (Malus $\mathrm{x}$ domestica (Borkh.) 'Scilate' apple and Vitis vinifera (L.) Syrah (Shiraz) grape, and grown in the same environmental conditions for apples, and different soil types for the grapes. Therefore, the only differences among plots will be plant and orchard leaf area, and their stomatal aperture, which is primarily affected by radiation absorbed and boundary layer conductivity (microclimates within the canopy).

\subsubsection{Light interception}

Solar irradiance is the power or energy per unit time received in the form of electromagnetic radiation from the sun at a point. At a point on the earth's surface, the amount and wavelength composition of this irradiance is dependent 
on factors such as sun angle (daily and annual) and atmospheric conditions. The light energy that is used for photosynthesis by a plant is described as photosynthetically active radiation (PAR) which contains the visible wavelengths within 400 to $700 \mathrm{~nm}$ (Jackson \& Palmer, 1979). PAR is not a measurement or metric; it describes the amount of light available for photosynthesis at a plant surface. Electromagnetic radiation describes the energy level of photons, which depends on their wavelength (blue>red). The density of photons depends on how bright the sunlight is. The photosynthetic photon flux density (PPFD) measures the amount of PAR, or "photosynthetically active photons" that fall on a plant surface each second, measured in units of $\mu \mathrm{mol} / \mathrm{s}-\mathrm{m}^{2}$ (Barnes et al. 1993). In this study, the difference between PPFD above the canopy and below the canopy was measured, as \% light interception, which is the percent of PAR that the canopy intercepted. The PPFD (hereafter light interception) intercepted by a crop primarily depends on orchard design (including trellis systems), leaf area index, and the length of the growing season (Jackson \& Palmer, 1979; Jackson, 2011; Wagenmakers \& Callesen, 1995; Wünsche et al., 1996).

Light interception is crucial for a plant as it is strongly related to crop evapotranspiration and crop water use (Green et al., 2003; Wünsche et al., 1996), dry matter production (Monteith 1977) and, in apples, fruit yield (Palmer 2002). Crop water use is affected by stomata number, and assuming genetically similar material between Scilate apple and Syrah grape, this will be primarily be affected by plant/orchard leaf area and the stomatal aperture, which is primarily affected by light interception and boundary layer conductivity.

A decrease in radiation absorption (PAR) generally causes a decrease in transpiration, and may result in inferior flowering and fruit quality (Tustin et al., 1988; Warrington et al., 1996). Orchards and vineyards are represented by areas of high-density leaf area which is the crop (where little radiation passes through), and by areas without crop leaves (within rows that is typically grass) (Allen et al. 1998). Therefore, the amount of radiation that is intercepted by the canopy and absorbed is dependent on tree spacing, row widths, canopy design and plant age. At a whole block level, light interception can range from as low as $11 \%$ in young conventional apple orchards with small canopies (Behboudian and Mills 2010), to as high as $90 \%$ in new two-dimensional planar canopy 
systems (Tustin \& van Hooijdonk, 2016), and up to $100 \%$ in old threedimensional systems (Warrington et al. 1996).

Internationally, modern fruit production has utilised the knowledge of plant light interception and used it to influence new growing systems for crops. Apple and grape crops are increasingly grown on trellis systems and at row spacing's which maximise the light environment and manage competition between trees. The majority of internationally planted apple crops are grown as tall spindle central leader trees or inclined-vee variations of central leader trees (Tustin \& van Hooijdonk, 2016). Studies have shown that this style of trellis system can intercept $65-75 \%$ (Breen pers.com) of incoming radiation and achieve high yields of premium quality fruit (Wunsche, Lakso, and Robinson 1995). New "planar cordon" trellis designs have been shown to reach 85 to $90 \%$ light interception (Breen et al., 2020), with improved yield and fruit quality (Tustin and van Hooijdonk 2016). For grapes, cane and spur pruning techniques have been established for a long time which allows for full vine canopy irradiance.

Due to the high leaf density in fruit trees and vines, radiation distribution within the canopy is affected by alterations in leaf angle (Palmer, 1981). Newly developed two-dimensional designs of apple canopies, where there is more uniform light distribution throughout the upper and lower canopy, has shown to increase light interception compared with the standard three-dimensional centre leader canopies (Tustin \& van Hooijdonk, 2016). In addition to light uniformity, leaf pubescence, and waxiness can differ among species (eg: grape and apples) which affects individual leaf radiation reflectance and light distribution (Wright et al., 2006). Increased soil reflectivity can also increase radiation absorbed by the leaves, and therefore crop water loss.

Orchards are grown as discontinuous canopies, which have large variations between the spatial distributions of leaf area in comparison to continuous canopies such as hedges (Jackson, 1970). These large variations are mostly due to differences in pruning, tree size, training systems, row and tree spacing which suggest that light interception and leaf area might not be as closely related as in continuous canopies. In addition, Palmer and Jackson (1977) found that seasonal patterns of light interception were similar to that of leaf area. However, the amplitude was reduced due to the mutual shading of the 
leaves. Therefore, the relationships between light interception and leaf area need to be explored more in these newly designed tree architectures.

The physical properties and distribution of individual leaves caused by different canopy designs only have a small effect on total transpiration. However, they can play a large role in the transpiration and leaf water potential of individual leaves. For example, shaded leaves tend to have a significantly higher water potential than those leaves directly exposed to the sun (Olsson and Milthorpe 1983; Jones and Cumming 1984). The amount of soil evaporation is also controlled by the amount of radiant energy intercepted by the crop canopy, as large shaded areas lead to lower evaporation rates (Green et al. 2003). Relationships between evapotranspiration and light interception will be explored in this thesis, as research suggests that it is an appropriate proxy for leaf area and radiation absorbed (Wünsche \& Lakso, 2000).

\subsubsection{Leaf area}

Another factor that plays a large role in controlling canopy conductance, and therefore transpiration, is leaf area. Stomata present on the leaf provide finescale control over evaporation as explained above, while leaf area is a more important long-term/course control for evaporation. Stomatal conductance describes the rate that carbon dioxide enters, or water vapour leaves through the stomata. When conductance at a stomatal or leaf level is scaled up to whole canopy, conductance declines with increasing leaf area. This is because as leaf area increases, the proportion of shaded leaves also typically increases, and these shaded leaves have a lower stomatal conductance (Syvertsen and Albrigo 1980; Warrit et al., 1980). In deciduous crops such as apple and grapes, the ability to drop leaves seasonally is a natural drought adaptation mechanism, but comes at a large carbon cost. The plant's ability to reduce leaf area under stressed conditions is due to several factors that include reducing addition of new leaves through shoot growth reduction, decreased total leaf count through leaf abscission, and reduced leaf area expansion (Lakso 1983). In apple trees, a decrease in leaf area will usually result in a decrease of light interception, which could reduce total carbon assimilation and dry matter production (Behboudian and Mills 2010; Hsiao 1993). 
In general, it has been established that fruit growth and yield, also fruit quality is proportional to the ratio of exposed leaf area to fruit weight (i.e., crop load (Wünsche \& Lakso, 2000). A range of 7 to $14 \mathrm{~cm}^{2}$ total leaf area per gram of fruit is required to achieve fruit maturity (Howell, 2001). This wide range is dependent on the environment, with higher ratios required in cold climates, so that essential physiological functions such as bud initiation/differentiation, crop ripening, carbohydrate storage, wood and bud maturation, and acclimation/tolerance to cold can all be accomplished with the available exposed leaf area (Howell 2001). The threshold leaf area: fruit weight ratio is also significantly impacted by the ratio of exposed versus non-exposed leaves, a relationship that is directly affected by the training system (Dokoozlian and Kliewer 1995).

Studies by Green et al. (2003) have revealed that light interception is most influenced by changes in leaf area and leaf optical properties (leaf angle etc.), whereas transpiration measured by sapflow was most influenced by changes in leaf area and leaf conductance. This further supports the statement that light interception is a proxy for leaf area and radiation absorbed when estimating crop evapotranspiration.

\subsubsection{Boundary layer conductance}

In addition to light interception and leaf area, it is also important to acknowledge that humidity and boundary layer conductance play a role in evapotranspiration in orchard settings. A decrease in the saturation deficit of ambient air directly reduces evaporation, which can also be partially offset by increases in stomatal aperture (Behboudian and Mills 2010). Advances in shade and hail netting technology used on vineyards and orchards have been shown to increase the saturation deficit of ambient air during high summer temperatures (McCaskill et al. 2016). In Royal Gala apple trees, hail netting has been shown to reduce the median fruit surface temperature by $1.5-2^{\circ} \mathrm{C}$, and $4^{\circ} \mathrm{C}$ in maximum fruit surface temperatures (McCaskill et al. 2016). Overhead sprinklers and microsprays have also been used to reduce fruit temperatures through evaporative cooling. It has been shown in Australian Royal Gala apples that evaporative cooling by overhead micro sprays can reduce transpiration by $50 \%$ which was associated with wet leaves, a more humid environment and lower temperatures 
(Green et al., 2014). Whereas transpiration in non-sprayed trees typically decreases by approximately $5 \%$ in response to changes in air temperature and humidity (Green et al. 2014).

Orchard and vineyard layouts tend to be aerodynamically rough because they have heterogeneous surfaces - the result of contrasting morphologies between the primary crop (e.g., apple trees and vines) and the cover crop (typically grass). The air turbulence created by this characteristic results in the boundary layer conductance being much greater than that for field crops at any wind speed. Actual values of layer conductance can depend on a number of factors which include wind orientation relative to rows, tree architecture, and tree spacing. It has been shown that orchards have a typically high boundary layer conductance $(100-300 \mathrm{~mm} / \mathrm{s})$, which shows that they are strongly coupled with the environment (Jarvis, 1981). In addition, the individual leaf boundary layers, which have the greatest effect on the boundary layer conductance, and which depend on wind speed, leaf size, shape and hairiness, are also important to account for.

There are a large number of unknowns as to how canopy morphology, which influences variability in light interception and leaf area, ultimately affects crop evapotranspiration and crop water use. This thesis was designed to explore these relationships in two different crop systems: Scilate apples and Syrah grapes. Firstly, due to their differences in morphology, and therefore expected differences in light interception, leaf area, and crop evapotranspiration. Two different aged Syrah grapes planted on different soils were used to determine whether morphology can differ, even though genotype is identical, and further explore whether vine maturity, as well as soil conditions influence crop evapotranspiration. And lastly, three different apple trellis systems were used to show that although genotype may be identical, differences in canopy design, and therefore light interception and leaf area are a stronger proxy for crop evapotranspiration. These hypotheses lead into the aims and objectives for this thesis. 


\subsection{Aims and Objectives}

Estimations of crop evapotranspiration do not currently account for different orchard designs, and therefore, different light environments. The aim of this thesis was to examine the effect of canopy architecture on evapotranspiration and water use in apple and grape crops, in order to improve estimations of crop evapotranspiration to account for different orchard designs. To this end, I examined the effect of trellis system (apples) and age and soil type (grapes), on light interception and leaf area in Scilate apples and Syrah grapes, and compared the actual versus estimated crop evapotranspiration.

To achieve the research aim, four research objectives were set;

1. To determine how canopy architecture in Scilate apple, and age and soil type in Syrah grape influence light interception and leaf area, alongside yield and fruit quality.

2. To quantify how canopy architecture in Scilate apple, and age and soil type in Syrah grape influence crop evapotranspiration and crop water use.

3. To compare measured crop evapotranspiration with estimated crop evapotranspiration in the different canopy architecture in Scilate apple, and age and soil type in Syrah grape.

4. The overall outcome will be to suggest how crop evapotranspiration can be estimated more accurately for orchard crops.

\subsection{Thesis Structure}

This thesis is designed to first investigate how crop evapotranspiration and crop water use differ among the different apple trellis systems, and age and soil type in grapes in Chapter 2 using soil water content and matric potential measurements. Chapter 3 explores the variability that different trellis designs and age and soil have on light interception and leaf area, including yield and fruit quality. The trends identified in Chapter 3 are used to examine patterns in the soil water content and matric potential results. Chapter 4 combines the 
results from Chapters 2 and 3 to estimate crop evapotranspiration, and compare it with soil water content results. Chapter 5 draws final conclusions.

\subsection{Experimental site}

Hawke's Bay is situated on the eastern side of the North Island of New Zealand, which contains the highly productive Heretaunga Plains. The Heretaunga Plains is an alluvial plain, $300 \mathrm{~km}^{2}$, where the permeable layers of gravel beds make up the Heretaunga aquifer system (an area approximately $510 \mathrm{~km}^{2}$ ), which underlies most of the Heretaunga Plains (Rakowski and Knowling 2018). This aquifer is a significant water resource for Hawke's Bay, with 161 million m $^{3}$ consented for domestic, municipal, industrial, horticulture and agriculture use annually (Rakowski and Knowling 2018). The Hawke's Bay region is the second-largest producer of wine grapes in New Zealand. In 2019, the Hawke's Bay region produced 37,173 tonnes of grapes second to Marlborough $(305,467$ tonnes), followed by Gisborne (16,238 tonnes) (Aitken 2020).

In general, Hawke's Bay has a temperate climate. Sunshine hours typically rank over 2329 hours annually, and growing degree days (a measure of heat accumulation $>10^{\circ} \mathrm{C}$ ) were 1329 for the $2019 / 2020$ season from 1st October 2019 to 1st March 2020 (data retrieved from MetWatch Roy's Hill climate station). Mean annual rainfall around Roy's Hill and Twyford (Heretaunga Plains) is around $750 \mathrm{~mm}$ per year.

\subsubsection{Research site locations in Hawke's Bay}

The apple and grape sites were located northwest of Hastings city on the Heretaunga Plains. The apple sites are situated on T\&G Global orchard on 241 Evenden Road, Twyford. Hereafter referred to as Evenden orchard (-39.6025, 176.8307). The grape sites are located on Villa Maria vineyard, Te Awa, on 2375 SH 50, Flaxmere, Roy's Hill (-39.6166, 176.7389) (Figure 2). 


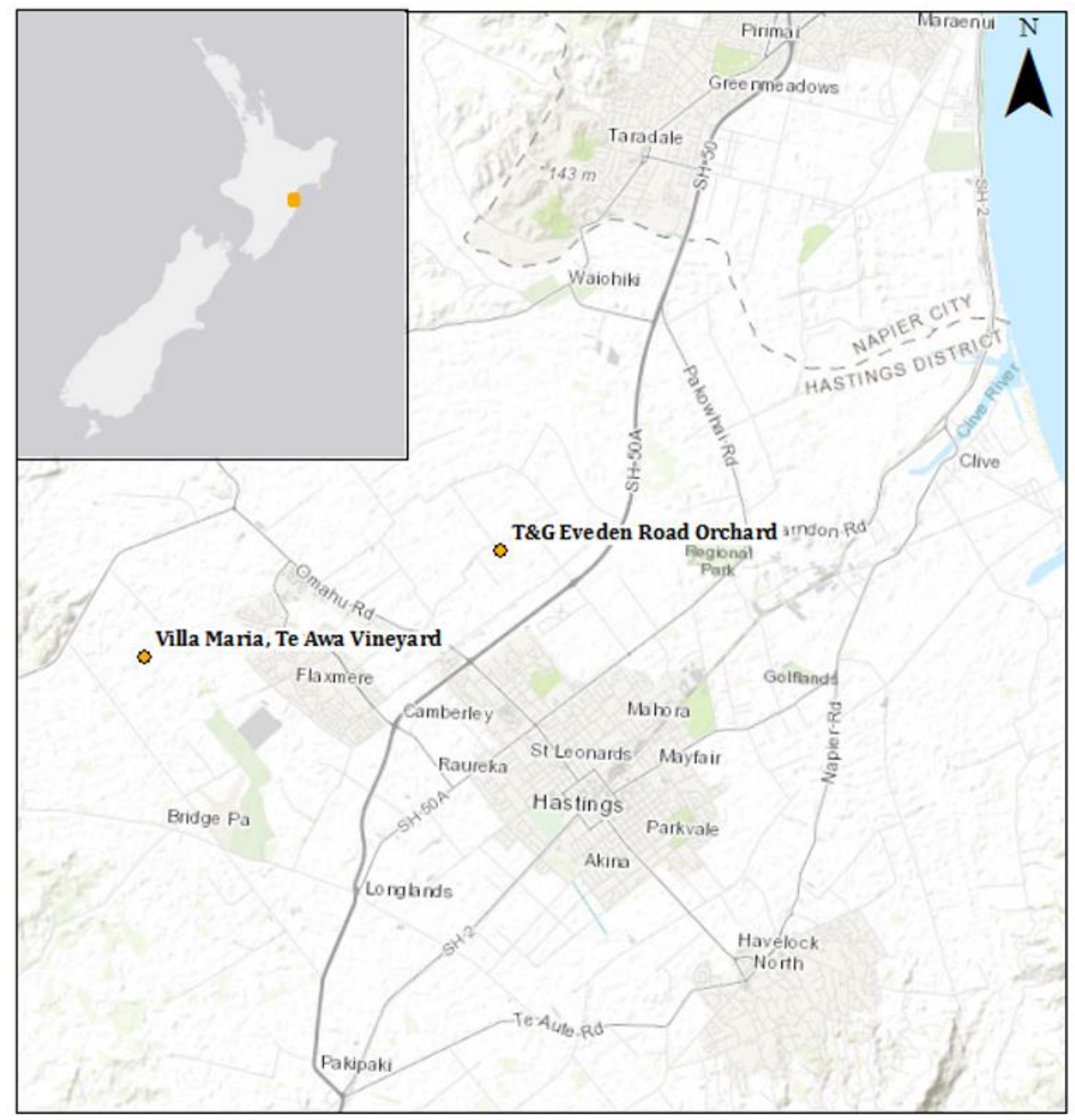

Figure 2: Map showing both apple and grape site locations within the Hastings region.

\subsubsection{Apple site information}

The apple site is located on Evenden orchard. The site is located on the Heretaunga Plains, northwest of Hastings City. This area mostly consists of orchard and vineyard cropping. The apple site consists of three sites which are approximately 0.5 hectares each. Each plot has a different trellis system: planar cordon, tall spindle and Washington Vee-2D system (hereafter vee) (Figure 3). There are three apple varieties grown in each plot that consists of Scilate, 'Scifresh'/Jazz ${ }^{\mathrm{TM}}$ and 'Galaxy'. Only Scilate trees were chosen for this research to ensure that there were negligible differences in crop morphology, such as stomatal density that could influence crop evapotranspiration. 


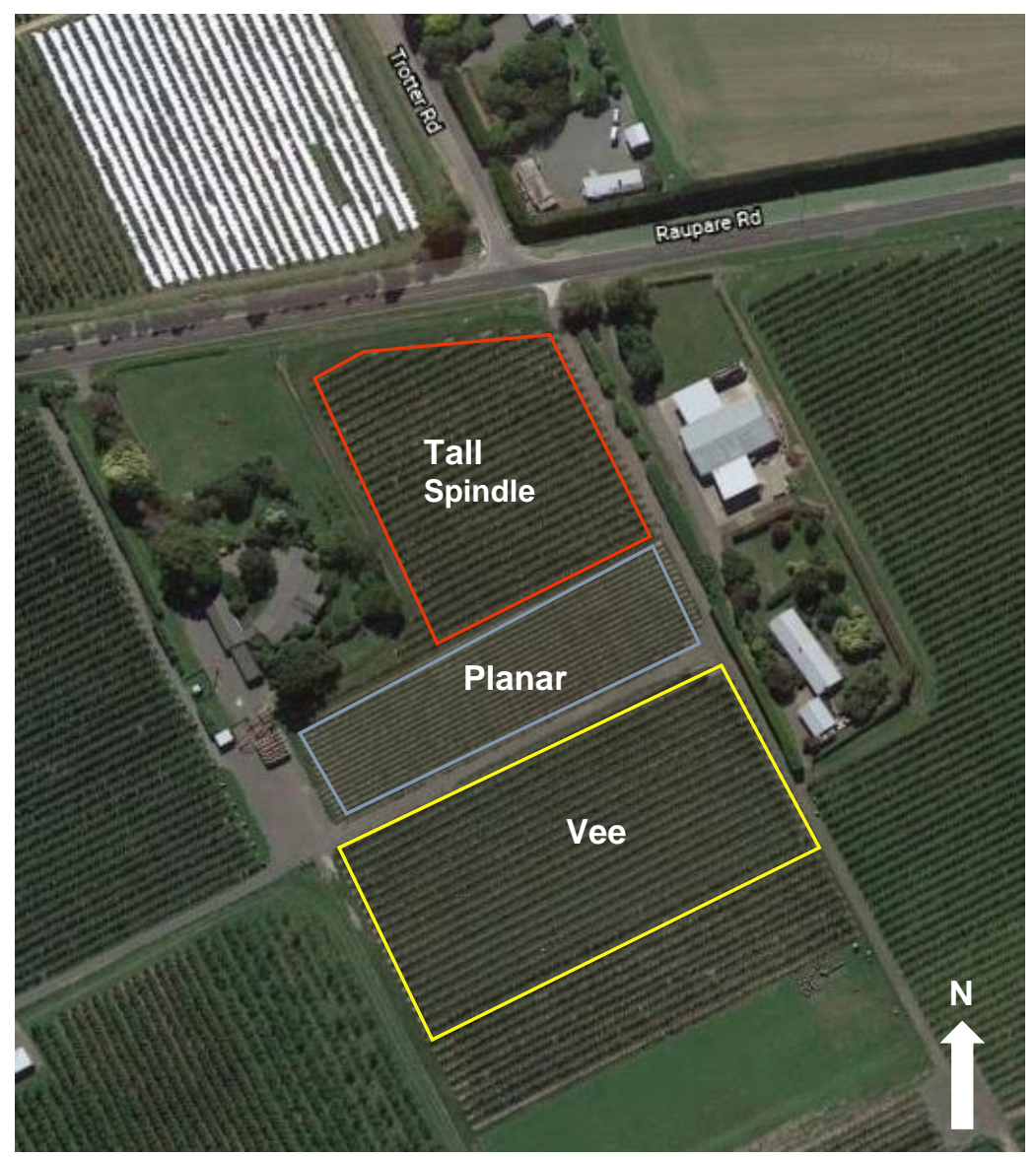

Figure 3: identifying the three different Scilate apple trellis sites at Evenden orchard; vee, planar and tall spindle. All planted within the same block.

A trellis system is the physical manipulation of a plants form. A thorough understanding of photosynthesis, canopy environment, fruit development, pruning, yield potential and fruit composition is needed to develop a successful trellis system. In this research, three trellis systems are analysed: tall spindle, planar and vee (Table 1).

Table 1: Orchard design characteristics between the three different trellis systems.

\begin{tabular}{lcccc}
$\begin{array}{l}\text { Trellis } \\
\text { system }\end{array}$ & $\begin{array}{c}\text { Tree } \\
\text { Spacing } \\
(\mathrm{m})\end{array}$ & $\begin{array}{c}\text { Spacing } \\
(\mathrm{m})\end{array}$ & $\begin{array}{c}\text { Trees/ha } \\
\text { (density) }\end{array}$ & $\begin{array}{c}\text { Age of } \\
\text { tree }\end{array}$ \\
$\begin{array}{lcccl}\text { Planar } \\
\text { Tall }\end{array}$ & 2 & 3 & 1667 & Fourth leaf \\
Spindle & 3.5 & 1.3 & 2198 & Fifth leaf \\
\hline Vee & 3.5 & 0.5 & 5714 & Fifth leaf \\
\hline
\end{tabular}




\section{Tall Spindle}

This trellis system trains trees as a traditional upright central leader tree, with row spacing, tree spacing and planting density shown in Table 1. A central trunk is developed, off which branches are arranged so that they don't compete with the central leader or each other. Following the most recent technology on precision orchard management (Breen et al., in press), Evenden orchard was pruned to have six branches per vertical metre of canopy arising off the central leader. This system is the oldest design out of the three here, yet it is still a common way to grow apples in New Zealand (Tustin and Van Hooijdonk 2016).

\section{Vee}

In the vee canopy, alternating trees are planted at angles of 30 degrees (Figure 4). The space between each alternating tree down the row is 0.5 meters, and the space between the same angled trees is one meter. This system has the highest planting density (Table 1). Each tree has a central leader with branches trained horizontally on six horizontal wires, $0.5 \mathrm{~m}$ in spacing. The angled canopy is expensive to set up as it requires more intensive support structures and tree training.

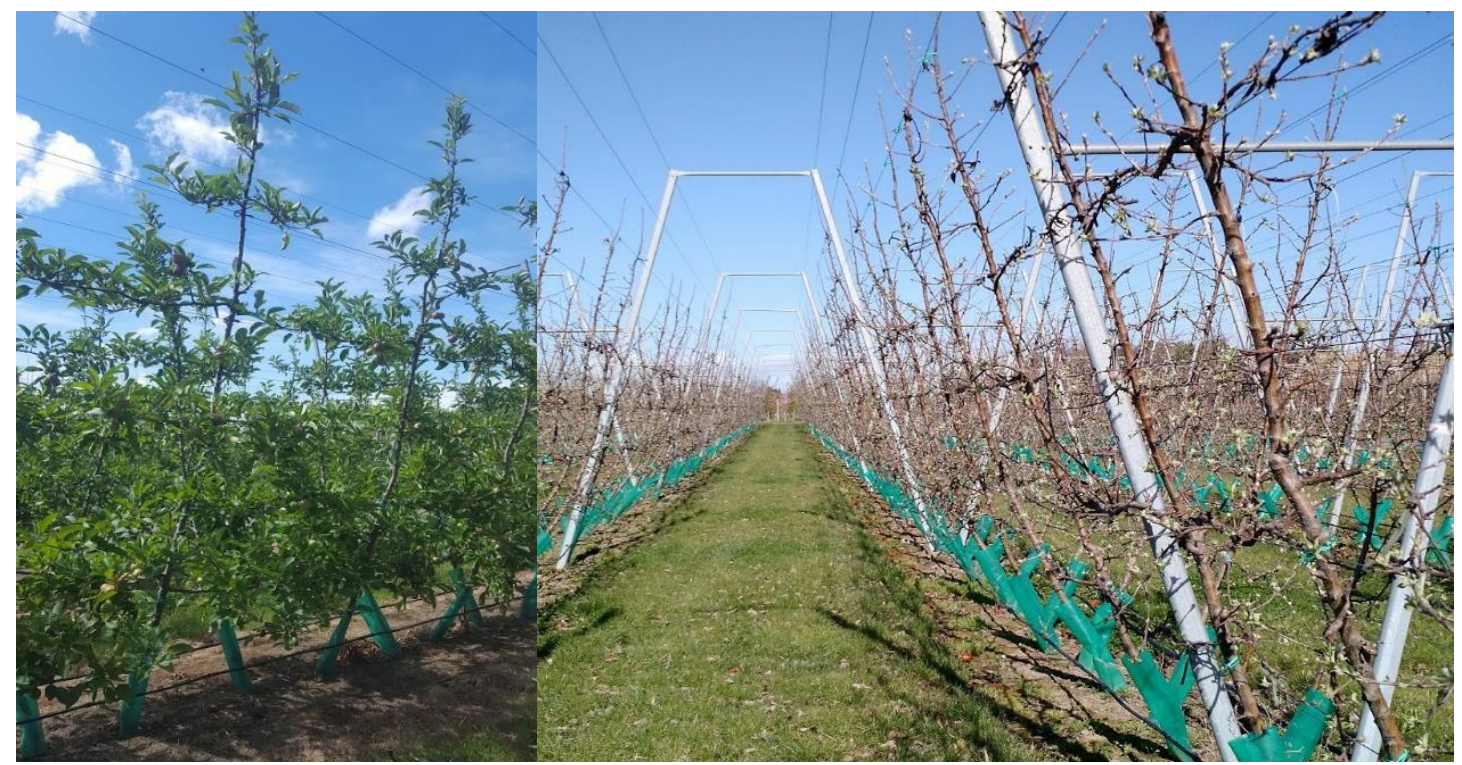

Figure 4: Images showing the vee trellis system at Evenden orchard. Each individual tree is growing at an alternating angle, spaced 0.5 meters apart.

\section{Planar systems}

Planar trees have two horizontal cordon leaders down the row (at the height of approximately $0.8 \mathrm{~m}$ ) with five vertically branching uprights per cordon, evenly spaced at $30 \mathrm{~cm}$ (Figure 5). This design creates a narrow, tall canopy that consists of minimally branched, fruiting uprights. It is designed to evenly space 
fruiting spurs in a spatial array to give a uniform leaf canopy that allows for even light distribution along the length of each fruiting branch during the daily solar arc. This new innovative design is achieved by reducing the row widths to two meters and plant spacing to three meters (1667 trees/ha). This specific training system requires a large intensity of training and pruning attention, but projected yield outputs in excess of $150 \mathrm{t} /$ ha make it viable (Table 1 ).

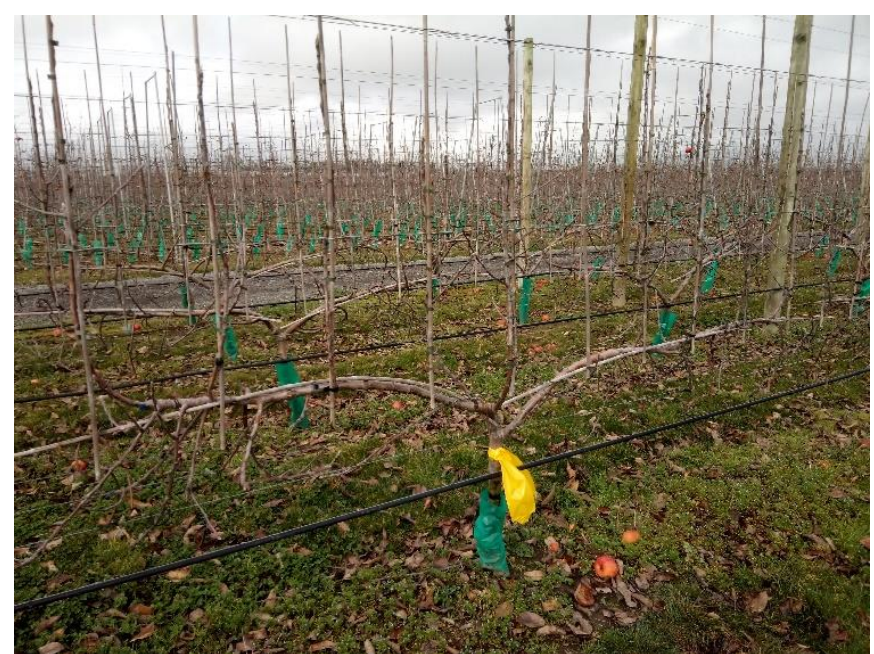

Figure 5: Image showing the planar trellis system, where there are two horizontal cordons with six uprights each side.

The trees in the three plots are all the same age from grafting. However, the planar trees are one fruiting year behind the rest (fourth leaf). This is because the biaxis structure was formed by heading back single-axis trees at planting, instead of the normal procedure of producing biaxis trees in the nursery.

\section{Apple site soils}

This site is part of the Flaxton family of soils. It is a silty, stoneless soil which originated from hard sandstone and rhyolitic rock (S-Map, Landcare Research). It has anoxic conditions as a rooting barrier and is classed as a poorly drained soil, with the topsoil clay range being $25-35 \%$. It has very limited aeration in the root zone, where the soil moisture is typically high $(150-249 \mathrm{~mm} / \mathrm{m})$. Flaxton soils have a high water logging vulnerability, and this coincides with the $T \& G$ growers' observation of the area having a high water table, often up to 30 $\mathrm{cm}$ soil depth. This was observed on $16^{\text {th }}$ October 2019, where there was a weather event that brought $134.2 \mathrm{~mm}$ of rain over 48 hours. This caused a large amount of waterlogging to occur at the site (Figure 6). 


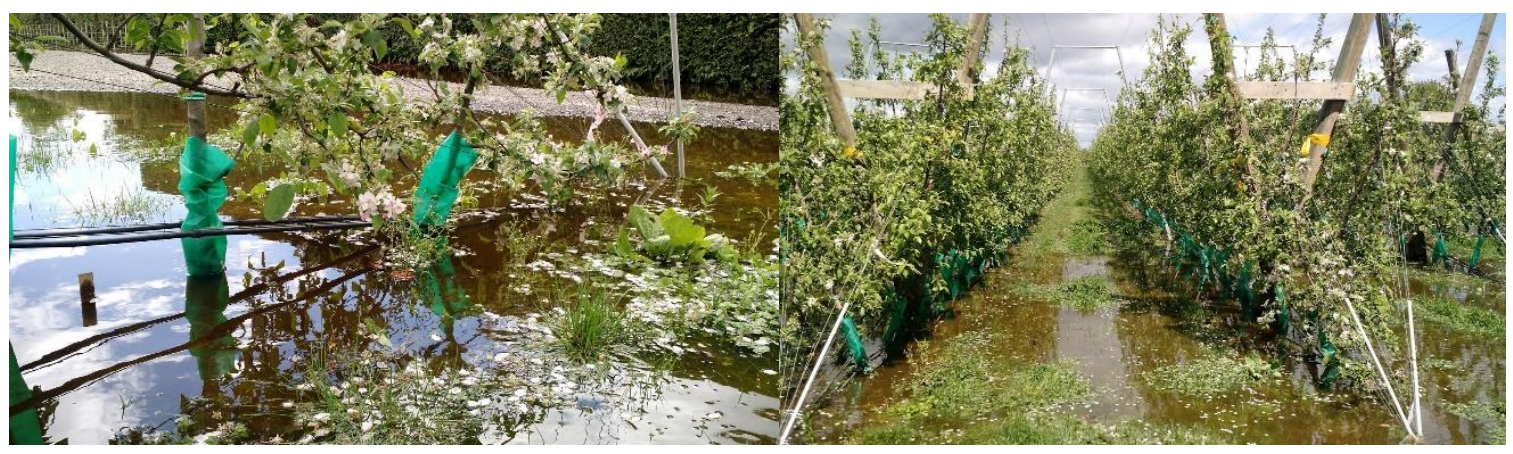

Figure 6: Photos taken from the Evenden orchard on 16th October after a large rainfall event $(134.2 \mathrm{~mm}$ over 48hrs) which resulted in a large amount of water logging. Photos taken at the vee system plot.

\subsubsection{Grape site information}

There are two different plot sites at the Te Awa vineyard which consist of Syrah vines that differ in vine age and soil type but are both grown on the commonly used vertical shoot positioning system (VSP) (Figure 7).

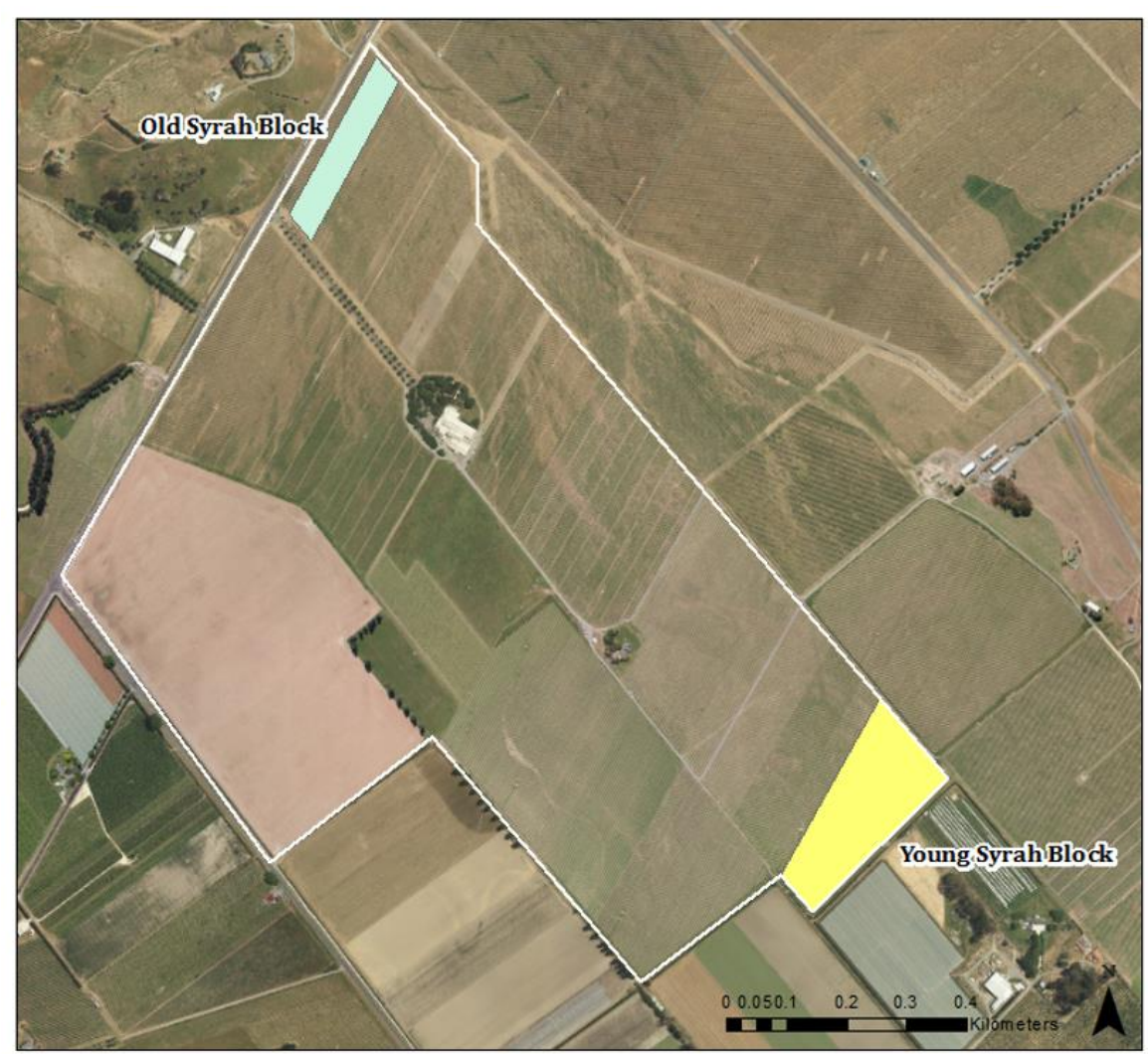

Figure 7: Map identifying the two Syrah grape plots at Te Awa vineyard; young Syrah and old Syrah.

The young Syrah block is 3.65 hectares in area and was planted in 2013. The old Syrah block is 1.15 hectares in area, and was planted in 2006 (Table 2). Both blocks have similar vine planting densities. In both Syrah blocks, irrigation 
is applied through a drip system. Drip spacing is $60 \mathrm{~cm}$, with a flow rate of one litre per hour. Rows are oriented north-south to ensure that both sides of the canopy receive similar amounts of sunshine.

Table 2; Orchard design characteristics of the two Syrah grape plots.

\begin{tabular}{lccccc} 
Plot & $\begin{array}{c}\text { Year } \\
\text { planted }\end{array}$ & $\begin{array}{c}\text { Trellis } \\
\text { system }\end{array}$ & $\begin{array}{c}\text { Row } \\
\text { width } \\
(\mathrm{m})\end{array}$ & $\begin{array}{c}\text { Vine } \\
\text { spacing } \\
(\mathrm{m})\end{array}$ & $\begin{array}{c}\text { Vine } \\
\text { density } \\
\text { (vine/ha) }\end{array}$ \\
$\begin{array}{l}\text { Young } \\
\text { Syrah }\end{array}$ & 2013 & VSP & 2.4 & 1.8 & 2315 \\
\hline Old Syrah & 2006 & VSP & 2.4 & 1.5 & 2778 \\
\hline
\end{tabular}

\section{Grape site soils}

The young Syrah plot is located in a site within the Patutahi family of soils (SMap, Landcare Research). It is a loamy, stoneless soil which originated from alluvial sand silt or gravel deposited by flowing water. It is an imperfectly drained soil, with the topsoil clay range being $10-14 \%$. Aeration in the root zone is limited, and the permeability profile is moderate. These soils have a high water logging vulnerability and low drought vulnerability, where soil moisture is typically high $(150-249 \mathrm{~mm} / \mathrm{m})$.

The old Syrah plot differ to the young Syrah, and is part of the Ashburton family of soils. This type of soil lacks distinct topsoil development or is fluid at a shallow depth. The lack of topsoil development is due to the rockiness from alluvial deposits. The subsoil is dominantly made of sandy loam textures and is moderately stony. Due to the stony composition, the soil is moderately well drained with low vulnerability to waterlogging, and has a low water holding capacity.

\subsubsection{Grape growing systems}

In vineyards today, there are two commonly used training systems for vines: cane pruned (Guyot) and spur pruned (Cordon). Cane pruning is typically used in cooler climates, where the spurs are pruned back to the cane to prevent frost damage during the winter months. The following season two new spurs are selected which will be responsible for the season's productivity. In comparison, 
spur pruning is more common in warmer climates such as Hawke's Bay, where two permanent long canes are left year-to-year fastened to horizontal wires, while the rest of the canopy is pruned.

The training system achieves many objectives, similar to the apple canopy. The main purpose is to design the vine in a way that maximises light interception from leaf area, and consequently maximises photosynthetic efficiency and therefore yield potential, fruit quality, and disease control (Reynolds et al., 2009). Modifications in canopy architecture can not only increase the amount of high-intensity irradiance that is exposed to leaves, and increase diffuse radiation interception (Smart 1973). It also helps improve the radiation microclimate of the remaining foliage (Smart et al.,1982). Training systems also facilitate the mechanism of vineyard operations such as shoot tipping, mechanical leaf plucking, mowing, spraying and harvesting. The trunks and canes of vines are trained to reduce competition between the vines.

There are several vine management practices that help to maintain an optimal radiation microclimate of vines. This includes training, pruning and defoliation (leaf stripping) which modifies the microclimate by controlling leaf density and leaf area. It is also important for fruit quality and production, as fruit in exposed sunlit areas exhibit high sugar levels, anthocyanins and total polyphenols, as well as lower levels of malic acid, potassium and $\mathrm{pH}$ compared with shaded fruits (Smart and Robinson 1991). All of these fruit quality variables are important in the winemaking process. Numerous studies have shown that photosynthesis in vines is affected by leaf temperature, orientation, light environment, and leaf age (Poni et al.,1994). The majority of pruning practices in vines are influenced by the idea that increasing the exposed leaf area maximises fruit quality, which is why the VSP system is so widely used in New Zealand.

\section{Vertical Shoot Positioning (VSP)}

In this system, vine shoots are trained upward in a vertical, narrow curtain with the fruiting zone below (Figure 8). The two cordons are perennial and are positioned horizontally. Winter pruning involves removing all upward shoots, pruned to two buds off the two cordons. This system typically consists of four to six levels of wire, which are used to train the growth of the shoots in an upward 
position. These upright shoots are typically trimmed so that the canopy does not reach a height of over three meters (Figure 9).

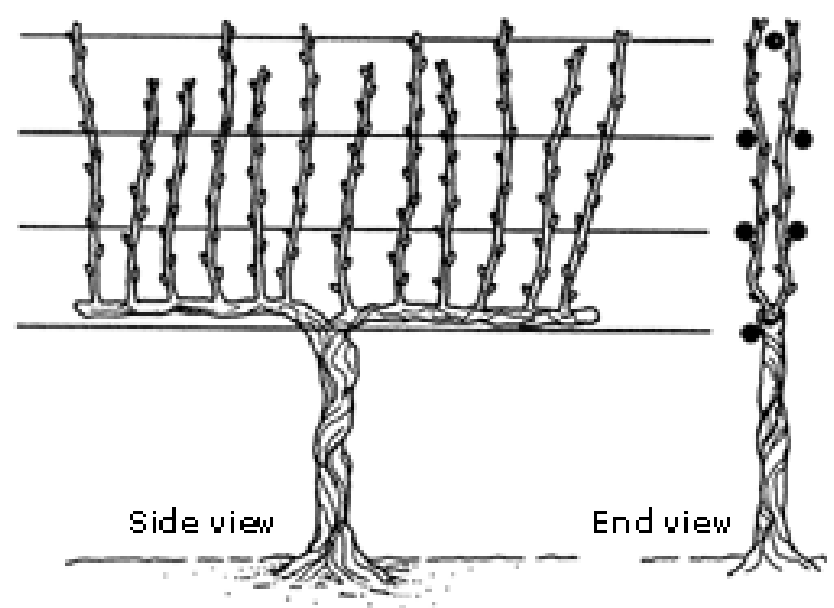

Figure 8: Diagram showing the Vertical Shoot Positioning system at both a side view (left) and an end view (right). Derived from Dami et al. (2005).

This type of training system eases the work of many canopy practices such as leaf removal, shoot removal and cluster thinning, as well as providing for more efficient spray coverage due to the two-dimensional planar canopy.

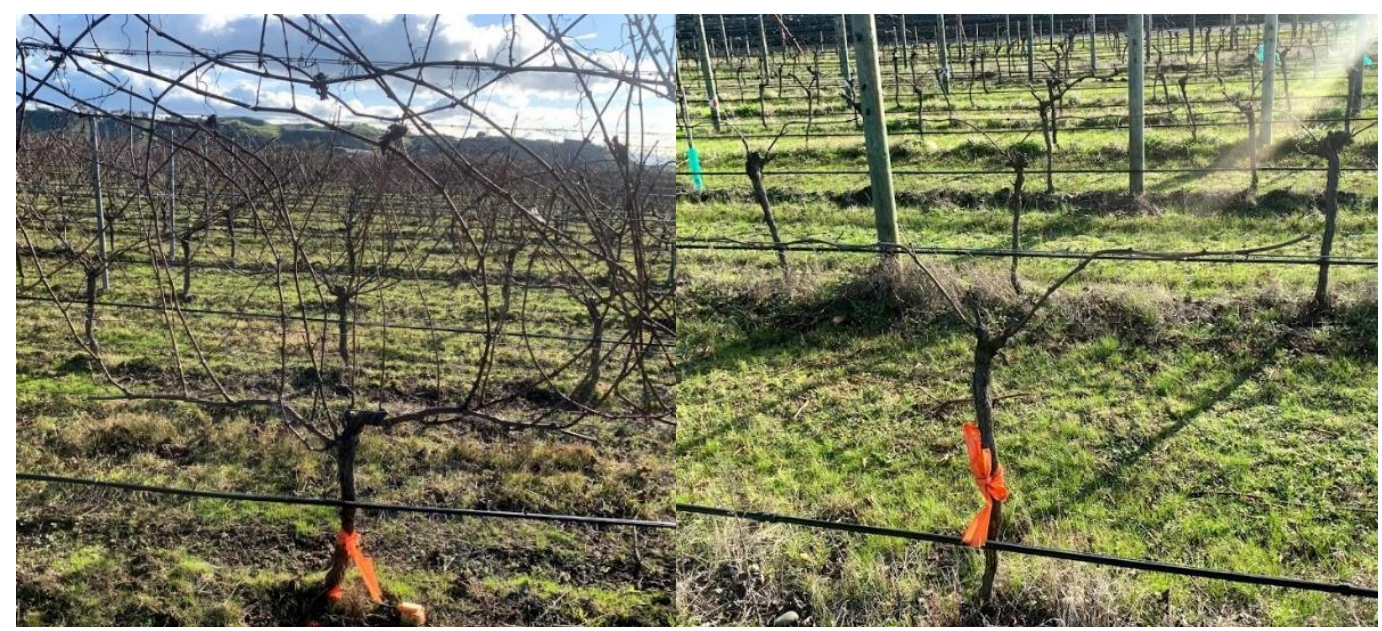

Figure 9: Images showing the VSP system pre-winter prune with all the vertically trained shoots, and post-winter prune where only the two cordon vines are left at Villa Maria Vineyard..

\section{Syrah characteristics}

In New Zealand, Syrah is the third most widely planted red-wine variety, behind Pinot Noir and Merlot (Aitken 2020). Over $77 \%$ of the Syrah variety is planted in the Hawke's Bay region, with a total of 329 hectares (Aitken 2020). It is also commonly known as Shiraz (from Australia). 
Syrah vines are anisohydric, which means that they have poor control of stomatal regulation in transpiration. This results in large fluctuations in leaf water potential under soil deficits and high evaporative demand, which has been observed by orchard management at Villa Maria. These anisohydric characteristics allow Syrah fruit to reach maturity during drought conditions, although the likelihood of mortality due to hydraulic failure is increased (although very uncommon in managed vineyards). In Syrah, uneven ripening of fruit is a recurring historical problem. Syrah performs better at sites that are relatively hot during the day and retain the heat at night. In the Hawke's Bay region, Syrah achieves ripeness late in the season, at the same time as Cabernet Sauvignon. In general stony, dry, low-fertile grounds are needed to reduce canopy vigour.

The rootstock Riparia Gloire is used at both vine blocks at Te Awa Vineyard. Riparia Gloire de Montpellier is the most widely planted pure Riparia stock worldwide, and the most popular rootstock in New Zealand. 


\section{Chapter 2: Dynamics of the soil water balance and crop evapotranspiration}

\subsection{Quantification of soil water content and soil matric potential}

\subsubsection{Introduction}

When measuring the water balance of an orchard or vineyard, it is important to identify, and record factors that are causing the flux: known as water inputs, and water outputs. The majority of climate factors influencing water inputs, such as rainfall, are typically recorded by a nearby weather station. In this thesis, rainfall was recorded at a weather station at each site. Irrigation is an additional water input to rainfall. Water outputs describe drainage to the groundwater, overland flow, and evapotranspiration. The amount of water consumed, and lost to the atmosphere through crop evapotranspiration requires more detailed measurements and understanding, which this chapter will explore through the use of soil water content and matric potential instruments.

\subsubsection{Soil Water Content}

Soil water content is an important variable that controls and modulates numerous physical, biological, and chemical processes in an orchard and vineyard setting. A primary factor of plant growth is the amount of soil water, and its availability to support canopy development. Low soil water content can cause yield loss and plant death, and very high soil water content (saturation) can cause root diseases, large water wastages and anaerobic soil conditions leading to plant death (Evert and Eichhorn 2013; Reece et al. 2010). Therefore, understanding the soil water content of the soil is vital for understanding crop health, growth and irrigation management.

It is important to account for temporal and spatial variability when measuring soil water content (Molina et al., 2014). A large number of soil water measurements are required at field or local scale for accuracy to account for soil heterogeneity. Sampling frequency is another important factor to account for when assessing soil water content. High temporal resolution of 15 - 30 
minutes are typically used sampling frequencies, which are appropriate for plot or local scale monitoring (Molina et al., 2014). These high frequency measurements are made available with sensors and data loggers that have high storage capacity for continuous monitoring.

The amount of water present in the soil is typically expressed in either volumetric $\left(\Theta_{\mathrm{v}}\right)$ or gravimetric $\left(\Theta_{\mathrm{g}}\right)$ terms. Neither the volumetric $\left(\mathrm{m}^{3}{ }_{\text {water }} / \mathrm{m}^{3}\right.$ soil), nor gravimetric ( $\left.g_{\text {water }} / g_{\text {soil }}\right)$ measurements have units. The gravimetric measurement is based on samples oven-dried at 105 degrees Celsius (Walker, Willgoose, and Kalma 2004). The volumetric soil water content may be estimated by reflectometers, and it is this technique that is typically used in research.

\section{Evaluation of soil water measurement techniques}

There are a number of methods used to measure soil water content which include bulk density, water density, dielectric properties, volumetric heat capacity, soil thermal conductivity and soil thermal diffusivity (Robinson et al., 2008). Direct techniques quantify gravimetric soil water content, while indirect techniques measure a property (e.g. dielectric properties), and infer volumetric soil water content from that property.

The standard oven dry method is a direct technique used to calculate the gravimetric soil water content (Walker et al. 2004). It is an inexpensive, simple and standard method. However, this technique which is carried out in the lab, is time consuming (can take up to 24 hours), destructive of the soil sample, and is limited by the likely loss of organic matter at high temperatures that might cause an overestimation of moisture content. In addition, it is unable to collect continuous soil water data, therefore, the volumetric method is generally used.

The volumetric soil water content is measured indirectly through in situ methods, and can also be measured in the lab by conversion using bulk density. These methods all rely on comparing measured field variables with known responses of soil water content in controlled environments. One of the oldest techniques used to measure volumetric soil water content is the neutron probe. The neutron probe contains a small nuclear unit (which is both a neutron source and detector) that starts scattering fast neutrons (Bell 1987). These are 
deflected by hydrogen (most commonly water) and are slowed down. The nuclear unit is able to detect and record the returning slow neutrons, which is directly related to the soil water content (Bell 1987). Advantages of this probe are that it has the largest sphere of influence $(10-20 \mathrm{~cm}$ radius) which helps eliminate issues with fine-scale spatial variability. It is not affected by temperature, soil type or $\mathrm{pH}$. The disadvantages of neutron probes are that there is a high set up cost involved, an operating license is required due to the radio-active source, it is not easily transportable, and is unable to take continuous measurements.

The dual probe heat pulse method (DPHP) is another method for measuring volumetric soil water content (Campbell et al., 1991). The instrument consists of two probes separated by a distance of $6 \mathrm{~mm}$. One probe contains a heating element, and the other contains a temperature sensor. A heat pulse created by the heating element causes a temperature change, which is measured by the other probe that contains the temperature sensor. The degree of change in temperature is a function of the distance between the probes, the amount of heat introduced, and the soil volumetric heat capacity (Campbell et al.,1991). Therefore, the soil volumetric heat capacity can be calculated as the heat pulse, and the probe distance are known variables. There is a strong linear relationship between the soil volumetric heat capacity and the volumetric soil water content, which allows an estimation of volumetric soil water content (Campbell et al. 1991). This method is used in measurements of sap flow in living plants. Advantages of the DPHP method include high spatial resolution of a few millimeters which is ideal for areas with heterogeneities such as soil surface. Disadvantages are that it is affected by temperature fluctuations in the soil, has a crucial needle spacing, which, if inaccurate (e.g. through needle diffraction) can cause as much as a six percent error. This is particularly a problem in stony soils.

Geophysical methods are increasingly gaining interest as an alternative to physically measuring soil water content. These methods include ground penetrating radar, electromagnetic induction and direct current resistivity. They use properties such as electromagnetic water propagation time and ground conductivity (Topp et al.,1980). Advantages of these techniques are that they are improving in accuracy as technology develops, and are effective at 
determining spatial variability for variables related to soil water content. However, since these techniques use properties such as ground conductivity and electromagnetic wave propagation to convert to soil water content, ground calibration is required which might be affected by spatial heterogeneity (Topp et al. 1980).

A commonly used method which has gained increased use throughout the years is sap flow sensors. Sap flow sensors use the heat pulse theory mentioned above, which is based on the idea that you can use heat as a tracer of sap flow (Cohen et al.,1981). They can accurately estimate the amount of water a plant is transpiring without disrupting the sap stream (Cohen et al., 1981; Green et al., 2003). Sap flow measurements are reliable, use inexpensive technology and are able to collect data continuously which is advantageous. However, in a water balance scenario, the sap flow sensors only provide accurate estimations of one output, which is plant transpiration. They are unable to record fluxes of soil water changes and pressure potentials unlike the instruments above.

Electromagnetic measurements calculate soil water content based on the charge in the soil. Dielectric permittivity describes the ability of a molecule to store charge. Water has a high dielectric permittivity, a consequence of its polar nature (Gaydon 1967). The dielectric constant is a quantity that characterises the ability of a substance to store electrical energy in an electric field, where the dielectric constant therefore changes with temperature (Gaydon 1967). In an instrument such as the time domain reflectometer, an electrical pulse is sent down its metal rods that are inserted into soil, and is then reflected back when it reaches the end of the rod. The travel time required for the pulse to reach the end of the rod and back, depends on the dielectric constant of the soil. The larger the dielectric constant, the longer the pulse travel time. Because the dielectric constant and permittivity of a soil depends strongly on the amount of water present in the soil, the soils' volumetric water content may be inferred from the reflected measurements (Gaydon 1967; Kirkham 2014; Topp and Davis 1985). Water has a relatively high dielectric constant (approximately 80), whereas dry soil has a dielectric constant of around 2 to 5 (Topp and Davis 2013). Hence, changes in soil water are easily monitored. Since water stores the bulk of all charges in the soil, and is one of the soil components that 
fluctuates in concentration, the reflected measurements are therefore used as a way to infer soil water content for the length of the rod.

Dielectric sensors may be used to measure the volumetric soil water content indirectly, through the use of dielectric permittivity (Kirkham 2014). There are two different sensors that can be used to measure dielectric permittivity; time domain and frequency domain. Time domain reflectometry (TDR) records the time it takes a propagated electromagnetic wave to travel over the length of the instruments probe rods. As water content increases, so does the travel time of the propagated electromagnetic wave. TDR is accurate if calibrated properly to different soil types, but they are quite expensive, consume a larger amount of power and are sensitive to air gaps in the soil. There are numerous studies that analyse the TDR method and its use for routine soil water measurements in fruit crops (Green et al., 2003; Green et al., 2006). For example, TDR studies in New Zealand apple and kiwifruit crops have shown that water uptake is dominated by surface roots (in top $0.2 \mathrm{~m}-0.4 \mathrm{~m}$ of root-zone) (Green et al., 2003; Green et al., 2006). Unlike sap flow sensors, TDR probes are not able to estimate crop transpiration directly (Green et al., 2003), instead they can be used to account for the whole soil water balance (crop transpiration, soil evaporation and drainage) which is crucial when developing a water management plan.

To improve on the problems found in TDR, the frequency domain reflectometry (FDR), or capacitance sensors are used. They measure the dielectric permittivity of the soil by measuring the difference between the output wave and return wave frequency. FDR probes are similar to TDR in which they require calibration to specific soils. However, they offer a faster response time compared to TDR probes and are cheaper to build. These soil water sensors are widely used and are considered a standard in-situ method in hydrological and horticultural research. They simultaneously measure soil water content and bulk electrical conductivity at frequencies that make it simple to separate the two properties. Therefore, due to the above reasons, similarities to TDR, and instrument availability, FDR were used in this study.

Complementary to soil water content is soil water potential, and more specifically matric potential. Both soil water content and matric potential help to 
gain a deeper understanding of the soil water balance, particularly in the presence of plants.

\subsubsection{Soil Water Potential}

Energy states of the soil, control the transport of water from the soil surface to beyond the root zone, down to the ground water, and vice versa. Soil water potential is important for understanding the water movement within plants.

Water moves from areas of high potential energy to areas of low potential energy (Hillel 1998). The speed of water movement is proportional to the energy gradient between different points of energy levels, for example, between the soil and the plant (Hillel 1998). This energy is expressed as soil water potential, which is the force that drives water to flow. It describes the energy requirement to pull water out of a soil sample. Water potential is expressed in units of pressure, kilopascals $(\mathrm{kPa})$ or in centimetres of water $\left(\mathrm{cmH}_{2} \mathrm{O}\right)$. The soil water potential energy (per unit of quantity of water) represents the soil energy status in relation to a reference energy potential of pure water (zero). This means that any water bound to surfaces (such as soil or roots), or diluted by solutes, will create a negative water potential as it requires the expense of energy to move it from its bound surface, back to a pool of free water.

The energy status of soil water has four contributing component potentials: gravitational potential energy, solute potential energy, pressure potential energy, and matric potential energy. The gravitational potential energy of soil water is determined by the placement of water in the gravitational force field (Hillel 1998). It depends on the elevation of water relative to a reference level such as the water table level, or soil surface. Simply, water at higher elevations in the soil profile relative to the reference point, have a higher gravitational potential compared with water lower down in the profile (Hillel 1998). Hence, water moves downwards from high potential energy to low potential energy, just like surface water in rivers always flows downhill.

Solute potential energy (or osmotic) is determined by differences in solute concentration between soil and free water, which causes a potential energy difference. This is always negative and typically occurs where there is a semipermeable barrier such a plant root (Hillel 1998). Water is able to pass into the roots, whereas the solutes can't. This causes a pressure potential energy from 
the hydrostatic pressure being applied to water (high solute potential region to low in roots). A positive pressure potential is present below the water table, where hydrostatic pressure (zero at the water table) is larger than atmospheric pressure (Hillel 1998). In plants, pressure potential can be seen in plant cells by turgor pressure. In unsaturated soil, the pressure potential of water is considered negative, which is often referred to as suction or matric potential (Hillel, 1998; Tindal et al., 1988). In these cases, both matric and suction potential can be classed as the same term based on the assumption that they are both positive values under saturated conditions, and negative under unsaturated conditions (Tindal et al., 1988).

Matric potential, not to be confused with water potential, is determined by capillary and adsorption forces (Tindal et al., 1988). It is typically the most important factor of total water potential as it binds the water to the soil. Capillary forces are based on soil matrix properties, which occur from the interaction of water and air in soil pores (Tindal et al., 1998). Adsorption forces are created from the adhesion of water to most surfaces which are bonded by relatively weak electric forces known as van der Waals-London forces, and hydrogen bonding (Tindal et al., 1998). Soil matric potential is always negative above the water table (unsaturated soil) because the atmospheric pressure is always higher, and increases to zero when the soil is saturated at or below the water table (Figure 10).

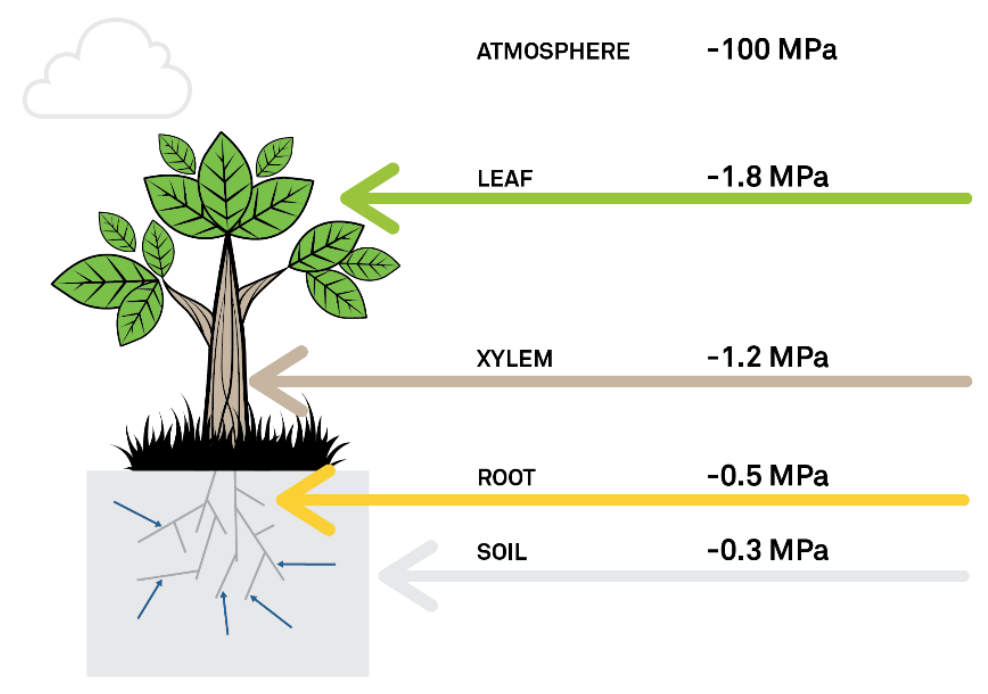

Figure 10: Diagram illustrating the differences in soil matric potential between the atmosphere, tree and soil. Image derived from: www.metergroup.com 
The soil matric potential is a realistic gauge for measuring the amount of soil water available to plants, as it constitutes the force with which water is held by the soil matrix. A description of how the matric potential changes in relation to saturated and unsaturated soils is described more in depth below, where the influence of pore volume and capillary force caused by plants is also explored. Lastly, the method by which matric potential is measured is by using tensiometers.

\section{Matric potential and water potential component relationships}

The matric potential is always negative in the unsaturated zone of the soil due to the atmospheric pressure being higher. This causes the unsaturated zone to act as a two-fluid porous media with both water and air. The matric potential, which is often referred to as capillary or pressure potential, is shown as a negative sign (Tindal et al., 1998). In a hypothetical unsaturated soil column that is one meter high, with a water table at $0.8 \mathrm{~m}$ depth (Figure 11), the matric potential above the water table would be negative $\left(\psi_{\mathrm{m}-}\right)$. As the soil saturates, the matric potential increases to zero at the water table, and positive $\left(\psi_{\mathrm{m}+}\right)$ below the water table. By convention, the positive matric potential below the water table becomes the pressure potential $\left(\psi_{p+}\right)$ which means that the soil is at hydrostatic pressure which is higher than that of the atmosphere (Tindal et al., 1988). Below the water table, the pressure potential is equal, and opposite to that of gravitational potential energy. For example, as pressure increases from zero at the water table to positive with depth, the pressure potential is equal, but opposite to gravitational potential. 


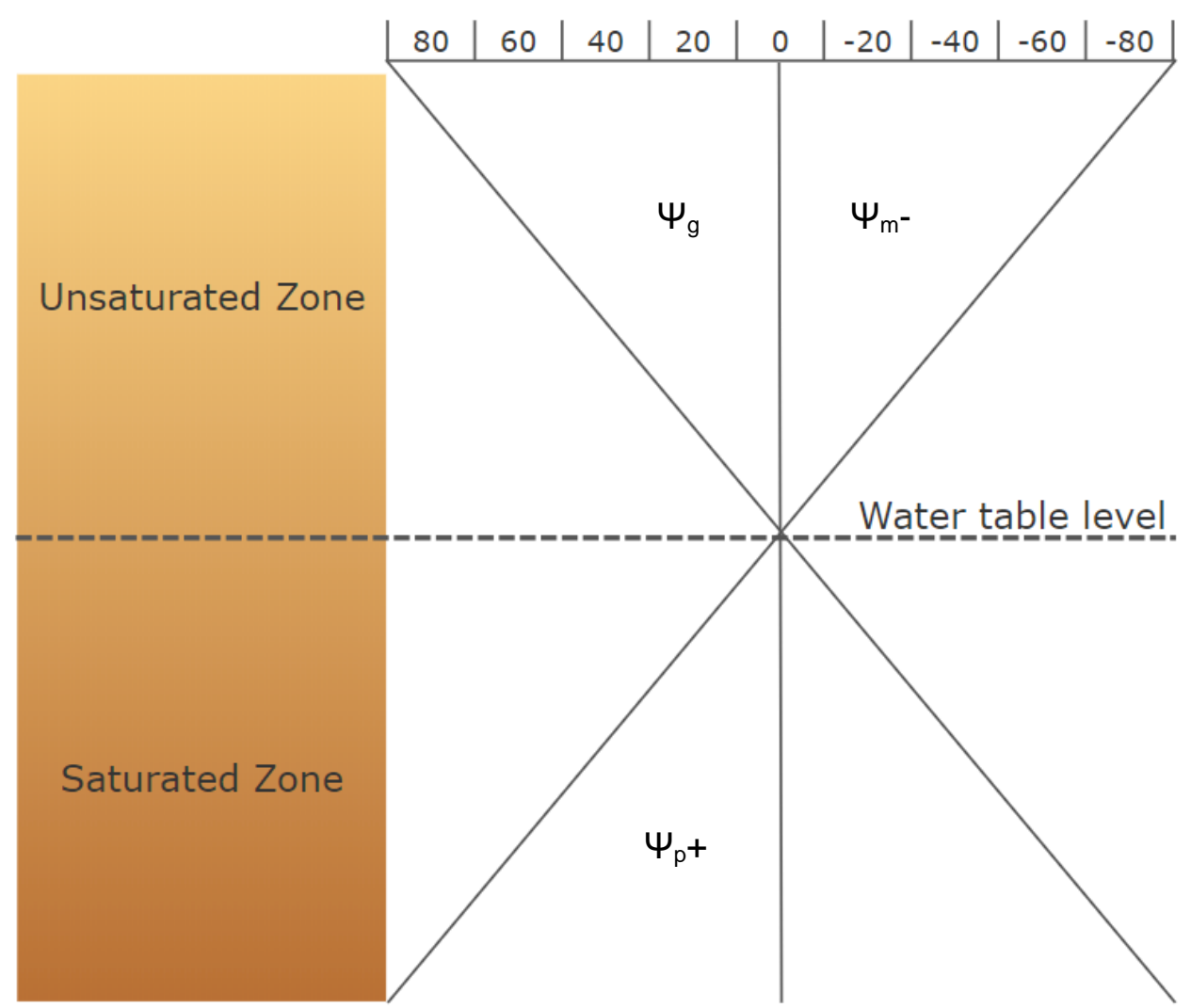

Figure 11: Soil column with the water table at $80 \mathrm{~cm}$ depth in the profile. The diagram illustrates the relationships between the soil potential components. Modified from Tindall et al. (1998).

\section{Pore volume and matric potential}

In saturated soil (e.g. surface of water table), the matric potential is zero which means that the soil water content is approximately the same as the volume of pore spaces in the saturated soil. When a suction pressure such as capillary force (negative pressure below atmospheric pressure) is applied, the soil water starts draining out. The large pores drain out first until they completely empty, then high suction will drain out the smaller pores. Only very narrow pores hold water at high suction levels (Martínez et al.,2014). The remaining moisture in narrow pores cannot contribute to water flow, this is known as residual soil water content (Martínez et al. 2014). The difference between residual soil water and saturated soil water content is the hydraulically active pore spaces that allow water to move through the soil. Soil type, more specifically pore size, is an important factor as it controls the adhesion forces in the soil matrix which should be accounted for (Trimble and Tyree 2007). In sandy soils with larger pores, less water is adsorbed at high suction pressure compared with clay soils. Therefore, since matric potential is a combination of water and soil matrix attraction, the smaller the pores (eg. Clay soils) are, the larger the soil surface 
area and adhesion forces making it harder for water to move through the soil matrix. Thus, as soil water increases, matric suction decreases. The amount of energy needed to move water in these smaller pores increases, resulting in slower moving water.

Plants affect the soil water retention through their influence on pore size and the utilization of water in transpiration. Plants create a suction pressure in the soil, causing moisture loss through transpiration (Trimble and Tyree 2007).

\section{Application of Matric Potential}

Currently, there is no instrument that can accurately measure matric potential within its full range. A common approach used to measure matric potential is through the liquid equilibrium method. Tensiometers use this method, where the instrument equilibrates under tension with the soil water, and measures the pressure of the water to retrieve the matric potential of the soil. Tensiometers were used in this study.

The range of matric potential measurement is typically 0 to $-80 \mathrm{Mpa}$ (Kirkham 2014). Tensiometers measure tensions in the soil that are expressed in terms of tension head (units of length) or potential energy per unit volume. Tensiometers consists of a porous, permeable ceramic cup connected through a water-filled tube to a pressure-measuring device. As soil dries out, water is sucked out through the porous ceramic cup, creating a partial vacuum inside the tensiometer that is read on the vacuum gauge. When the soil is wetted through irrigation or rainfall, water flows back into the tensiometer where the vacuum decreases and the gauge reading decreases.

The type of soil that a tensiometer is installed in is important. Sandy soils will reach a high tension faster than a clay soil, as sandy soils cannot supply as much water to the plant and is therefore, used up more quickly. A limitation for tensiometers is that they have reduced accuracy in dry soil, as the pores in the ceramic cup drain and air is sucked in through them, which breaks the vacuum seal between the soil and the gauge (Kirkham 2014). Therefore, checks and refilling is required to maintain the water level in the ceramic cup. The placement of tensiometers must be near the midpoint of the main root system where water is sure to wet the soil to get accurate readings of soil matric potential (Kirkham 2014). 


\subsubsection{Soil water retention}

As shown in section 2.1.3, the matric potential depends on the soil water content, and this relationship is used to establish a soil water retention curve (SWRC). The SWRC is used to predict useful "hydrolimits" such as wilting point, field capacity, and plant available water (Novák and Hlaváčiková 2019). The SWRC is characterised by a hysteresis-like form, where the relationship is different for wetting and drying processes in the soil. It shows that as soil water increases, matric suction decreases. The effect soil texture, such as silt versus stoney soil on water retention can be shown by comparing SWRC for both soil types. For example, less water is adsorbed at high suction pressure in stoney soils compared with silt soils. In addition, vegetation can influence the SWRC by its effects on pore size (due to roots), and the use of water through transpiration. Hence, the SWRC is a useful tool to explore as it can explain differences in crop performance, water use and plant water demand.

\subsection{Methodology}

Frequency domain reflectometry probes (FDR) and tensiometer instruments were used to measure soil water content and the matric potential of the soil at all research sites. Unfortunately, due to the lack of data logger availability, tensiometers were not installed at the old Syrah site.

\subsubsection{Installation of frequency domain probes}

The FDRs used in this study were the CS-615 Water Content Reflectometer (Campbell Scientific, Inc. Logan, UT). They were attached to a single ended analogue input of CR1000 (Campbell Scientific, Logan, UT, USA) data logger which was powered by a $12 \mathrm{~V}$ battery. This was contained in a water-tight container. The loggers were programmed to collect data continuously every 15 minutes. The probes produced a square wave output which was converted to a volumetric water content through insertion of a conversion equation into the logger programme. At the old Syrah site, Villa Maria Vineyards already had their own FDR setup there in which I was granted access to the data. Hence no FDR was installed there.

The probes were installed vertically, to a depth of $30 \mathrm{~cm}$. Therefore giving average soil water content readings for the top $30 \mathrm{~cm}$ of the soil profile. The 
vertical position was chosen due to limitations in the number of instruments available, and considered sufficient because in apple trees, approximately $70 \%$ of soil water is taken up in the top $0.4 \mathrm{~m}$ of the rooting zone, where $~ 70 \%$ of a tree's fine roots are found (Green and Clothier 1998).

The reflectometers were inserted approximately $30-40 \mathrm{~cm}$ from the trunk in line with the drip irrigation, and midway between a drip emitter (Figure 12). This was to ensure that the root distribution and the wetted volume of the drip irrigation are accounted for (Coelho et al.,2007; Levin et al.,1985). If instruments were placed directly under a drip emitter, then the concentration of water would be the highest (centre of the wetted area), and not representative of what was applied per tree. In addition, if the instruments were installed too far away from the trunk, then the root distribution will not be representative of the whole tree, and therefore underestimate crop water use. When installing the reflectometers, the sensor rods had contact with the soil substrate, shown by the ease of insertion, because air gaps can lead to incorrect measurements due to soil and air having different dielectric constants (Gaydon 1967).

Initial tests of FDR probes were taken before installation. Readings in open air were recorded, in which the FDR's should have a value of zero. If readings were greater than zero, then the instrument measurements were zeroed. Readings of open air were taken before and after the installation. At the start and the end of the experiment, a calibration was carried out in the lab. The probes were placed into a bucket of distilled water and readings were recorded, and any adjustments were made as needed to the programme.

Each plot (individual tree per treatment, eg, vee) was chosen by healthy plants that represented the block, as well as being within 10 meters of each other due to data logger and instrument length restrictions. At all sites, one reflectometer per tree was installed per plot, with three plots per treatment. In the vine, and apple tall spindle and apple planar cordon sites, each plant was considered a single plot. In the vee system, each plot consisted of two adjacent trees oriented in opposing directions, with a $0.5 \mathrm{~m}$ spacing's between them ( $0.5 \mathrm{~m}$ distance). 


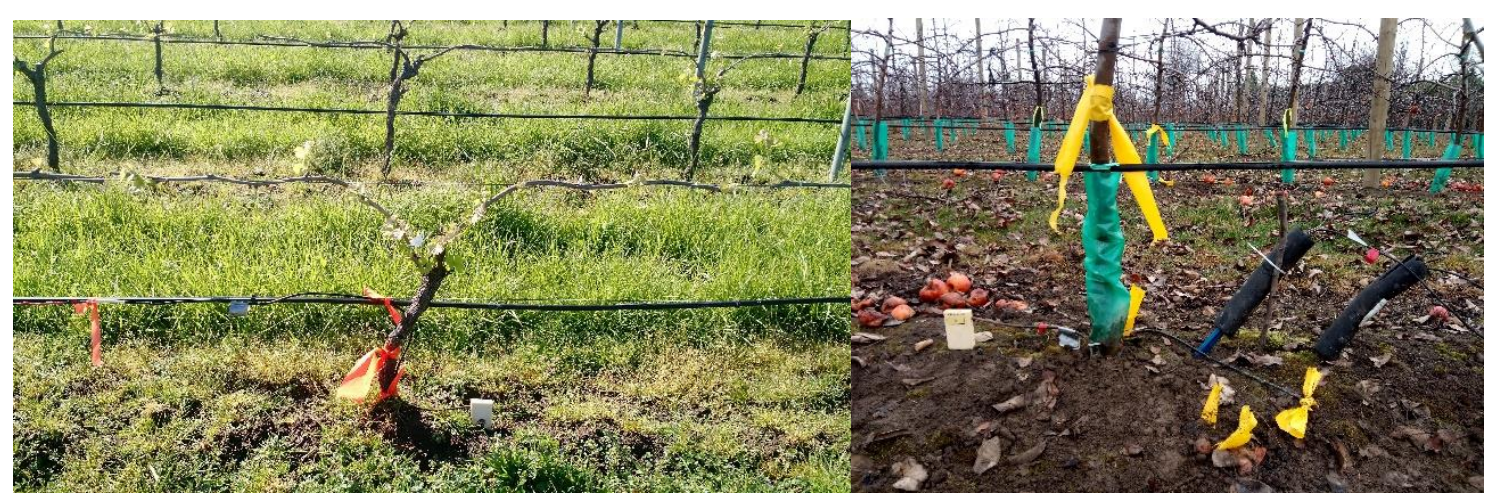

Figure 12: Photos showing the soil water probe position in grapes plot (left), and tensiometer in apples plot (right).

\subsubsection{Installation of tensiometers}

In each plot UMS T4e (UMS GmbH München) tensiometers were installed. These sensors were chosen as they had the desired sampling frequency and suited the characteristics of the vine and tree plots. At Evenden orchard, the soils are characteristically prone to water logging, and at Te Awa vineyard, the soils are characteristically dry during the summer months due to their alluvial origins. The sensors chosen for this study are capable of accurately measuring both scenarios of wet and dry conditions, and tensiometers have the highest accuracy when measuring saturation. The tensiometers function within a range of $+100 \mathrm{kPa}$ (water pressure) to $-85 \mathrm{kPa}$ (suction pressure).

The T4e tensiometers comprise of a $40 \mathrm{~cm}$ long body shaft which contains the pressure transducer, and a semi-permeable ceramic cup (AL203) at the bottom. During dry periods in summer, degassed water was used to refill the tensiometers to ensure reliable measurements were taken and cavitation didn't occur. The refilling tubes and part of the body shaft tensiometers were covered with a thermal insulation tube to protect the equipment against ultraviolet radiation.

A total of eight tensiometers were installed across all four sites (vee, tall spindle, planar and young Syrah) in July 2019. At each site, apart from the old Syrah, two tensiometers were installed in one plot (one selected tree/vine). The tensiometers were installed at different depths; $10 \mathrm{~cm}$ and $30 \mathrm{~cm}$ at an angle of approximately 60 degrees from horizontal. They were both installed under the drip irrigation line, and the first tensiometer was installed approximately $40 \mathrm{~cm}$ 
from the trunk, with the second tensiometer installed approximately $10 \mathrm{~cm}$ further away. All tensiometers were connected to a CR 1000 data logger (Campbell Scientific, Logan, UT, USA) which was powered by a $12 \mathrm{~V}$ battery to enable continuous measurements. The data loggers were programmed to record soil suction pressure at five minute intervals.

Calibration of tensiometers was tested in the lab. Tensiometer pressure transducers are normally calibrated with an offset of $0 \mathrm{kPa}$ when in a horizontal position. However, this offset can drift over the years which needs to be checked. To check this, the tensiometer was connected to a data logger and placed in a bucket of de-ionised water to a height of $7.5 \mathrm{~cm}$. Once the reading was stable, the reading should show $0 \mathrm{kPa}$. For all tensiometers used in this research, they all showed $0 \mathrm{kPa}$ readings when in de-ionised water, therefore no further calibrations to the programme needed to be followed through.

\subsubsection{Rainfall and irrigation}

Hourly rainfall was recorded at both the apple and grape sites by individual weather stations owned by the site that was recorded by an online server. Weekly irrigation (L/week) was recorded for the apple blocks at the Evenden orchard was also recorded by an online server. Unfortunately, irrigation applied at the Te Awa vineyard was not recorded. However, the orchard management has confirmed that they only irrigated when necessary (based their scheduling on pressure bomb readings), and would irrigate for no longer than two hours at a time.

\subsection{Results}

This section presents the results gathered from the reflectometer and tensiometer instruments. Results on physiology and evapotranspiration will be reported in Chapters 3 and 4.

\subsubsection{Soil matric potential}

The soil matric potential results were recorded continuously from September 2019 to February 2020 in five minute intervals. 


\section{Apple matric potential}

The matric potential results in Figure 13 show the three different trellis systems in the apples. Overall, changes in matric potential of tensiometers installed at 10 $\mathrm{cm}$ and $30 \mathrm{~cm}$ depths appear to have been mostly in response to rainfall and irrigation, and diurnal fluxes in evapotranspiration, but also suggest complexities in drainage/groundwater interactions. In the early season, until late November, there was a rapid decline in soil matric potential at both 10 and $30 \mathrm{~cm}$ depths, corresponding with rapid development of leaf area in spring. From August to November, there were obvious wetting and drying events primarily corresponding to rainfall (irrigation was applied post-December) and groundwater interactions with the soil, where large differences in the matric potential were recorded at the different depths; $10 \mathrm{~cm}$ and $30 \mathrm{~cm}$ (Figure 13). During this period, the soil stayed saturated for longer during rainfall events compared with the hotter summer months when the soil dries up (November February 2020).

The soil matric potential results from the $10 \mathrm{~cm}$ tensiometer showed that during October to mid-November, the matric potential of the planar and tall spindle (vee was missing data) followed similar patterns of changes in matric potential in response to rainfall events (Figure 13). However, there is a large difference in vee and planar matric potential from November to the start of December when a rainfall event occurs. This suggests that the rain input was sufficient to bring the planar site to saturation, whereas the tall spindle shows a gradual increase in matric potential at $10 \mathrm{~cm}$. This could be caused by the tall spindle plant water demand for transpiration during this stage of canopy development. The results at $30 \mathrm{~cm}$ depth during this period show that all three systems reach nearsaturation from this rainfall event. From mid-December to March, the vee tree had much larger fluctuations in matric potential, both positive and negative which appeared to be in response to diurnal temperature and radiation fluxes. Daily matric potential readings above zero suggest soil saturation, which was likely the result of over irrigation. It is important to note this over irrigation may have impeded plant growth, due to a lack of oxygen available to the roots when soil is at or very close to saturation.

From late November, the planar trees showed very small diurnal fluctuations around a matric potential of about zero (near saturation) which suggests that it 
was sufficiently watered, if not too much. The tall spindle trees appeared to have greater periods when there was soil suction (pressure below zero), which suggests that plant demand for transpiration was higher in the tall spindle. From December to March when irrigation was applied, the matric potential at $30 \mathrm{~cm}$ depth remained around zero (near saturation) for all three trellis types. The vee and tall spindle trees fluctuated a little more than the planar canopy, suggesting that at $30 \mathrm{~cm}$ depth, they are both influenced by diurnal effects.

$10 \mathrm{~cm}$ tensiometer results

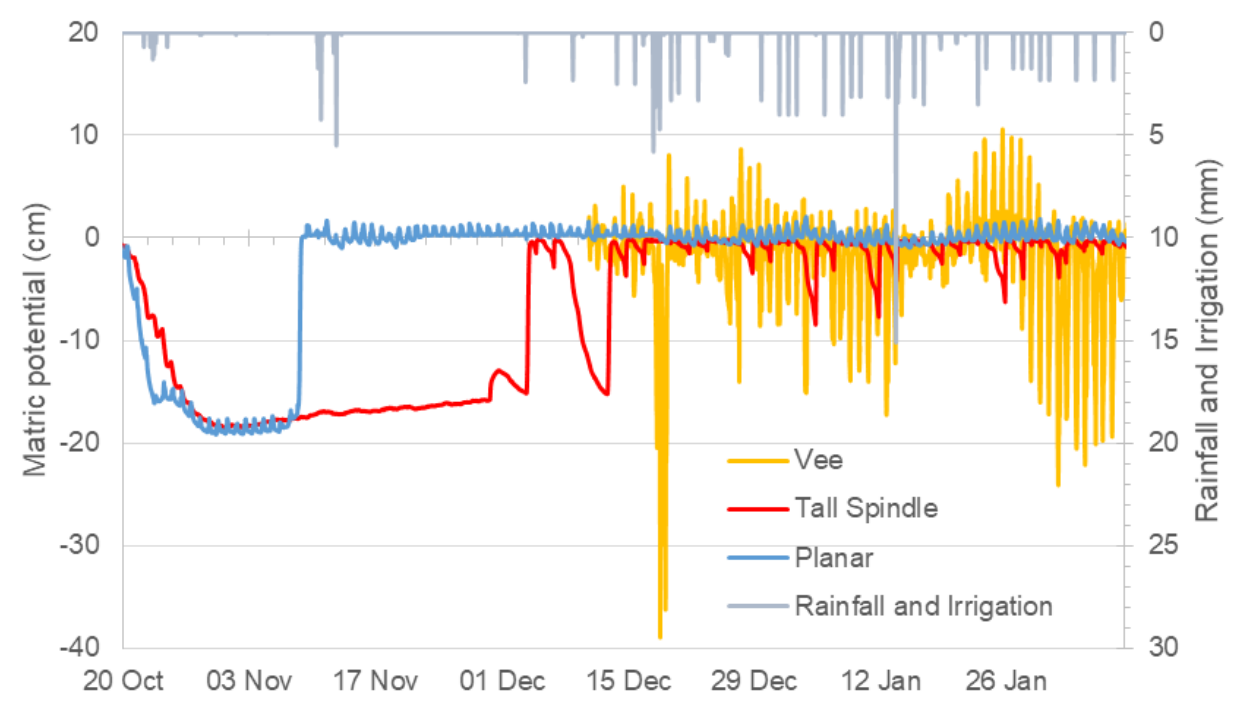

$30 \mathrm{~cm}$ tensiometer results

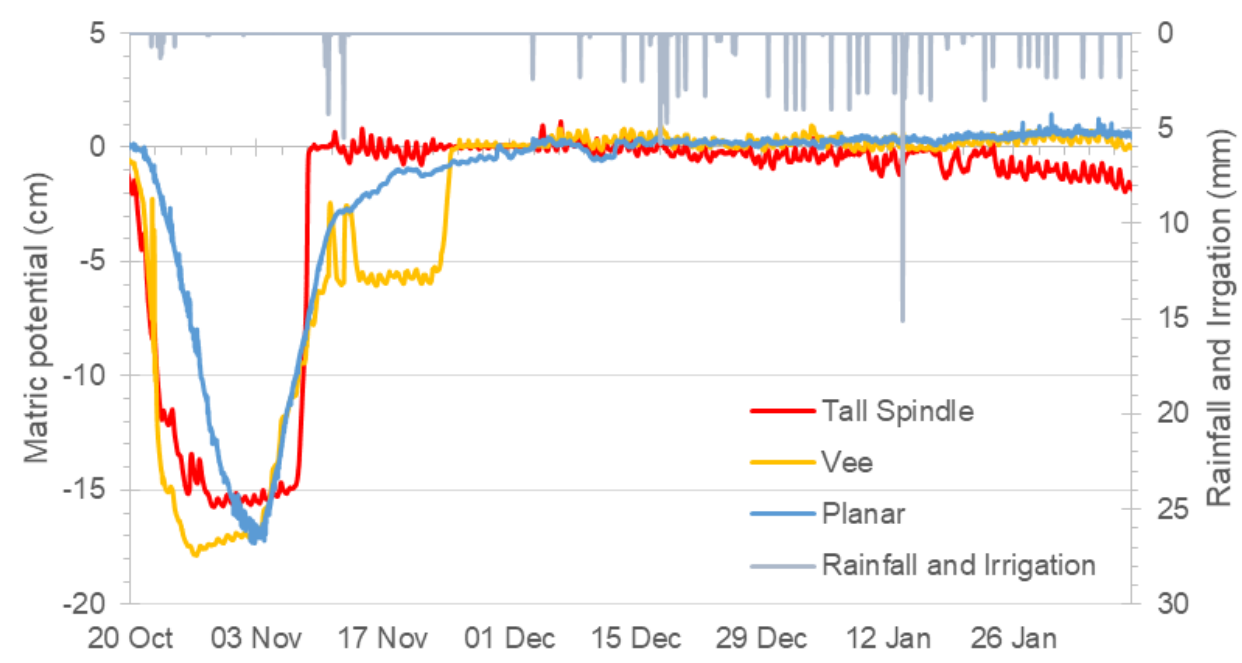

Figure 13: Suction matric potential recorded with tensiometers at $10 \mathrm{~cm}$ soil depth (top figure), and $30 \mathrm{~cm}$ (bottom figure) in three 'Scilate' apple canopy types over the 2019/2020 growing season. Note the difference in $y$-axis scale for the $10 \mathrm{~cm}$ and $30 \mathrm{~cm}$ tensiometer 


\section{Diurnal trends of apple matric potential}

To more clearly observe diurnal trends of the matric potential results, a zoomedin period was selected which shows the response to a rainfall event on $20^{\text {th }}$ December, and an irrigation event on the $21^{\text {st }}$ December (Figure 14). During both wetting events, the vee site responded quickly by showing a sharp increase in matric potential (MP) at both $10 \mathrm{~cm}$ and $30 \mathrm{~cm}$ depths to above saturation. The matric potential at $10 \mathrm{~cm}$ quickly decreased again showing an increase in suction which correlates to approximately the hottest part of the day (around $2 \mathrm{pm}$ ) where atmospheric demand will be high. Whereas the matric potential at $30 \mathrm{~cm}$ depth showed a more gradual decrease in matric potential post-rainfall water input, which was the same for all three trellis systems. At 10 $\mathrm{cm}$ depth, the planar and tall spindle showed different responses to water inputs than the vee site. The matric potential at the planar site rises above saturation during the water input event, followed by a gradual decrease. At $30 \mathrm{~cm}$ depth the matric potential remains above saturation for the entire period at the planar and vee site. This suggests that the water table was higher in these areas. The tall spindle follows a similar trend of gradual decrease in matric potential following the water input at $10 \mathrm{~cm}$ depth. However it was the least responsive to the water inputs, where matric potential did not reach saturation at either $10 \mathrm{~cm}$ or $30 \mathrm{~cm}$ depths, with the exception of the first rainfall at $30 \mathrm{~cm}$ depth. The noise shown in both figures between the main wetting and drying events can be explained through hourly changes in climatic conditions such as temperature and solar radiation, as well as groundwater recharge.

Overall, these diurnal periods show that the largest amount of change in matric potential occurs around midday. This is explained by the combination of water input and plant transpiration. The decrease in matric potential at both $10 \mathrm{~cm}$ and $30 \mathrm{~cm}$ depths slowly decreased throughout the night as plant transpiration rates were reduced (leaf stoma close in darkness). 


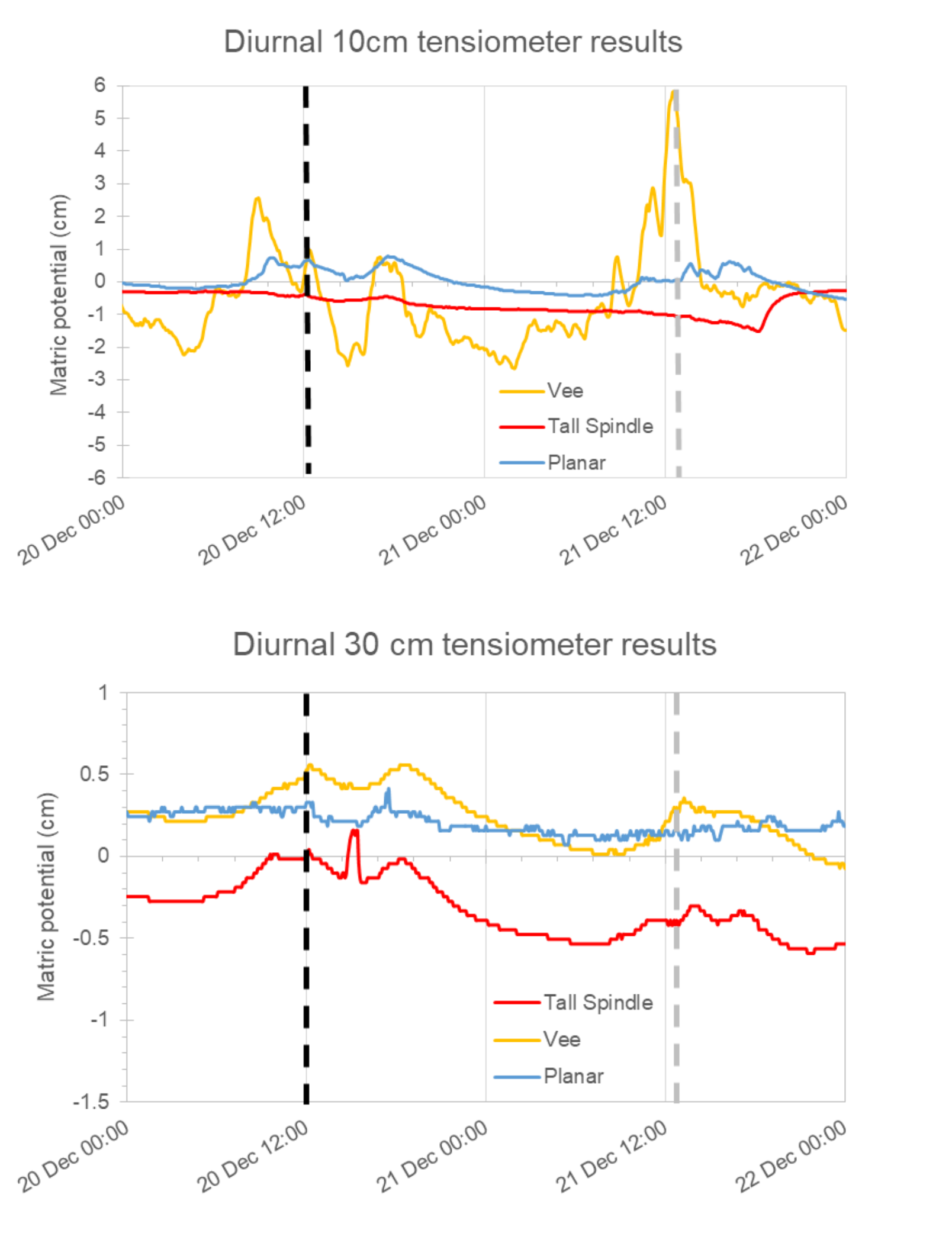

Figure 14: Diurnal trends of matric potential at both $10 \mathrm{~cm}$ depth (top figure), and $30 \mathrm{~cm}$ depth (bottom figure) for three Scilate apple trellis systems for a two day period. Vertical black-dashed line indicate the rainfall event, and the grey vertical-dashed line indicates irrigation event. 


\section{Grape matric potential}

The matric potential results shown in Figure 15 are for the young Syrah site. Unfortunately, there were no tensiometers installed at the old Syrah site due to data logger limitations. Throughout the season we encountered difficulties with the young Syrah data logger (CR10), which was not responding to the programme sent to it, and not recording the data properly. Therefore, results for these vines were limited to data collected in October and November. The $10 \mathrm{~cm}$ tensiometer showed greater fluctuation than the $30 \mathrm{~cm}$ in matric potential during the period from $21-27^{\text {th }}$ October. Obvious diurnal fluxes in matric potential suggesting that vine water demand and transpiration were highest during midday. The rainfall event that occurred on $28^{\text {th }}$ October, showed that the soil reached above saturation at $10 \mathrm{~cm}$ depth. The $30 \mathrm{~cm}$ tensiometer almost reached saturation.

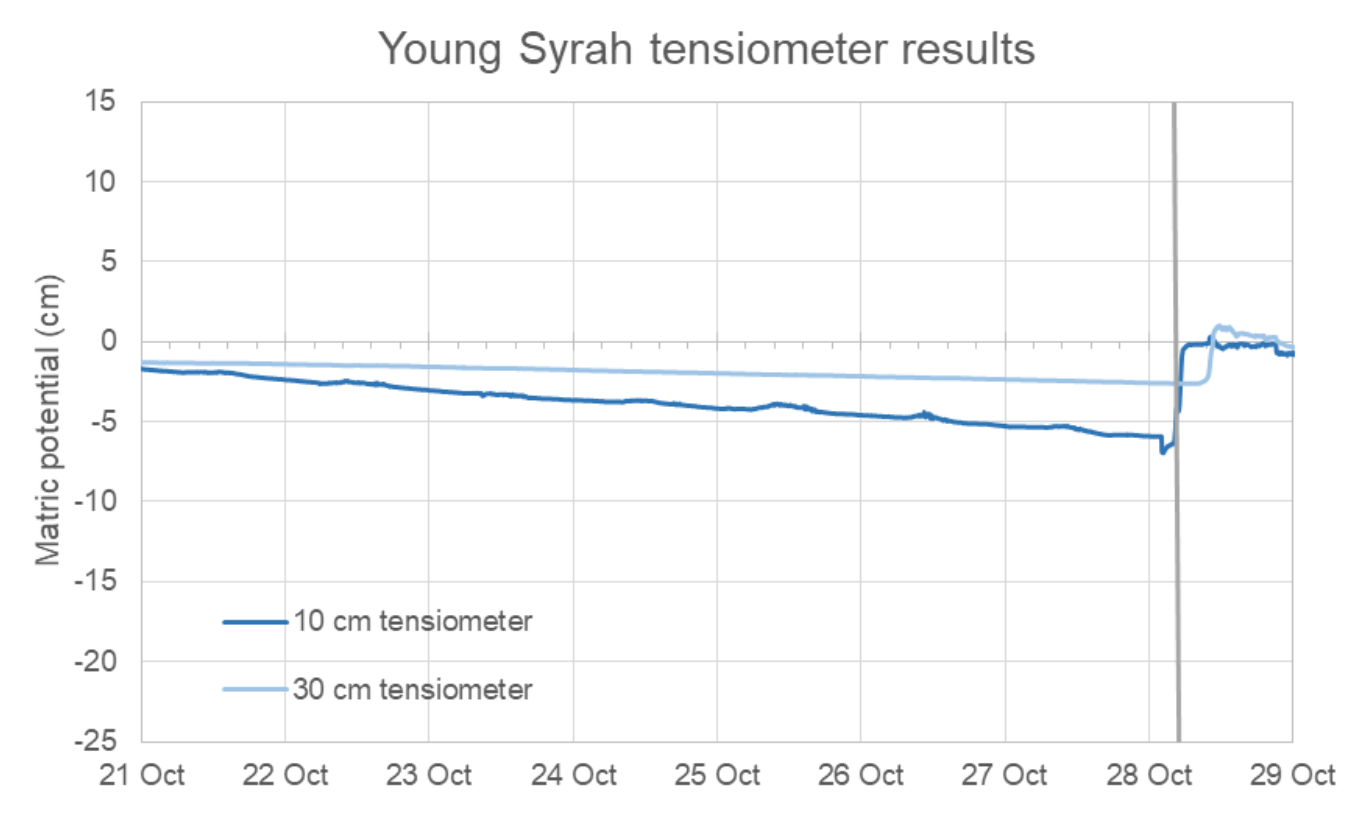

Figure 15: Tensiometer results for the young Syrah site showing changes in the matric potential at $10 \mathrm{~cm}$ depth and $30 \mathrm{~cm}$ depth. Rainfall event illustrated by the grey line.

\subsubsection{Volumetric soil moisture content}

\section{Soil moisture content in three apple trellis systems}

Volumetric soil water content estimated using FDR in the apple trellis systems sites is shown in Figure 16. Throughout the growing season the planar trees appear to consistently have a lower soil water content compared with the vee 
and tall spindle trees. This is particularly noticeable after December when the SWC in the planar trees remained between 0.2 and $0.3 \mathrm{~cm}$ while in the other treatments it rose to $>0.35$. In the months preceding December (when leaf canopy was developing and irrigation had not been applied), all three trellis systems follow a similar wetting and drying trend as the soil moisture content responds to rainfall inputs.

Following December, the planar canopy SWC showed less response to water inputs (irrigation and rainfall) and losses (eg: through evapotranspiration) than the other two canopies. This result is supported by the matric potential results in Figure 13, where there is less suction, suggesting that less evapotranspiration was occurring. The tall spindle and vee trellis systems had very similar, but not identical responses to changes in soil water content.

\section{Soil water content at three apple sites}

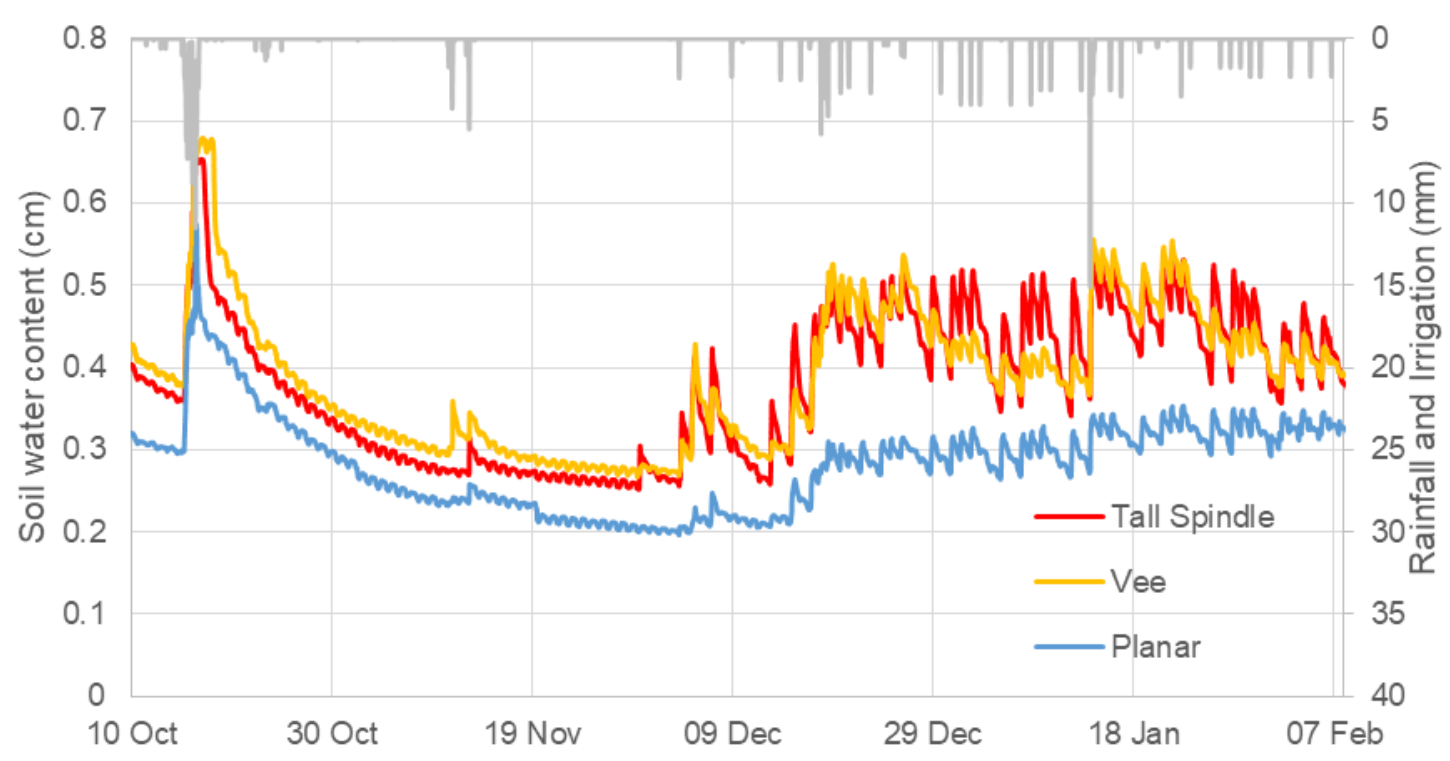

Figure 16: Volumetric soil water content $(\mathrm{cm})$ recorded using frequency domain reflectometry in the top $30 \mathrm{~cm}$ soil depth in three Scilate' apple canopy types over the 2019/2020 growing season. Each trace represents the mean of three FDR sensors.

\section{Soil moisture content results in Syrah grapes}

Soil water content changes in the young Syrah grapes are shown in Figure 17. The young Syrah shows similar wetting and drying trends happened diurnally in respect to transpiration peaking around midday. The SWC increased at midday 
on October $28^{\text {th }}$ in response to a rainfall event. Unfortunately due to instrument failure, SWC was unable to be recorded for the rest of the season.

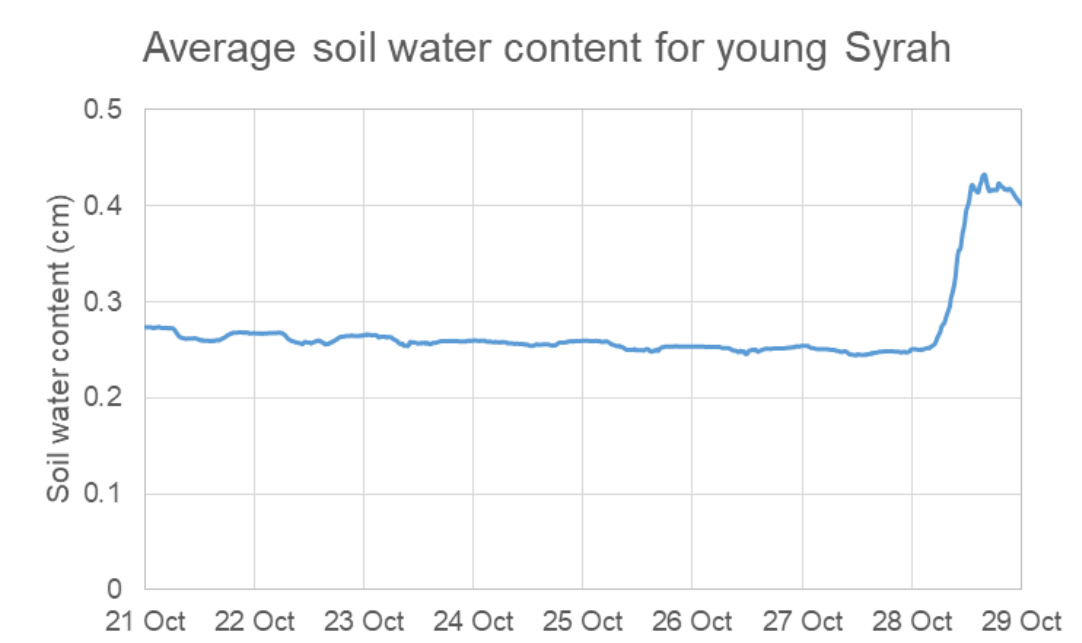

Figure 17: Average soil water content for the young Syrah plot for the month of October.

In the old Syrah grapes, there was continuous data collected throughout the season. Prior to October, soil water content remained consistently around $0.55 \mathrm{~cm}$ with small fluxes in response to rainfall events (Figure 18). From budbreak in October, as the vine canopy developed, fluctuations in SWC became greater and showed frequent wetting and drying cycles corresponding to diurnal trends.

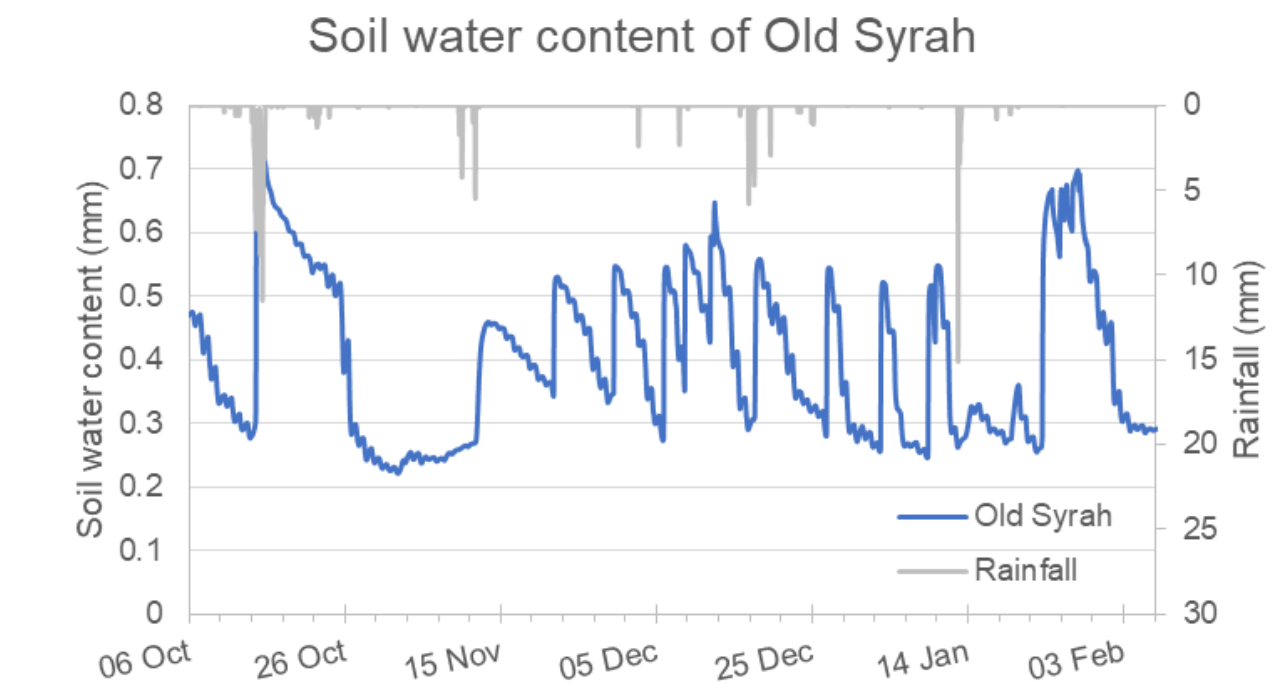

Figure 18: Temporal changes in soil water content of the old Syrah grape over the 2019/20 season. Rainfall showed by grey lines. 


\section{Temporal changes in soil water content}

Daily changes in SWC (flux) show differences among the three apple trellis systems (Figure 19). Prior to December, before all canopies had reached full canopy, the vee trellis showed the largest fluctuations in SWC, although trends were similar in all canopies. Following December, when the trees had reached full canopy, and irrigation commenced, the tall spindle site had the largest fluctuations in soil water content, followed by vee and planar sites in that order.

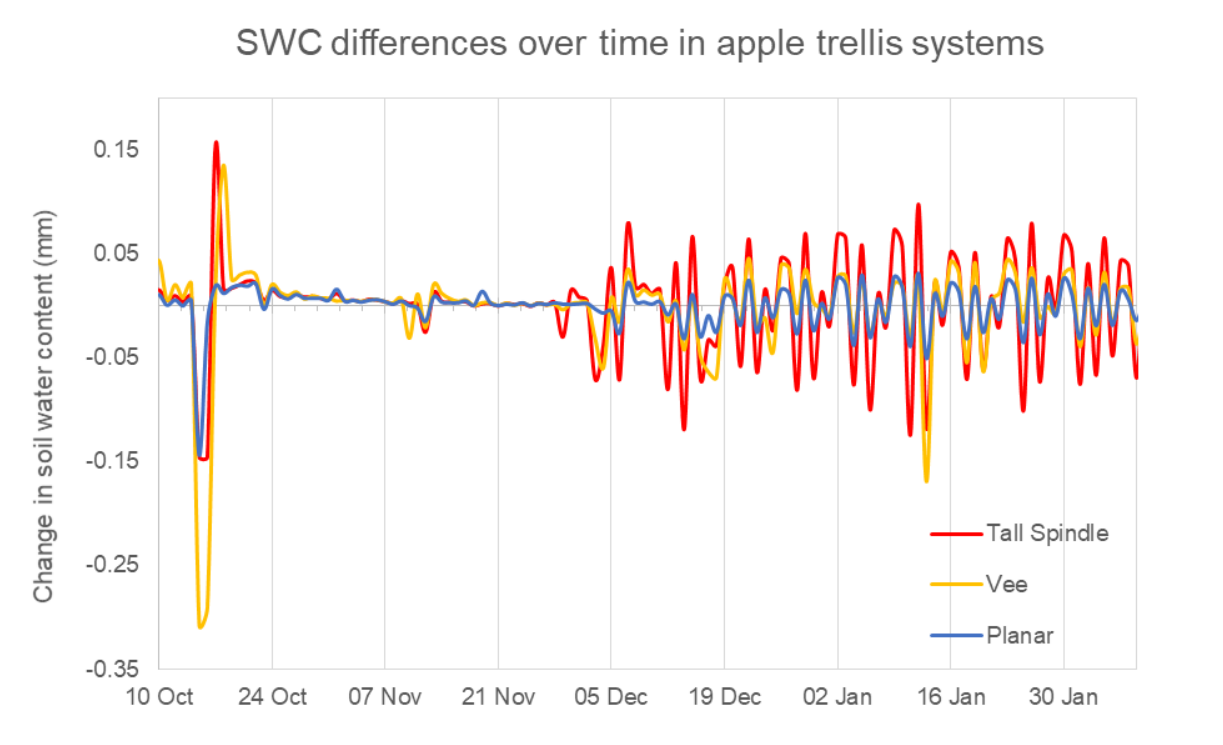

Figure 19: Changes in soil water content over time for all three apple trellis system sites.

\subsubsection{Changes in soil water content}

The hourly changes (flux) in soil water content give an indication of the amount of water added and removed from the soil during that period (Figure 20). Prior to December, i.e. before the canopy had fully developed, the cumulative changes in SWC for all three apple trellises were broadly similar. From December onwards, the tall spindle and vee trellis systems had similar trends of changes in SWC, and were generally positive, indicating water uptake by the tree. The planar canopy system showed a very different trend in soil water content flux - where changes in SWC were always negative, showing that more water was added to the soil profile than was removed by the plant. The planar system still showed the same diurnal fluxes as the tall spindle and vee, however the amplitude was much smaller. 


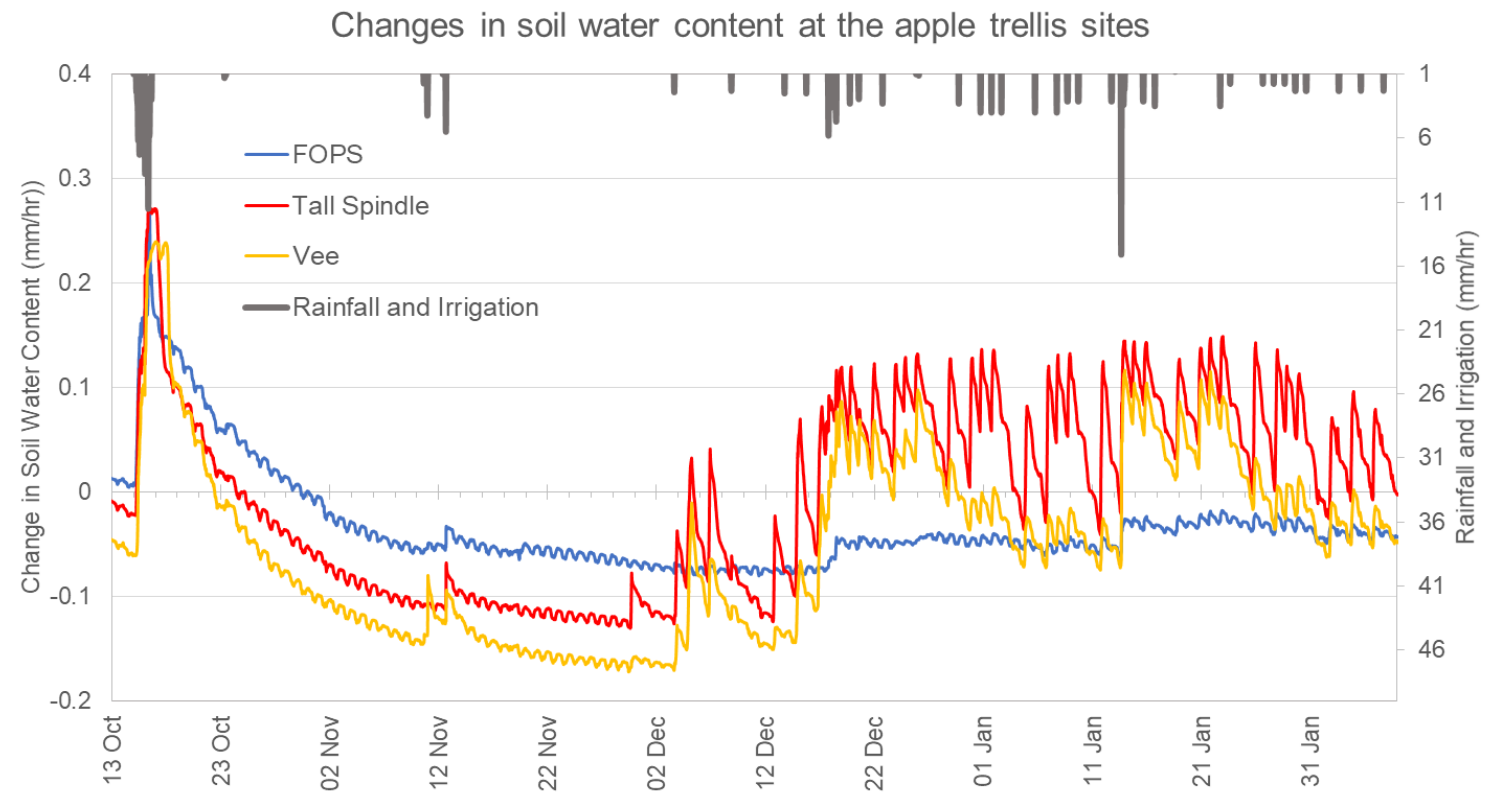

Figure 20: Changes in soil water content for all three apple trellis systems. Rainfall and irrigation shown on top axis.

Changes in the grape soil water content are mostly shown for the old Syrah, due to instrument recording issues in the young Syrah (Figure 21). The old Syrah showed mostly positive changes in SWC over the season, where the large increases post mid-November can most likely be explained by soil water drainage. The sharp increases, and decreases in SWC can be explained by the stoney soil type which has a very small water holding capacity, meaning that it is a fast draining soil.

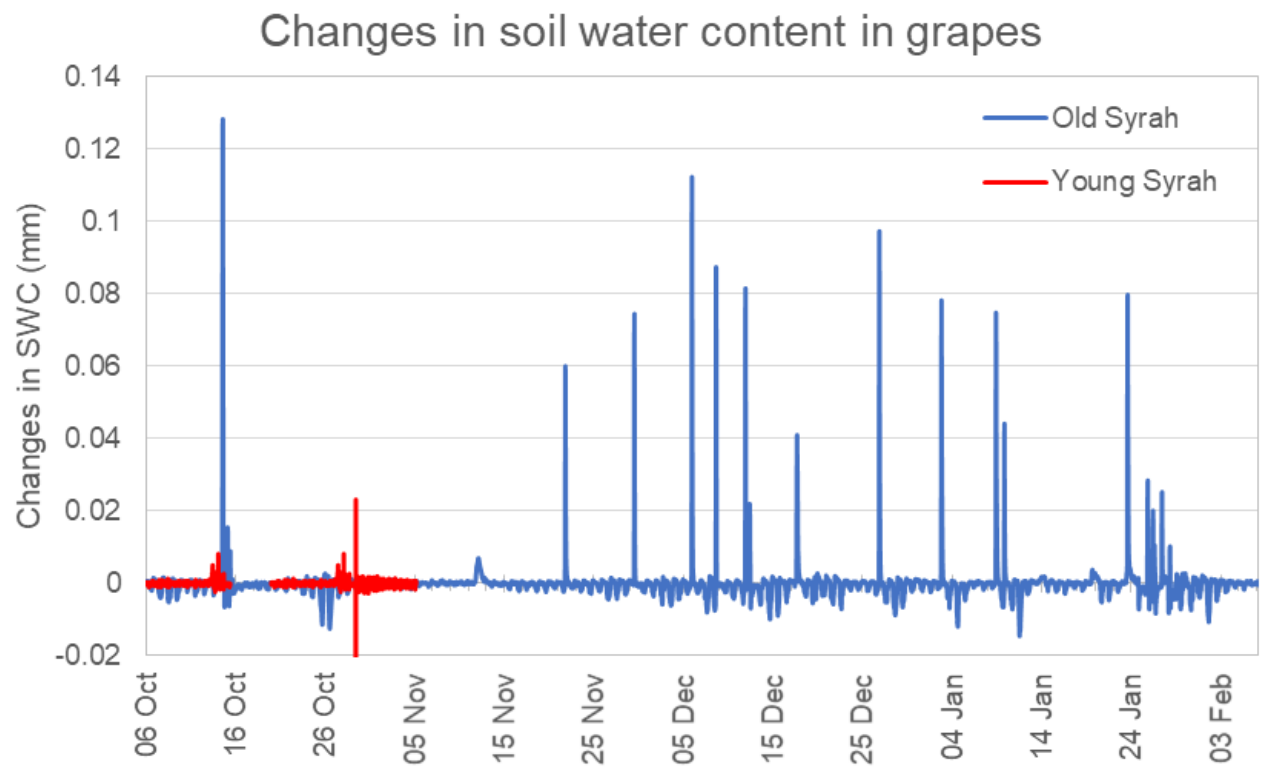




\section{Cumulative changes in soil water content}

When looking at cumulative positive differences in soil water content (soil water exiting the soil profile), there are three evident trends (Figure 22). Firstly, prior to $16^{\text {th }}$ October, the planar and tall spindle systems showed a similar increasing trend of SWC, whereas the vee system showed a steeper increase in slope of SWC. This suggests that during this period, the vee site was using more water than the planar and tall spindle through evapotranspiration. Secondly, on October $16^{\text {th }}$ there was a large rainfall event that brought $134.2 \mathrm{~mm}$ of rain over 48 hours. This event shown in Figure 22 where there is a near-vertical incline of SWC difference, represents drainage after the rainfall event. Following the rainfall event, water held in large pores was quickly drained to the groundwater. In the days after, a slower draining rate (lower gradient slope) occured where high suction drains out the smaller pores, showing a smaller SWC change.

From the $20^{\text {th }}$ October until mid-December, the slope of all three trellis systems followed the same trend. The vee site shows the largest change in SWC, followed by the tall spindle, and lastly the planar. There was little rainfall during this period, therefore the majority of SWC changes can be considered due to transpiration.

From December onwards, the slopes of all three systems increase significantly and show more frequent incremental increases (Figure 22). The start of this slope increase marks the time when irrigation was first applied, and it was applied until the end of the season. It is important to note that although all three trellis sites were irrigated under the same schedule and pump, the volume applied per tree differed due to emitter spacing and differences in tree spacing. Irrigation per tree $(\mathrm{mm} / \mathrm{hr})$ was: vee $=9.5 \mathrm{~mm} / \mathrm{hr}$, planar $=11.1 \mathrm{~mm} / \mathrm{hr}$ and tall spindle $=7.3 \mathrm{~mm} / \mathrm{hr}$. The steepness and noise of the slope can be explained primarily by soil complexities at the site, coupled with more transpiration occurring as the crops reach full canopy and production. At the tall spindle site, the area is well draining compared with the other two system, which was observed during the large rainfall event on $16^{\text {th }}$ October, where no water logging occurred. This well-draining site, coupled with less irrigation applied per tree area $(7.3 \mathrm{~mm} / \mathrm{hr}$, compared with the vee: $9.5 \mathrm{~mm} / \mathrm{hr}$ and planar: $11.1 \mathrm{~mm} / \mathrm{hr})$, 
suggests that transpiration plays a large role in the steepness of this slope as well as drainage. In comparison, the planar and vee sites show lower cumulative SWC changes of similar trends. These could be explained by too much irrigation being applied, causing water logging (which we know are both prone areas), and therefore, stomatal closure due to anaerobic conditions. This results in reduced transpiration rates, meaning lower changes in soil water content. In addition, if the water table is already high at these two sites (proven from the large rainfall event), changes in SWC will be less dramatic during irrigation drainage events. Unfortunately, from the instruments used in this research, we are unable to differentiate the effects of drainage and crop evapotranspiration.

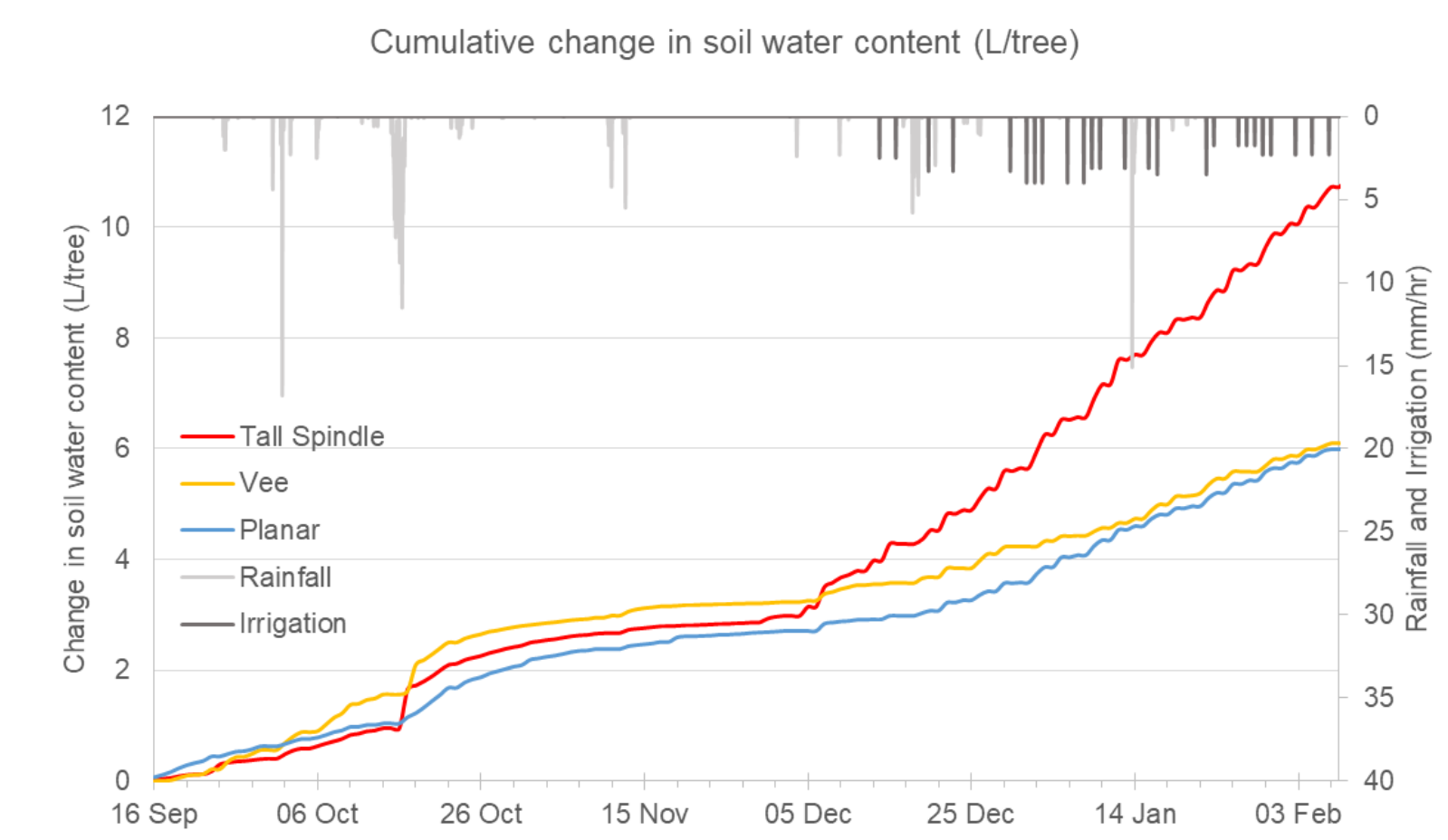

Figure 22: Cumulative change in soil water content ( $L$ per tree) for the three apple trellis systems. Irrigation and rainfall shown on the top axis.

Cumulative changes in SWC between the two soil sites is shown in Figure 23. The young Syrah appears to follow the same trend as the old Syrah in October. However, due to a lack of data we were unable to observe trends past this date. The old Syrah shows a higher SWC difference, where the increment increases can be explained by rainfall events. 


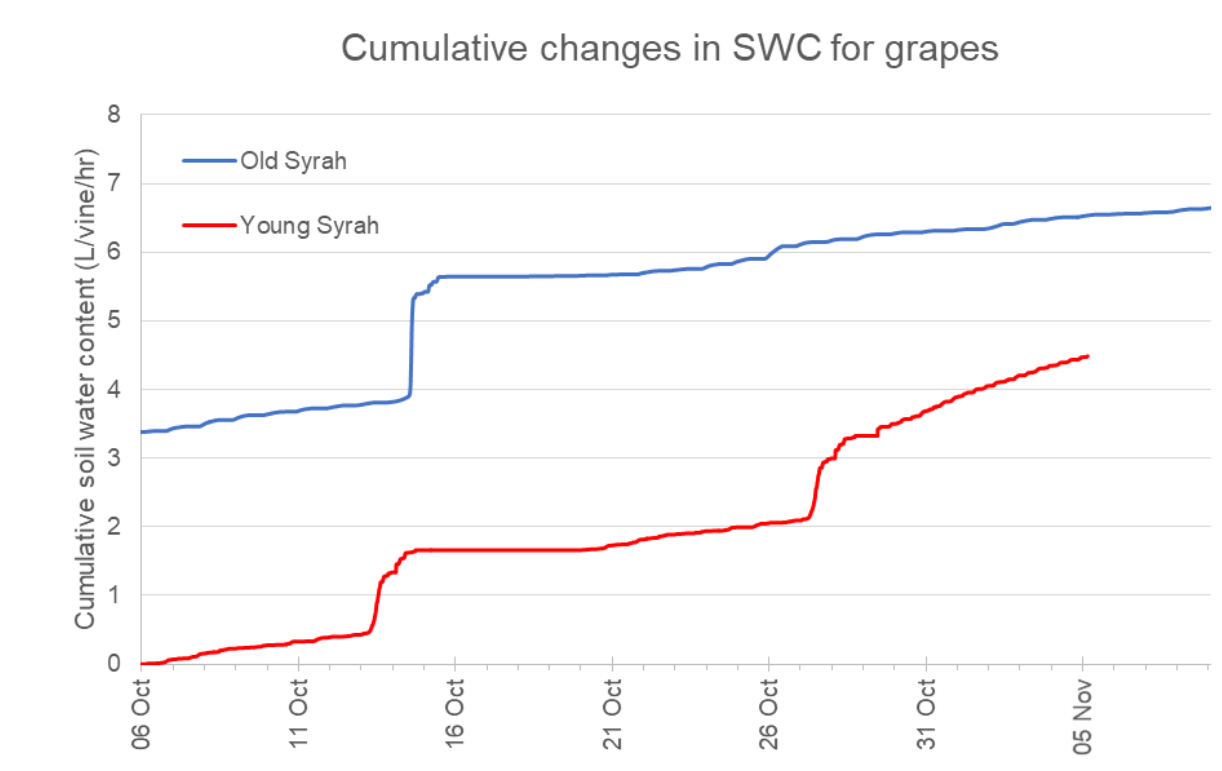

Figure 23: Cumulative changes in SWC for both grape sites for October, when the young Syrah instrument was working.

Post-December, the slope of SWC difference in the old Syrah increases where the increment increases can be explained by both crop transpiration and drainage from irrigation and rainfall events (Figure 24). Irrigation events were not recorded for both grapes unfortunately.

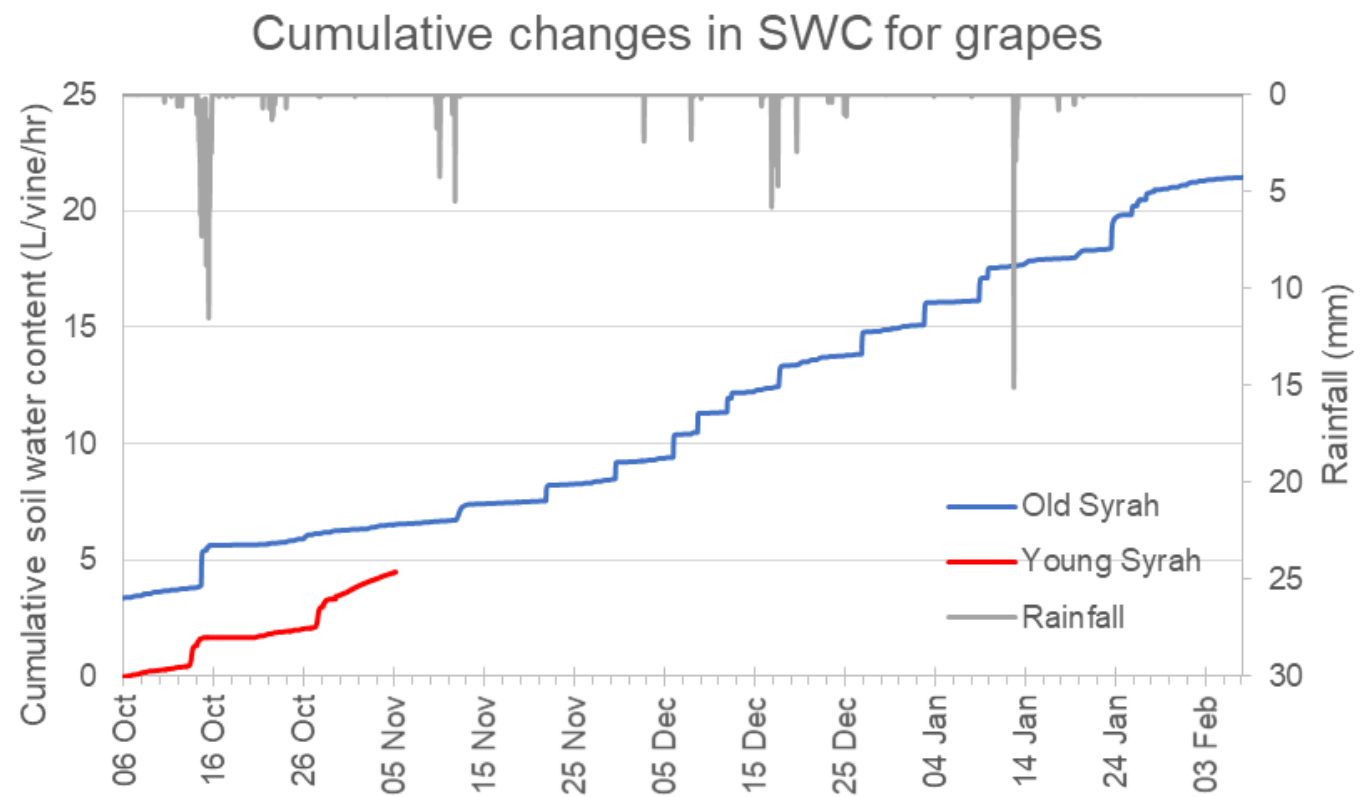

Figure 24: Cumulative changes in soil water content for both grape plots over the season. Note the young Syrah ends at the start of November due to instrument recording issues. 


\subsubsection{Soil water retention curves}

Unfortunately SWRC were not able to be plotted for this research as SWC and matric potential results do not follow the expected positive SWC:matric potential relationship. For example, the soil water content trend in the tall spindle system showed a slight increase over the season, whereas the matric potential results showed a general decrease (increase in suction). Since both tensiometers were installed at the same tree, on the same side of the tree, and the reflectometers on the opposite side of the tree, this might explain the discrepancies between readings. This could be due to the placement of instruments near or away from an irrigation emitter, or heterogeneities within the soil profile and root distribution.

\subsection{Discussion}

\subsubsection{Effects of trellis system and vine age-soil type on soil water balance}

\section{General trends observed}

Overall, the results above have highlighted some significant differences between the three apple trellis systems in terms of volumetric soil water content and matric potential.

\section{Vee}

The vee system showed the largest flux in matric potential for the top $10 \mathrm{~cm}$ of soil during the months following December, which was also complimented by the soil water content results, showing the same trends in changes of SWC. These large fluxes in both matric potential and SWC were due to responses to irrigation events applied, as well as crop evapotranspiration during the day when radiation and temperatures were high. The plants demand for water (shown through a negative matric potential - suction) suggests that within the top $10 \mathrm{~cm}$ of soil, there is a strong response to diurnal climatic changes (atmospheric demand), and that evapotranspiration influences a large amount of the water balance flux in this trellis system. However, the matric potential results also showed that the vee system was mostly kept at soil saturation which has implications for plant transpiration and overall production. 


\section{Tall Spindle}

The tall spindle trellis system showed similar trends to the vee in SWC, where there is a strong diurnal flux suggesting that evapotranspiration was a dominant factor controlling changes in SWC. The matric potential results mostly show a negative matric potential from December to February. This suggests that the irrigation applied was meeting the plant's demand (shown through a low negative matric potential value), and that it wasn't causing the soil to reach saturation, when anaerobic conditions could cause stomata to close and decrease in transpiration. The matric potential results, coupled with the SWC results show that the level at which the soil water content was kept at from irrigation application, was the right amount for this system.

\section{Planar}

The planar trellis system showed that it had the lowest SWC throughout the season, where it had very little influence by diurnal changes suggesting that evapotranspiration was not as much of a dominant process. This could also be explained by the fact that the planar trees are one growth year younger than the other two trellises, therefore lack the same vegetative and reproductive growth which would influence crop evapotranspiration (O'Connell et al.,2008). Due to the two-dimensional shape of the planar trees which is designed to intercept more incoming light, it creates less under-canopy shading compared with the other systems. This means that in the planar canopy, the soil/herbicide strip where the tree is planted and irrigation is applied, is more exposed to sunlight. This could help explain the low SWC results for the planar system. If the rainfall and irrigation applied to the soil is evaporated before it can infiltrate into the soil profile, there will be less water added to the soil water balance than the other trellis systems. In addition, the fact that the matric potential results for the planar system (both the $10 \mathrm{~cm}$ and $30 \mathrm{~cm}$ tensiometer) stayed mostly around saturation, suggests that the plant's might be responding to anaerobic conditions which is inhibiting crop evapotranspiration, causing the smaller diurnal fluxes in SWC.

\section{Young and Old Syrah grape}

Due to instrument errors identified above, I believe that the data collected from the young Syrah site lacks sufficient integrity and detail to allow further 
conclusions. Prior to December, the soil water content results for the old Syrah show fluctuating trends in response to rainfall. Post-December, the large positive fluxes in SWC were a result to both rainfall, and assumed irrigation events. Where daily transpiration influences are clearly shown by the small-step decreases in SWC. These step-decreases in SWC due to transpiration increases towards January and February when full canopy is reached and high radiation and air temperature are combined with low atmospheric humidity.

\section{Temporal changes in soil water content}

The results have highlighted that changes in soil water content have been caused by both crop evapotranspiration, and drainage from rainfall and irrigation events, identifying that the soil water is a complex system and not easily disentangled. The main factor that has been made clear through these results, is the high water table of this area, which appears to be slightly higher in the vee and planar sites, than the tall spindle. However, since all apple sites have very similar topography (flat), and soil type (Flaxmere soils), then there may be additional problems with the drainage system, in which it is not working to the same degree in all areas. The Evenden Orchard has a tile system drainage network, which could be used to explain the differences in what appears to be groundwater influences.

Post-December, the tall spindle site had fluctuating changes in SWC that remained mostly positive, particularly from December to February. As identified in section 2.3.3, this suggests that the soil water environment was at the right balance to allow for active transpiration, as well as drainage from irrigation events. The vee system showed both positive and negative fluctuations in soil water content changes, suggesting that although crop transpiration was occurring, there were other soil processes influencing the change which may be related to the high water table. The planar system appears to have more water entering the water balance than leaving it (shown by negative difference), suggesting that evapotranspiration was not as predominant. This is backed up by matric potential results, where the planar sites remained mostly above saturation for the duration of the season, suggesting that there was too much irrigation applied, due to groundwater contributions below. The younger age of the planar trees could help explain this difference, as their canopy will not be as 
far developed as the tall spindle and vee, causing differences in plant water demand for transpiration.

Positive cumulative changes in SWC illustrated the clear trends in the results above. From September to the $16^{\text {th }}$ October (before the large rainfall event), when the canopy is in its first stage of development post-budburst, the vee site shows the largest change in SWC, followed by the planar, and then the tall spindle. Since all sites received the same amount of rainfall, it will be interesting to investigate whether there are any trends in light interception or leaf area that relate. From the $20^{\text {th }}$ October until mid-December, before irrigation starts, the trend changes slightly where vee still had the largest change in SWC, followed by the tall spindle, and lastly the planar. This change in trend could be described by the large rainfall event causing changes in groundwater levels, or there could be other physiological factors in play, which will be built on in Chapter 3. Post-December, when full canopy is reached by the trees, the tall spindle shows the largest change in SWC post-December when irrigation is applied. As suggested above, this shows that the tall spindle trees had the right soil-water balance to effectively transpire, causing larger changes in SWC. Whereas the planar system has the lowest cumulative change in soil water use, which is very similar to the vee system. These trends are unexpected which suggests that the high water table, caused more vulnerability to water logging, and therefore stomatal closure from anaerobic conditions, is a possible explanation for this result. These tensiometer and FDR results alone do not identify the cause for the differences seen between soil water content and matric potential as there are other physiological and climatic differences between these systems.

\section{Further research and exploration}

To further explore and build on what is causing these differences in cumulative changes in soil water use, matric potential and volumetric soil water content between the apple trellis systems and Syrah sites, a focus on physiological and light environments is needed. In addition, to be able to differentiate crop evapotranspiration from drainage, sap flow meters would be a useful technology to use to explain these results further. 
Chapter 3 explores the main factors that affect crop evapotranspiration: light interception and leaf area in the three different trellis systems, as well as in the grape sites. It will first introduce differences in tree and vine physiology to identify differences between the orchard designs. Then the light environment of each system will be explored through measurements of leaf area and light interception. Fruit quality aspects such as yield, fruit maturity and quality will also be analysed as this can also affect crop water use and evapotranspiration. The results identified here will be built on in the next chapter to develop a better understanding of relationships between these water balance scenarios, the climate, and differences in orchard designs. 


\section{Chapter 3: Understanding the effect of canopy architecture and orchard designs on evapotranspiration}

\subsection{Introduction}

Section 1.2, Chapter 1 described the main factors that affect evapotranspiration in commercially grown apple and grapes, as light interception and leaf area index, because evapotranspiration is primarily driven by photosynthesis. Light interception at an orchard level is primarily controlled by canopy architecture and orchard designs, such as row and tree/vine spacing, tree height, row orientation and leaf area index which have all been well researched over the years (Jackson, 1980; Wagenmakers \& Callesen, 1995; Wünsche \& Lakso, 2000; Wünsche et al., 1996). Whole canopy light interception is linearly related to fresh fruit weight yield in apples (Palmer, 2002), and whole plant dry matter production (Monteith, 1977). This relationship relates high light interception, to high yield. Light interception can be increased by increasing the leaf area index (LAI) to a certain threshold, in which Wagenmakers (1991) has shown that this threshold is a LAI of 2-3, and increases beyond this point show no further yield gains.

The tree/vine requires adequate light distribution within the canopy to produce high fruit quality, where shading caused by large, excessive leaf area has been shown to reduce fruit quality by causing a reduction in fruit weight, maturity, decreased fruit colour, dry matter and fruit soluble solids (Doerflinger et al., 2015; Robinson et al., 1983). To counter this, leaf stripping approaching harvest is a common practice in both apple orchards and vineyards, to increase fruit exposure to sunlight and improve fruit quality (K. Breen pers comm. 2020).

Section 1.2.1 showed productivity of modern apple systems is limited by light interception at a whole-orchard level (Breen et al. 2016, 2020; Tustin, van Hooijdonk, and Breen 2018). Lakso (1994) has shown through multiple comparative studies on apples, that the practical maximum light interception of a whole-orchard level is $60-70 \%$ of incoming light. In New Zealand, the highest light interception measured in a commercial dwarf, centre leader 'Royal Gala' apple orchard was $64 \%$. This produced a calculated fresh yield of 129 tonne per 
hectare (Breen et al. 2016). Palmer et al. (2002) has also shown in earlier studies that centre leader apple trees intercepted $55-60 \%$ of light, achieving yields of 90-110 tonnes per hectare. In that paper, Palmer showed that a theoretical $90 \%$ light interception should produce yields of 169 tonne per hectare. This suggests that a biological limit of apple productivity in New Zealand is in a range of 160-180 tonne per hectare if light interception can be increased to $85-90+\%$. To reach these upper limits of light interception, and therefore yield, innovative orchard designs and tree architecture are required to intercept more light by increasing the canopy area per unit of land area. This is the basic principle on which vee, and more recently planar trellis systems have been designed. The planar system has been designed to maximise light interception throughout the whole canopy by dispersing fruiting structures spatially on verticle uprights, and keeping LAI within the optimum limits (Wagenmakers, 1995).

As outlined above, new orchard and canopy architecture is designed to reach productivity that is close to the biological potential of orchard systems (Tustin \& van Hooijdonk, 2016). Light interception and LAI have also been shown to be strongly related to crop evapotranspiration in both apple and grape crops (McClymont et al. 2009; O'Connell, Goodwin, and Wheaton 2008; Williams and Ayars 2005). What is currently unknown, is how these differing designs and their resulting light and LAI environments effect crop evapotranspiration, and ultimately crop water use and requirements. This chapter investigates the role of light interception and leaf area index on productivity and quality in three apple trellis systems, and two grape plots. This will then be used to explore how these factors affect the crop's water balance, and ultimately evapotranspiration. It was hypothesised that the tree/vine that intercepted the largest amount of light would have the highest crop evapotranspiration rates based on previous research such as Goodwin et al. (2008). 


\subsection{Methodology}

\subsubsection{Pre-season measurements}

The size of a tree may be broadly described by its trunk cross-sectional area (TCA). It is the most common tree size measurement and can indirectly indicate the potential yield of a plant (Miranda and Royo 2004; Wright et al. 2006).

TCA measurements were taken on all apple and grape trunks $20 \mathrm{~cm}$ above the graft union before budburst in July 2019, and post-season in July 2020 to account for growth.

\subsubsection{Leaf area}

Leaf area (LA) can be measured directly by harvesting individual leaves or indirectly using regression models. Direct methods involve measuring LA of the harvested leaves by a leaf area meter, or by processing photographs of leaves (Demirsoy 2009). These methods are destructive, time-consuming, and prevent consecutive measurements of whole canopy LA due to the removal of leaves for measurement. To overcome these limitations, studies of this nature usually indirectly estimate tree LA from measurements made on a sample of leaves from the canopy (Palmer et al., 1992; Wünsche \& Palmer, 1997). Leaf length and/or width are correlated to leaf area, and this relationship then allows leaf area to be estimated in the canopies of interest without their removal.

There have been numerous models, and regression equations developed for various fruit trees including apple (Demirsoy 2009; Sala et al. 2015), and grape (Buttaro et al., 2015; Eftekhari et al., 2011). These models are typically developed for just one or two genotypes, which means that a new relationship needs to be developed for each new genotype to account for physiological and phenotypic differences (Palmer, 1986). Leaf shape (length: width ratio) can vary significantly among different genetic materials, soil types and plant age, which is important to identify when calculating leaf area (Demirsoy, 2009; Palmer, 1986).

Within an apple canopy, there are different types of leaves that contribute to different functions of the plant. In apple trees, there are three main leaf types; spur, bourse, and vegetative leaves (Ghosh 2016). Spur leaves (or primary spur leaves) are the first to form on an apple tree in spring, and are usually small, 
rounded, pre-formed leaves emerging at budbreak. They play an important role in providing carbohydrates produced from photosynthesis for fruit growth, as well as bourse shoot growth (Wünsche \& Lakso, 2000). Primary spur leaves form on both floral and vegetative spurs, and on floral spurs they subtend the floral cluster. Bourse shoots emerge laterally from the axil of one (or more) of the primary spur leaves. Leaves of bourse shoots are typically larger leaves that make up the main leaf area in commercial orchards (Ghosh 2016). Vegetative shoots produced from a vegetative bud can arise anywhere on the apple canopy and have similar leaf sizes to bourse shoot leaves.

Studies by Wünsche and Lakso (2000) have found that spur leaf light interception and LA are strongly correlated with fruit yield as spur leaves are the main bearer of carbohydrate support for fruit development. In comparison, large vegetative shoot growth can cause a reduction in yield, due to this type of shoot growth being located on the exterior of the tree, intercepting a disproportionate amount of light (Wünsche \& Lakso, 2000). Fujii and Kennedy (2008) found that photosynthetic rates are up to $25 \%$ higher on a leaf area basis in spur leaves than shoot leaves during the bloom period. Hence the importance of recording all types of shoot leaves counted.

In grapevines, leaf area has a strong relationship to dry matter production, as it is the primary photosynthetic surface (Smart et al. 1982). Where dry matter production is often directly proportional to the amount of light intercepted by the leaf surface (Monteith 1965; Smart et al. 1982). Similar to apple trees, leaf shape and size can differ among grape genotypes, as well as different aged vines which is why it is important to establish a cultivar and age-specific leaf area relationship with leaf size.

The widely used unit to describe the density of leaf cover is Leaf Area Index (LAI). LAI is defined as the total area of leaves per ground surface area $\left(\mathrm{m}^{2} / \mathrm{m}^{2}\right)$ which will be used in this research (Wünsche \& Lakso, 2000).

\subsubsection{Establishing leaf area relationships}

For the apple plots, 30 selected leaves of each leaf type (bourse, spur and vegetative) and covering the range of leaf sizes observed were taken from a number of trees within the trial block (from all three trellis systems). For the grape plot, a random selection of 30 leaves was taken from several vines within 
each block. These collected leaves were then run through a leaf area meter (LI3100 Area Meter, LI-COR inc, Lincoln, Nebraska, USA) where the leaf area was recorded for each leaf. The width and length of each leaf were then measured manually, as shown in Figure 25.

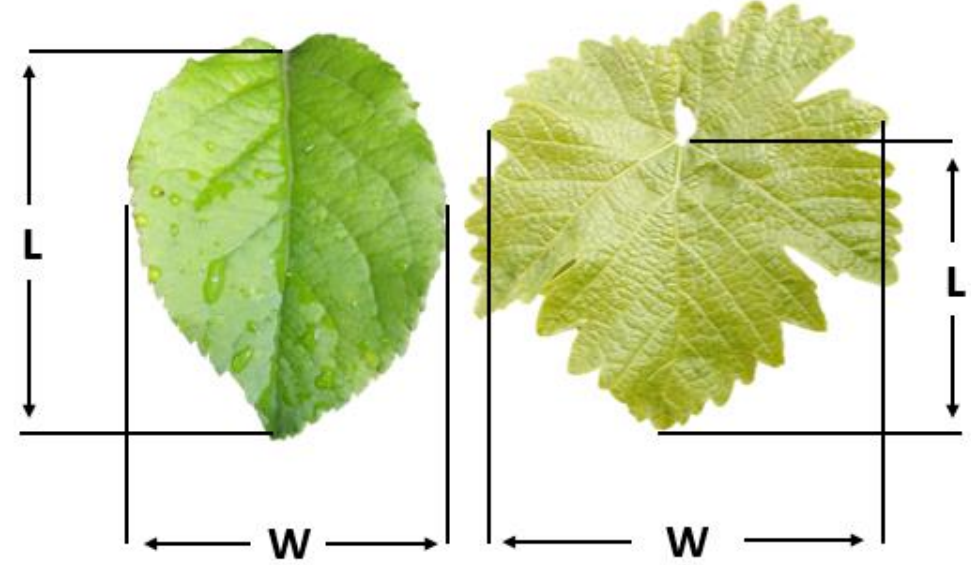

Figure 25: Annotated images of a Scilate apple leaf (left) and Syrah grape leaf (right) showing the positions at which leaf length and leaf width were measured for regression against leaf area.

A regression analysis was conducted between leaf area, and leaf length and width. Individual leaf length, width, and length $\mathrm{x}$ width were plotted against leaf area for all sampled leaves, and simple regression lines (linear or power) were tested for fit against the data set using regression functions in Excel (Windows 2013). All regression relationships were strong $\left(r^{2}>0.90\right)$ (Table 3$)$. The length $x$ width relationships improved predictability by $\sim 3 \%$ over either length or width, but it was decided that this gain in clarity was negligible given the high precision and the extra work involved to measure two variables. Plotting individual leaf types in apple reduced coefficient of determination (Table 4) and so the whole population of all leaves were considered together. The single variable (length or width) and regression model of best fit (that had the strongest R-squared value) was selected to be used to estimate leaf area from leaves subsequently measured at four dates in the field. R-squared values for each variable and relationship can be seen in Table 3 to 5 . Using leaf length in apple and leaf width in grape, a power regression was fitted to the apple dataset and a linear regression fitted to the grape dataset and achieved $R^{2}$ values of 0.96 and 0.93 respectively (Table 5). 
Table 3; R-squared values for relationships between leaf area and leaf width, length or length $x$ width calculated for Scilate apple and Syrah grape

\begin{tabular}{cccc}
$\begin{array}{l}\text { Crop } \\
\text { type }\end{array}$ & $\begin{array}{c}\text { Leaf area vs } \\
\text { width }\end{array}$ & $\begin{array}{c}\text { Leaf area vs } \\
\text { length }\end{array}$ & $\begin{array}{c}\text { Leaf area vs length } \mathrm{x} \\
\text { width }\end{array}$ \\
\hline Apple & 0.95 & 0.96 & 0.99 \\
\hline Grape & 0.93 & 0.91 & 0.96
\end{tabular}

Table 4; R-squared values for leaf area relationships between leaf area and leaf width or length for the three different leaf types in Scilate apple trees

\begin{tabular}{lccc} 
Measuring type & Spur leaves & Bourse leaves & $\begin{array}{c}\text { Vegetative } \\
\text { leaves }\end{array}$ \\
Leaf width & 0.84 & 0.89 & 0.88 \\
\hline Leaf length & 0.95 & 0.89 & 0.86
\end{tabular}

Table 5; Linear regression equations for lines of best fit for Scilate apple and Syrah leaves to allow calculation of leaf area $(y)$ from leaf length $(x)$ in apple and leaf width $(x)$ in grape.

\begin{tabular}{lcc} 
Crop Type & Regression equation & $R^{2}$ values \\
Apple & $y=0.7779 x^{1.6768}$ & 0.96 \\
\hline Grape & $y=16.461 x-81.962$ & 0.93 \\
\hline
\end{tabular}

\subsubsection{Leaf area collection}

Leaf area was sampled for every monitored tree and vine throughout the growing season (August 2019 until February 2020). A minimum of 100 leaf measurements (width/length) per tree were taken at each sample date throughout the season. This sample was taken by measuring every $2^{\text {nd }}$ (in August) to $50^{\text {th }}$ leaf (later in the season) dependent on the leaf number in the canopy, to ensure that the minimum leaf sample number was taken. Every leaf was systematically counted from the trunk of the tree or vine towards the top of the canopy. In apple canopies, the leaf type: bourse, spur or vegetative was recorded along with the length. However on analysis of these individual leaf types, it was discovered that relationships between LA and individual leaf types did not differ appreciably, and so a single model for all leaves was used. The measured leaf dimension was then converted to leaf area using the established 
regression equation (Table 5). The (number of leaves sampled $x$ sampling rate + remaining leaves) $x$ mean leaf area, gave whole canopy leaf area.

\subsubsection{Light interception}

There are several approaches used to measure the amount of incoming radiation that is intercepted by a canopy (light interception). From a productivity point of view the most important section of electromagnetic radiation is photosynthetically active radiation (PAR), measured in $\mu \mathrm{mol} / \mathrm{m}^{2} / \mathrm{s}$. This constitutes wavelengths of 400 to $700 \mathrm{~nm}$ (Palmer \& Jackson, 1977). In this document the term "light Interception" refers to interception of light in this PAR range. There are a number of methods to measure light interception, such as fisheye photography, ceptometer, multiple light sensors and point grid (Wunsche et al. 1995). These all have different advantages and disadvantages which should be selected based on the application.

Fisheye photography indirectly measures PAR by taking photos from the underneath of the canopy, and then modelling PAR via image analysis software (Robinson \& Lakso, 1991). This method also provides information on the light microclimate (Lakso, 1980), several components of the canopy structure such as leaf area and leaf angle distribution, and sunlit foliage area (Bonhomme and Chartier 1972). However, fisheye photography has a large processing and analysis time which can also have additional costs for the analysis software.

The point grid method appeals most to growers and farmers, as this is the most simplistic, and inexpensive way to measure PAR. This method records the sun exposure on a white sheet (or flat surface) with grid/points laid on the orchard floor underneath the selected tree. The amount of shaded grids versus sunlit grids provides an estimate for PAR. This method has been proven to underestimate PAR values, and is a time consuming task (Wunsche et al. 1995). However, it provides a simplistic way for farmers and growers to get an approximate estimate of PAR, and can further be used to estimate crop water requirements (Goodwin et al.,2015).

Photoelectric sensors such as the ceptometer have been used to measure PAR (McClymont et al. 2009), but are limited in their sensitivity problems which limit their use (Maggs and Alexander 2006). More advanced photoelectric quantum light sensors have been developed and used extensively in research (Goodwin 
et al. 2015; Green et al. 2003; O'Connell et al. 2008; Palmer 2002), which can more accurately estimate PAR by using an average of multiple, single point sensors. Although this is the most accurate method to date, it requires significant expense for sensors, data loggers, and operator time. This is the methodology used in this research.

\section{Light interception measurements}

Whole canopy light interception was conducted according to the methodology of Palmer 2002. PAR above the canopy was measured by a photodiode quantum sensor (LI-COR, Lincoln, Nebraska, USA) fastened to a vertical pole attached to a trolley. Understorey light interception readings were captured by individual sensors based on a selenium cell quantum sensor, which has a good cosine response constructed as per Palmer (1987). This cosine response shows that there is typically a good response to all angles of incidence light from 0 to 80 degrees (Palmer \& Jackson, 1977). The wavelength sensitivity of the sensor is shifted towards the red end of the spectrum because of the perspex diffuser and overall gives excellent response to PAR.

The quantum light sensors were positioned on a 1.5 meter horizontal bar, fastened on a trolley. The eleven light sensors were positioned evenly, covering the area from the trunk of the tree, to the middle of the row (Figure 26). Each light sensor produced a millivolt output which was recorded every 0.25 seconds. The readings were recorded on a data logger (CR10, Campbell Scientific Inc, Logan, USA ).

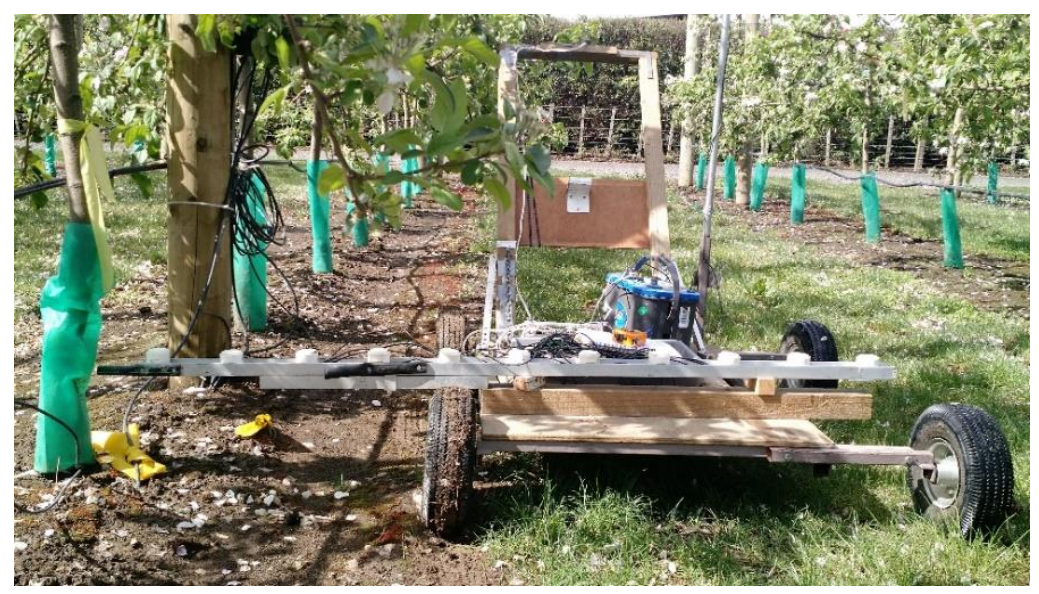

Figure 26: Quantum sensors were positioned at equal spacing's on a horizontal bar situated below the canopy on a trolley. Above-canopy (incoming) PAR was recorded by a sensor placed on the top of a pole attached to the trolley (right). 
Immediately prior to and after recording light readings, an open sky reading was recorded in an area where PAR on all sensors was $100 \%$ of incoming light. This was a neighbouring open area. These data allowed calibration of all sensors with the above canopy sensor. Readings were taken for each treatment plot by pushing the light trolley down the row on one side of the canopy. The same was repeated on the other side of the canopy. The light interception of the monitored trees was considered to be from the middle of the previous tree in the row (the trunk), through to the middle of the following tree (Figure 27). Despite relatively low cosine errors of these sensors, light readings were taken in cloudy weather when there was diffuse light, to reduce the effect of sun angle (Palmer 2002) and eliminate shadow interference.

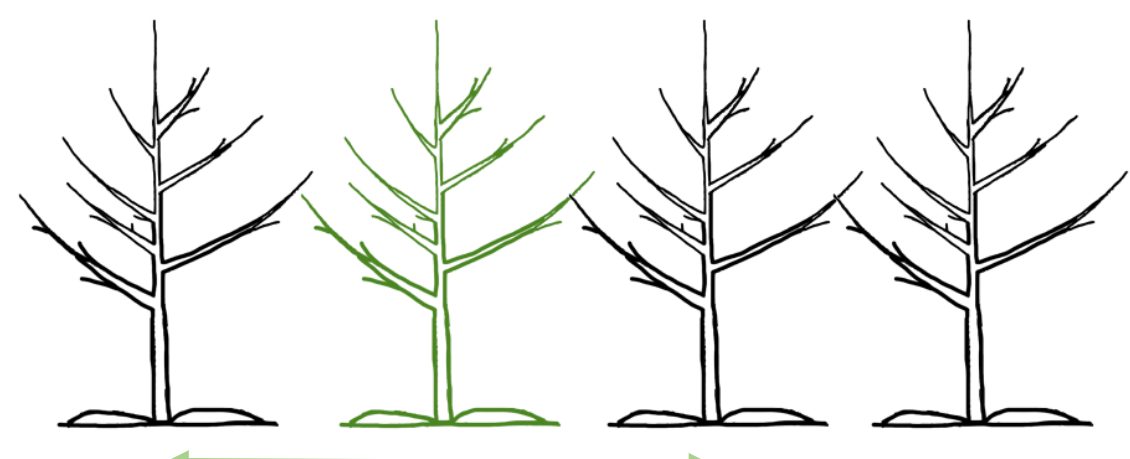

Figure 27: Image showing the monitored centre leader tree (green), and the arrow represents the area measured by the light meter during one reading.

The number of sensors used to record light interception was dependent on row width. The planar trellis system had a row spacing of two meters, therefore, measurements made from the tree trunk to the middle of the row covered one meter ( 7 sensors) on one side of the tree. The same is applied to the other side of the tree. In Vee (3.5 m spacing) and Tall Spindle (3.5 m spacing) trees 11 sensors were used.

\section{Light interception analysis}

Calculation of the total amount of light intercepted by each tree was conducted in the following fashion. Firstly, the open sky readings taken at the start and end of each plot were averaged for each sensor as a calibration to show what each sensor would be reading in full diffuse light. Then, for each 0.25 second 
reading, the percentage of shading caused by the canopy was calculated for each sensor using the following equation:

$\%$ shading $=($ average open sky reading - actual reading $) /$ averaged open sky reading * 100

The proportion of area that each light sensor represents within the given row width is calculated (dependent on the row width, sensor positions and the length of the light meter bar). The proportion area is then multiplied by the \% shading values for each sensor. Finally, the mean percentage of light interception of all sensors, and both sides of the tree is calculated for each tree.

\subsubsection{Yield}

Crop load can greatly affect whole canopy transpiration (Auzmendi et al., 2011; Reyes et al., 2006; Wünsche \& Ferguson, 2010). Consistent with this, fruit removal after harvest typically causes a decline in crop evapotranspiration (Auzmendi et al. 2011; Girona et al. 2011). Hence, it is important to manage and record fruit set and final yield numbers. Controlling yield and fruit set using thinning techniques is common practice in commercial vineyards and apple orchards, which was also carried out in this research. In addition, artificial spur extinction (ASE) was used as a thinning technique.

\section{Artificial spur extinction in apples}

Artificial spur extinction (ASE) is a form of crop thinning. This method controls crop load by reducing floral sites that can develop during spring growth in apple trees (Lauri et al., 1997; Tustin et al., 2012). Typically, commercial apple trees are managed by chemical thinning soon after bloom, followed later on by hand thinning to ensure that the correct fruit numbers are set so the tree can produce high quality and sized fruit. Fruit size can be improved significantly by thinning as soon as possible after flowering, which is a practice that relies heavily on chemical thinners (McArtney et al. 1996). Tree responses to chemical thinners are unpredictably variable. This is due to the growth rate-induced competition of young fruit for carbon resources which is limited at crucial times during early fruit development (Lakso et al., 1997).

Research has shown that ASE can increase the proportion of buds that set fruit, as well as increase the number of fruit set on individual buds (Breen et al. 2015; 
Tustin et al. 2012). There are positive return bloom responses which prove that ASE treatments induce a high proportion of buds into return bloom each spring (Breen et al., 2015; Tustin et al., 2012). ASE is a valuable practice for optimising crop load and fruit development, which was applied to the apple trees in this research. The number of buds per branch was set based on the branch cross-sectional area per $\mathrm{cm}^{2}$ (BCA). Bud numbers were set to 6 buds per $1 \mathrm{~cm}^{2} \mathrm{BCA}$.

\section{Yield estimation}

Fruit thinning was carried out in all three apple plots on 12 December 2019, within the commercial hand thinning window. Fruit was thinned to 5 fruit per 1 $\mathrm{cm}^{2}$ BCA. A fruit count was taken pre-harvest in February 2020. Fruit count numbers were used to estimate yield (Table 6). Fruit weight per tree was estimated based on the average fruit weight collected in the 30 samples, multiplied by the fruit count numbers per tree.

Unfortunately due to COVID-19 lockdown restrictions in New Zealand, the total harvest yield could not be collected. A sample of 30 fruit per tree and vine was harvested prior to these restrictions which was two weeks prior to commercial harvest. The most mature looking fruit from all trees was collected. Due to the planar trees being one growth year behind the other trellis systems, they had not quite reached harvest maturity, and required another one to two weeks more on the trees. However, 30 fruit was still harvested from them.

Table 6: Numbers of fruit per tree recorded pre-harvest in February 2020 for all apple trellis systems.

\begin{tabular}{lcccccc} 
& Tree 1 & Tree 2 & Tree 3 & Tree 4 & Tree 5 & Tree 6 \\
Vee & 50 & 84 & 94 & 80 & 141 & 109 \\
\hline Planar & 150 & 132 & 161 & & & \\
\hline Tall Spindle & 190 & 153 & 197 & & & \\
\hline
\end{tabular}




\subsubsection{Fruit quality assessment}

Fruit quality is important because it determines the fruit value in market. The success of an orchard or vineyard is often measured in yield and/or fruit quality. Therefore, it is an important metric to measure to ensure all trellis systems and orchard designs reach highest quality. Dry matter content is an important variable as it allows determination of actual plant growth (Monteith, 1977), and biomass allocation to certain plant organs, such as the fruit (Baïram et al. 2019). In apples, fresh fruit weight, and dry matter content are used as quality metrics. In grapes, dry matter content and soluble solids content are used as quality metrics (Cozzolino et al. 2008).

\section{Fresh weight}

In apples, 30 individual fruit were harvested per tree and individually weighed. In grapes all bunches from each vine were harvested and individually weighed.

\section{Starch pattern index (SPI)}

SPI is a measurement of maturity carried out on apples. It is a crucial factor in determining actual ripeness and storage potential of apples (Doerflinger et al. 2015). During growth, apples store fruit carbohydrates as starch (amylose), which is degraded at the onset of ripening. The SPI identifies the distribution of starch in the fruit tissue, which is shown when an applied iodine solution reacts with the starch still present in the fruit (Doerflinger et al. 2015). The iodine applied creates a black stain in distinctive patterns that were matched against the standard New Zealand Apples and Pears 0-7 chart scale (Figure 28). A rating of 0 means that it is too immature for harvest and a rating of 6 means the tree is ripe. Scilate have a target harvest SPI of 2. SPI was carried out on 20 fruit per tree sample. 


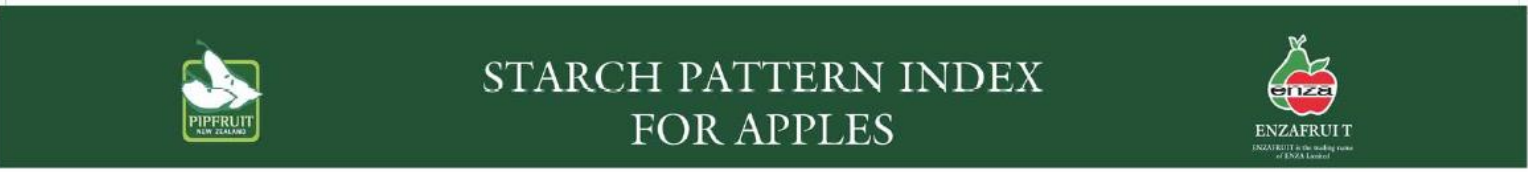

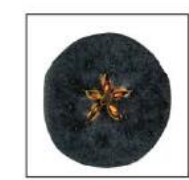

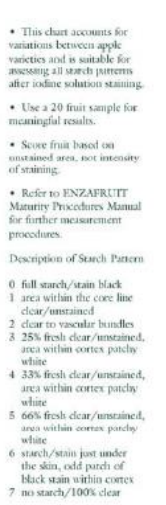

0

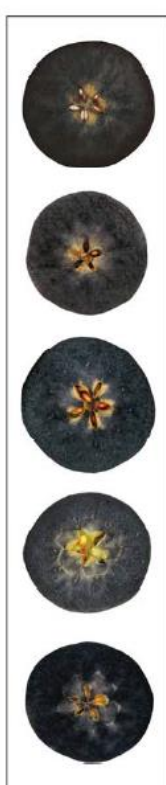

1

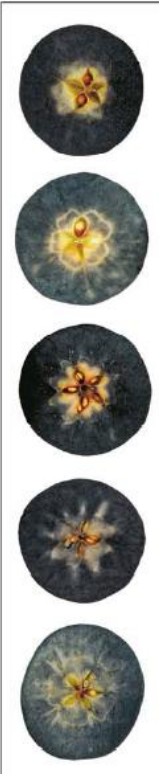

2

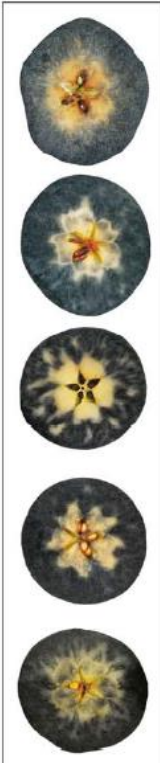

3

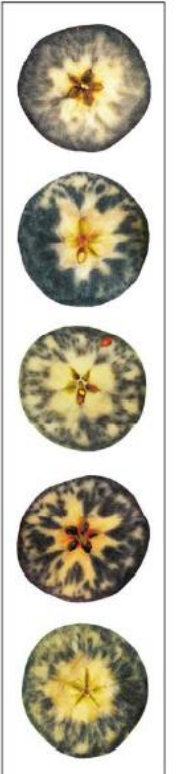

4

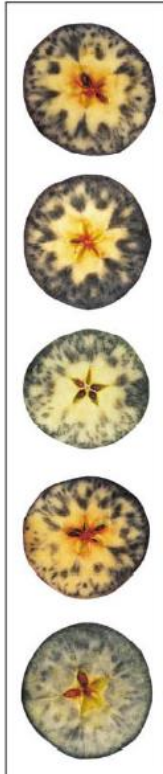

5

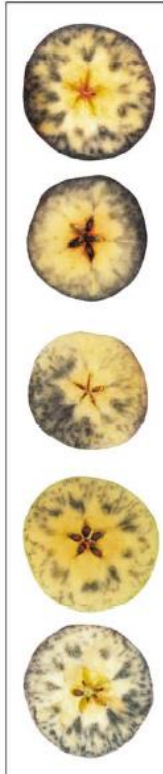

6

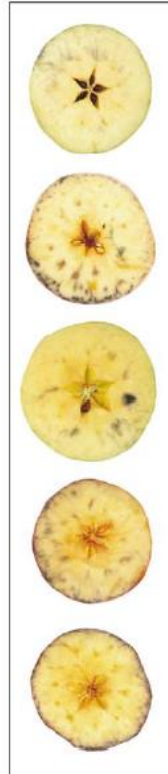

7

Figure 28: Image showing starch pattern index stages SPI 1,4 and 7 and the iodine patterns associated. Where SPI1 shows immaturity (no starch clearance) compared with SPI 7 (full clearance) which is tree ripe.

\section{Dry matter content}

Dry matter content (DMC) describes the solid component of fruit, which is essentially what is left once all the water is removed. In apple fruit, dry matter mainly consists of starch, soluble carbohydrates such as fructose, sucrose and glucose and cell walls etc. In apples, dry matter is an indicator of both taste and texture, and DMC just prior to harvest is an indicator of consumer preference (Palmer et al., 2010). DMC has been shown to relate to storage potential, where apples with high DMC at harvest hold their structural integrity for longer under storage conditions (Palmer et al. 2010).

\section{Soluble solids concentration}

Soluble solids concentration (SSC) is a measure of all sugars: both fructose and glucose, acids and minerals. The concentration of acids and minerals are minute compared with sugars, so their contribution is negligible. SSC is a common quality measurement for grapes and apples. However, in apples, DMC is a more accurate determinant of quality. At ripening in grapes, both fructose and glucose are present in equal amounts. They are fermentable sugars, where 
yeast converts these to alcohol and carbon dioxide. Sugar levels are typically expressed in ${ }^{\circ}$ Brix (a scale to measure soluble solids). In grapes, levels between 18 and $24{ }^{\circ}$ brix are desirable depending on the variety and wine style. The SSC is measured using a refractometer where grape juice is placed on the refractometer glass. Light travels through the juice to register on a degree scale. The denser the juice, the sweeter the juice is which causes the light to bend, and the refractometer records it as a high 'brix number. SSC was only recorded for the grape samples, where SSC for 30 individual berries per vine was recorded.

\section{$3.3 \quad$ Results}

Firstly, tree growth results will be shown in the results section of pre-season measurements, followed by leaf area results for both apple and grapes. Then light interception results will show the differences between different apple trellis systems and different aged grape vines, and after that, fruit quality. Lastly, the relationships between leaf area and light interception will be explored in both apple and grape crops to see how these factors affect evapotranspiration.

\subsubsection{Pre-season measurements}

In the pre-season measurements, the tall spindle had the largest TCA, followed closely by the planar, which also had the least variability from the mean (SE \pm 0.1 ). The vee had the lowest TCA, with the highest variability from the mean $(S E \pm 0.5)$ (Table 7). In the grapes, both vines appeared to have similar means, however the old Syrah showed larger variance from the mean ( $S E \pm 3.2)$. End of season mean TCA can be found in Table 7. In the apples, the planar showed the largest change in growth over the season, followed by the tall spindle and vee which were identical. In the grapes, the old Syrah did not grow at all during the season which is a result of its older age, whereas the young Syrah did. 
Table 7; Showing mean TCA at the start of the season, mean TCA at the end, and the change in TCA for the $2019 / 2020$ season. Standard error \pm are shown in brackets

\begin{tabular}{lccc}
$\begin{array}{c}\text { Mean TCA at } \\
\text { start }( \pm S E)\end{array}$ & $\begin{array}{c}\text { Mean TCA at } \\
\text { end }( \pm S E)\end{array}$ & $\begin{array}{c}\text { Change in TCA } \\
( \pm S E)\end{array}$ \\
Tall Spindle & $14.9(0.4)$ & $18.1(0.9)$ & $3.2(1.2)$ \\
Vee & $10.9(0.5)$ & $14.2(0.5)$ & $3.2(0.3)$ \\
\hline Planar & $14.8(0.1)$ & $19.6(0.9)$ & $4.9(0.9)$ \\
\hline Old Syrah & $13.3(3.2)$ & $12.7(2.9)$ & $0(0)$ \\
\hline Young Syrah & $13.2(0.4)$ & $16.2(0.6)$ & $3.0(0.9)$
\end{tabular}

\subsubsection{Leaf area}

\section{Apple leaf area}

On an individual tree basis, all systems showed similar trends of rapid leaf area growth from budbreak (10 September for vee and tall spindle, 14 September for planar) through the early part of the season. In the Vee systems, leaf area increased rapidly until early November, and then more gradually thereafter, reaching $\sim 5 \mathrm{~m}^{2} /$ tree by the end of December. In the vee systems, there was more variability in measured leaf area between the individual trees than that of the planar and tall spindle systems, shown by the standard errors (Figure 29). In the planar cordon and tall spindle systems, leaf area increased more slowly until mid-November. Then there was a subsequent rapid increase until midDecember in the planar trees (reaching $6.7 \mathrm{~m}^{2}$ ), and end December in tall spindle trees (reaching $6.4 \mathrm{~m}^{2}$ ). All trees continued to gradually increase in leaf area until the last measurement at the end of February. Between the three trellis systems, the planar canopy had the largest average leaf area at full canopy which was $7.6 \mathrm{~m}^{2}$, followed by the tall spindle which was $7.2 \mathrm{~m}^{2}$, and then vee which was $5.6 \mathrm{~m}^{2}$ (Figure 29). 


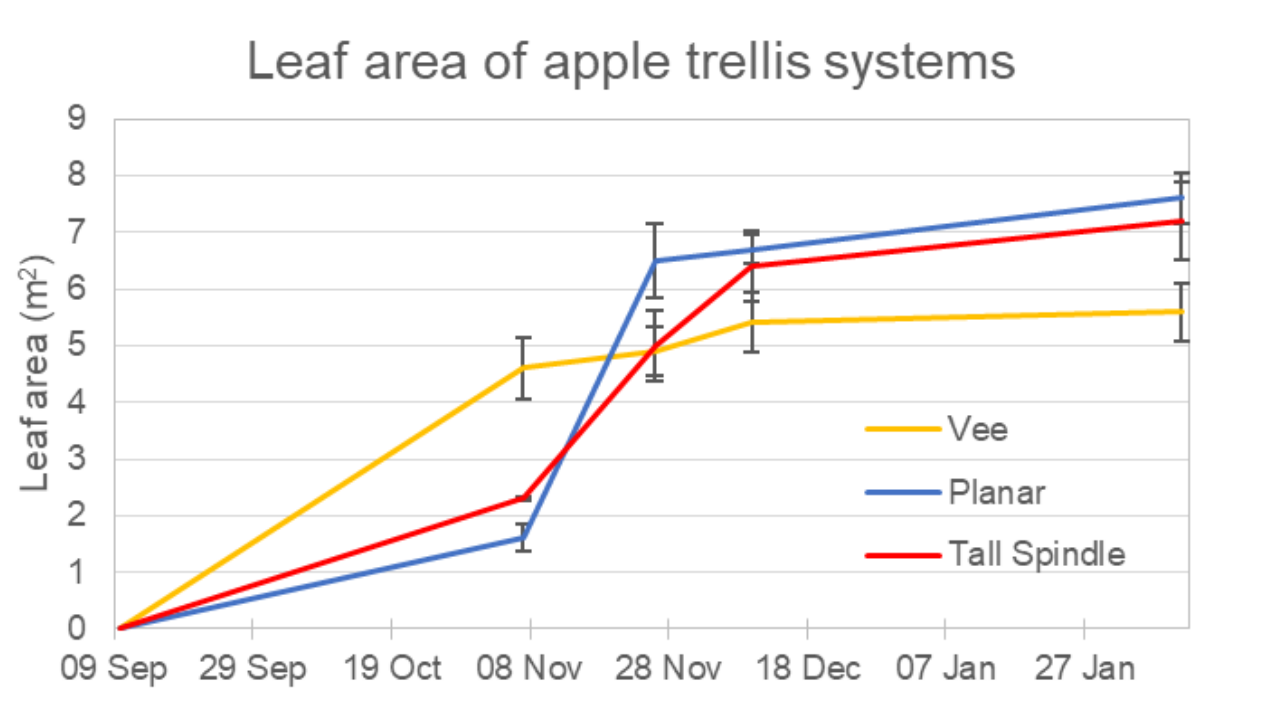

Figure 29: Mean leaf area per tree for three Scilate apple trellis systems over the 2019-20 growing season. Error bars represent standard errors ( $n=3$, in Vee $n=6)$.

Mean leaf area for each trellis system at each date was used to calculate LAI (Figure 29). Results show that the vee system had about twice the LAl of the planar and tall spindle systems. The vee LAI had a mean maximum value of 3.2, which also showed the greatest variability shown by error bars. Whereas the planar LAI had a mean of 1.3, showing the least variability, that was similar to the tall spindle ( $\mathrm{LAl}$ of 1.6).

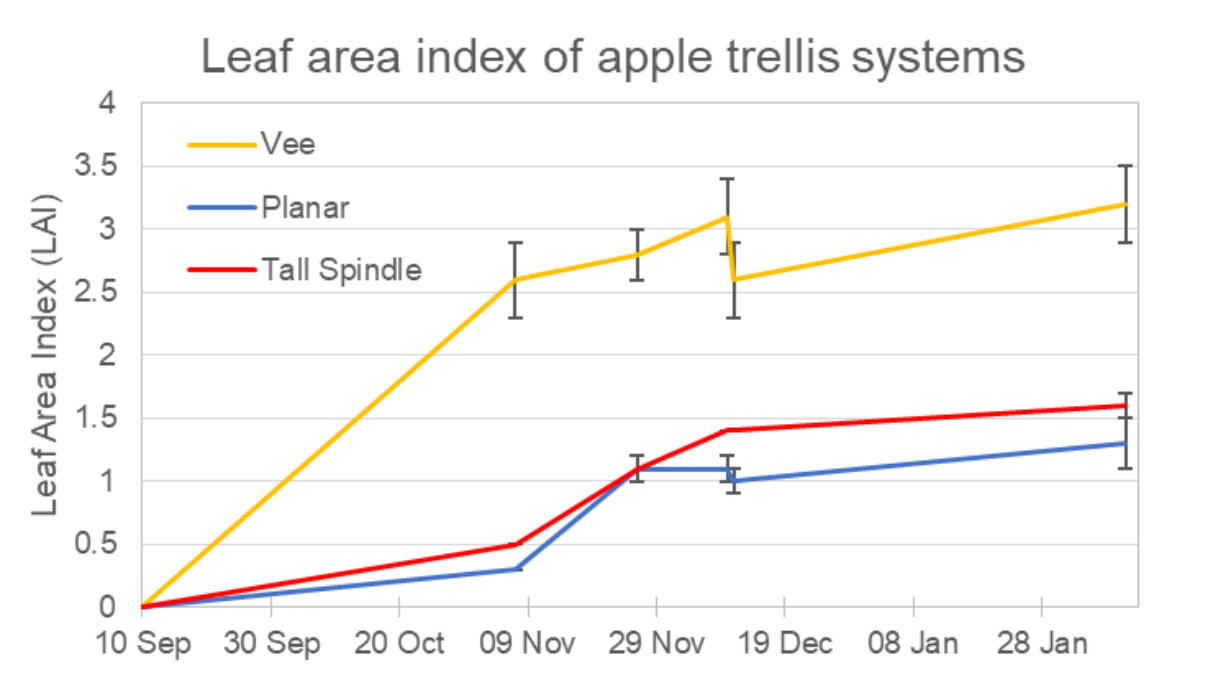

Figure 30: Mean Leaf Area Index for three Scilate apple trellis systems over the 2019-20 growing season. Error bars represent standard errors ( $n=3$, in Vee $n=6)$. 


\section{Grape leaf area}

Assessment of grape leaf area (LA) showed a distinct difference between leaf areas in the two different aged Syrah vines (Figure 31). From mid-November to early December, the old Syrah vines rapidly increased to a LA of 2.2, followed by a more gradual increase to a maximum LA mean of $2.4 \mathrm{~m}^{2}$, which also showed little variability shown by error bars.

In the young Syrah vines, leaf area rapidly increased to a mean LA of $3.6 \mathrm{~m}^{2}$ during November until mid-December. From December 2019 to mid-February 2020 , the maximum LA reached was $5.3 \mathrm{~m}^{2}$, which is more than twice the leaf area of the old Syrah $\left(2.4 \mathrm{~m}^{2}\right)$. The LA values for the grapes appear to be relatively similar to that of the apples, however, the LAI results differ.

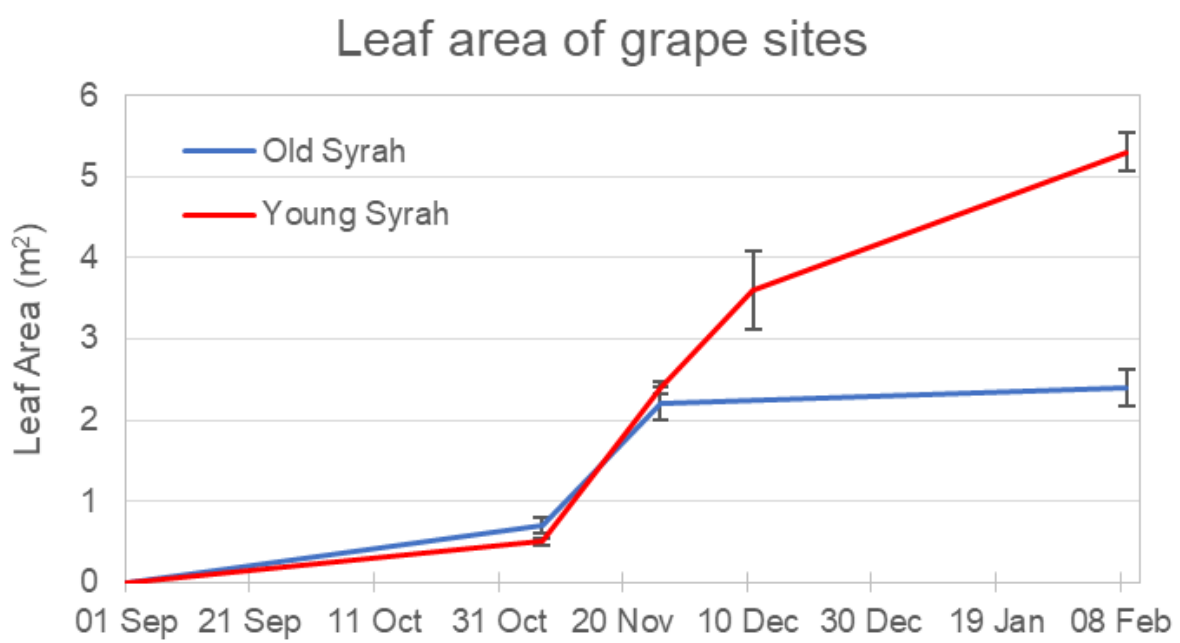

Figure 31: Mean leaf area per vine for two Syrah vineyards of different ages over the 2019-20 growing season. Error bars represent standard errors $(n=3)$.

The LAl results show that the young Syrah vines ranged from a LAI of 0.1 to a maximum LAl of 1.3 at the end of the season (Figure 32). Whereas the old Syrah has a much lower LAl, ranging from 0.2 at the start of the season to 0.7. Both Syrah vines have a similar planting density, with young Syrah being slightly higher, suggesting that planting density was not the primary contributor to differences in LAl, as was seen in the vee apples. 


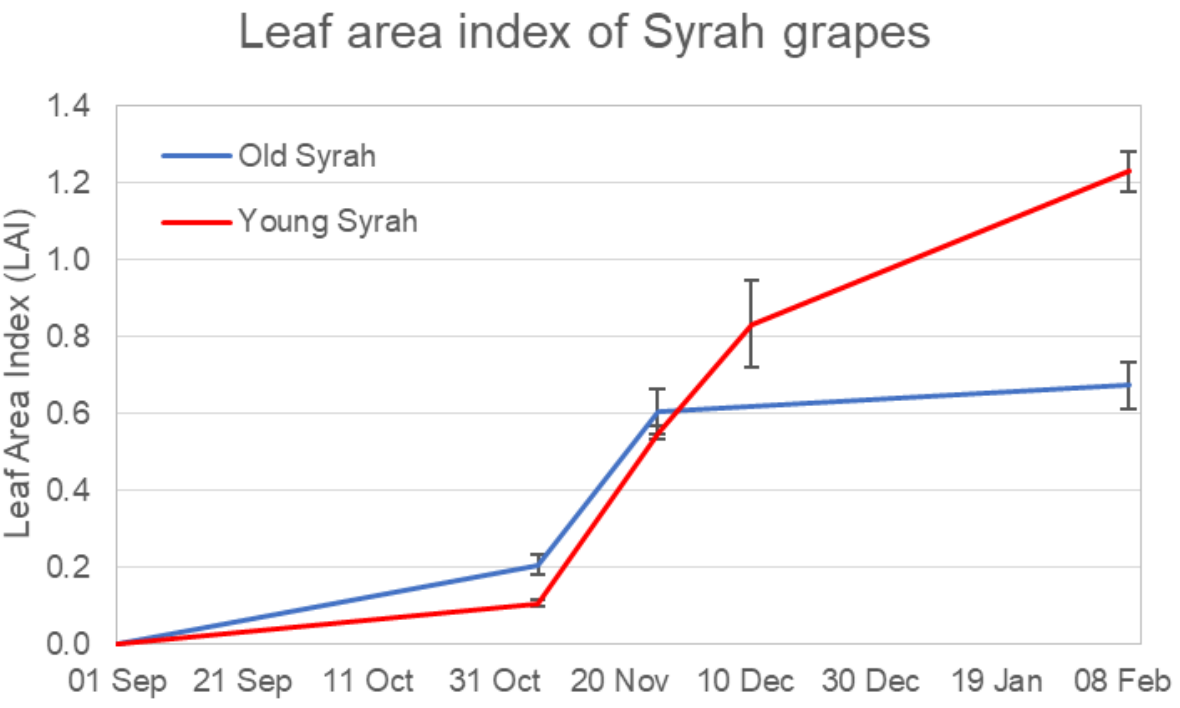

Figure 32: Mean leaf area index for Syrah grape vines of two ages over the 2019/2020 season. Error bars represent standard errors $(n=3)$.

\subsubsection{Light interception}

\section{Apple}

Mean light interception at full canopy for the tall spindle system was $49 \%$ (Figure 33). The vee system intercepted the largest amount of light, reaching a maximum 55\%. The planar system showed the lowest light interception out of all three trellis systems where it reached a maximum of $35 \%$, however it showed the lowest variability shown by error bars (Figure 33). The planar trees are one-year younger, which may explain this result. A comparative study (Breen et al. 2020) has measured light interception in 'Royal Gala' planar apple systems that are in their fourth leaf, showing that they reached 54-56\% light interception which is greater than that of the vee (Figure 33). This suggests that had the planar trees been in fourth leaf, they would have reached these mean values too. The small decrease in light interception during mid-December is due to a pruning event where leaf area was removed, and resulted in a small decrease of light interception. 


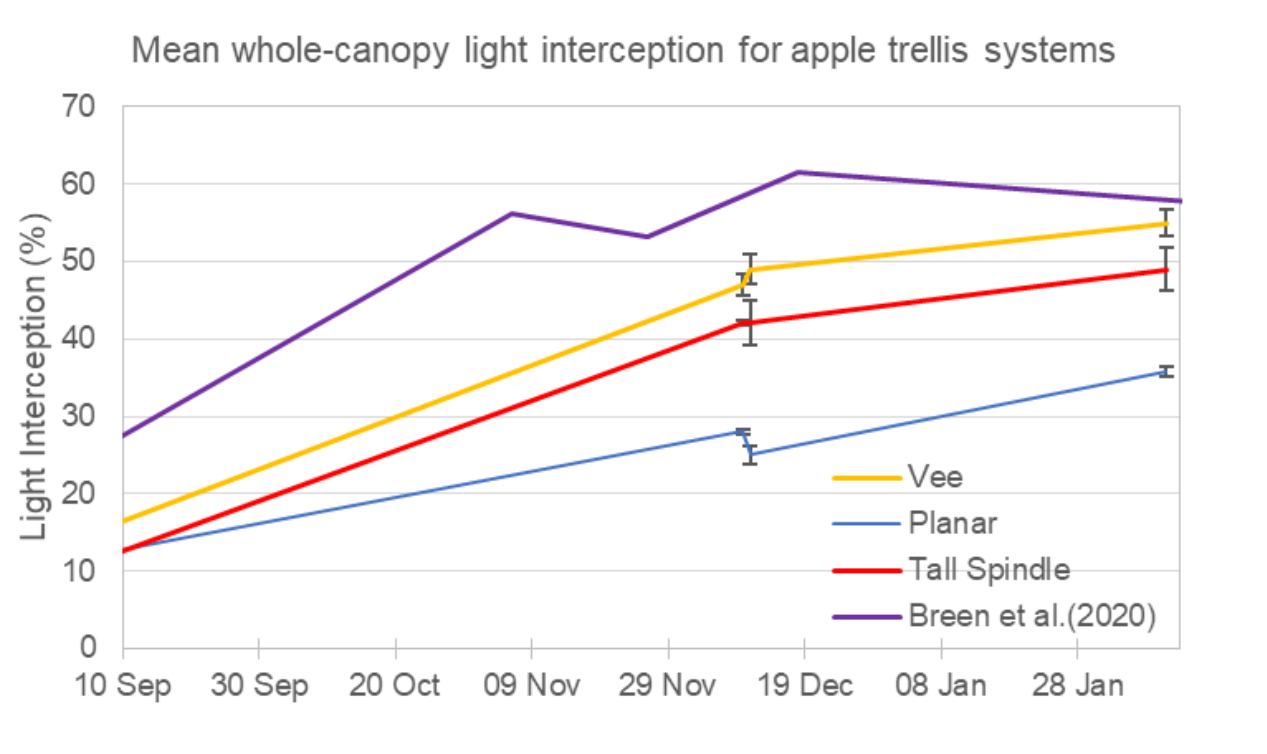

Figure 33; Mean whole-canopy light interception of three Scilate apple trellis systems through the 2019-20 growing season. Figure also shows 'Royal Gala' fourth leaf planar system light interception from Breen et al. (2002) illustrating the potential light interception that the planar system could reach if it was the same age as the Vee and Tall Spindle systems (fourth leaf). Error bars represent standard errors $(n=3$, in vee $n=6)$

\section{Grape}

The young Syrah vines intercepted the largest amount of light at full canopy, which increased from a mean of $1.6 \%$ before budburst, to $36 \%$ at full canopy in December 2019 (Figure 34). In comparison, the old Syrah vines intercepted 2.7\% light before budburst, then at full canopy in December 2019, intercepted a maximum of $22 \%$ light. Light interception in the young Syrah plot showed very little variability among vines (see error bars in Figure 34). In contrast, the old Syrah plot showed more variability in light interception among individual vines.

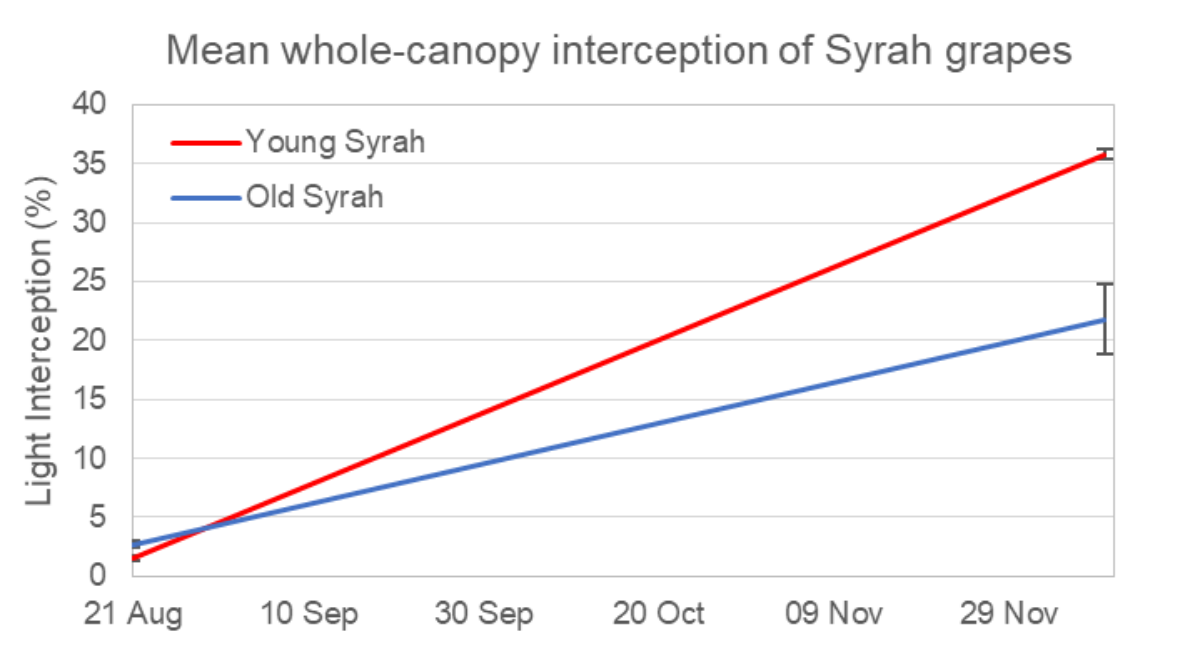

Figure 34; Mean Whole-canopy Light interception in Syrah grape vines of two ages in the 2019-20 season. Error bars represent standard errors $(n=3)$ 


\subsubsection{Apple fruit quality and yield}

\section{Average fresh fruit weight per tree}

All fruit samples were harvested on 24 March 2020 because of imminent COVID-19 lockdown restrictions. The lower fresh fruit weight of fruit from the planar system compared with the other two trellis systems (Table 5) may be explained in part by their lower maturity (SPI 1.5 compared with SPI 2, Table 6). A fresh weight accumulation curve established for planar Scilate apples (B. van Hooijdonk pers comm 2020) was used to estimate mature fresh fruit weight, and therefore potential fresh yield weight. This curve suggests that if the planar trees had been harvested approximately 16 days later (177 days after budburst), then the average fruit weight would have reached $260 \mathrm{~g}$, which would not be different to that of the tall spindle.

\section{Estimated yield per tree and trellis system}

On an individual tree basis, tall spindle trees yielded around $49 \mathrm{~kg} / \mathrm{tree}$, about $50 \%$ more than planar trees, and $100 \%$ more than vee trees (Table 8 ).

However, because tree spacing differed among trellis systems, estimated yields per hectare were the greatest in the vee system (141 tonnes/ha) followed by tall spindle and planar (Table 8). If the planar system had been harvested at the same maturity as the others, increased fruit weight would have resulted in an estimated yield of $64 \mathrm{t} / \mathrm{ha}$ (B. van Hooijdonk pers comm 2020). It should also be remembered when comparing these systems that the planar system is a year younger than the other two.

Table 8; Mean fruit yield and weight of Scilate trees grown on three trellis systems during the 2019-20 season. Standard errors for each variable \pm are shown in brackets $(n=3)$.

\begin{tabular}{|c|c|c|c|c|}
\hline $\begin{array}{l}\text { Trellis } \\
\text { system }\end{array}$ & $\begin{array}{l}\text { Average fruit } \\
\text { count pre- } \\
\text { harvest }\end{array}$ & $\begin{array}{c}\text { Average } \\
\text { fruit weight } \\
\text { (g) }\end{array}$ & $\begin{array}{c}\text { Estimated } \\
\text { yield per tree } \\
(\mathbf{k g})\end{array}$ & $\begin{array}{l}\text { Estimated yield } \\
\text { per hectare } \\
\text { (tonne) }\end{array}$ \\
\hline Planar & 147 & $220.2(4.0)$ & $32.6(2.7)$ & 54. (2.7) \\
\hline Vee & 93 & $272.3(5.7)$ & $24.6(2.7)$ & $141(2.7)$ \\
\hline Tall & 180 & $271.6(4.0)$ & $48.9(3.9)$ & $108(3.9)$ \\
\hline Spindle & & & & \\
\hline
\end{tabular}


Starch pattern index (SPI) results illustrated that fruit from the planar system (SPI 1.5) were less mature than the tall spindle and vee (SPI 2), and as suggested above, required another approximately 16 days to reach maturity (Table 9).

Dry matter content (DMC\%) means, plus the standard error show us that all trellis systems were not different (Table 9). The tall spindle showed slightly more variability, however there was a small sample size $(n=15)$. DMC weight per hectare was the largest in the vee, followed by the tall spindle, and lastly the planar. This result was primarily driven by the high tree density per hectare in the vee system.

Table 9; Mean starch pattern index, dry matter content and dry matter yield of Scilate trees grown on three trellis systems during the $2019-20$ season. Standard errors for each variable \pm are shown in brackets $(n=3)$.

\begin{tabular}{|c|c|c|c|c|}
\hline $\begin{array}{l}\text { Trellis } \\
\text { system }\end{array}$ & $\begin{array}{l}\text { Starch } \\
\text { pattern } \\
\text { index } \\
\text { (SPI) }\end{array}$ & $\begin{array}{l}\text { Average } \\
\text { fruit dry } \\
\text { matter } \\
\text { content } \\
(\%)\end{array}$ & $\begin{array}{l}\text { Calculated fruit } \\
\text { dry matter } \\
\text { production per } \\
\text { tree }(\mathbf{k g})\end{array}$ & $\begin{array}{l}\text { Calculated fruit } \\
\text { dry matter } \\
\text { production per } \\
\text { ha (tonne) }\end{array}$ \\
\hline Planar & $1.5(0.1)$ & $17.6(0.1)$ & $5.7(0.05)$ & 9.5 \\
\hline Vee & $2(0.1)$ & $17.8(0.4)$ & $4.4(0.06)$ & 25.1 \\
\hline $\begin{array}{l}\text { Tall } \\
\text { Spindle }\end{array}$ & $2(0.1)$ & $17.6(0.8)$ & $8.6(0.07)$ & 18.9 \\
\hline
\end{tabular}

\subsubsection{Grape fruit quality and yield}

Average bunch weight was significantly higher in the young Syrah vines compared with the old Syrah vines (Table 10). This was also shown in the total fresh bunch yield per vine, and, because vine spacing's were near-identical in both vineyards, fresh yield per hectare. However, the results for fruit dry matter content (DMC) did not differ between vine ages. On a per hectare scale, the young Syrah showed a slightly higher DMC weight compared with the old Syrah. 
Table 10; Mean fruit yield and fruit quality characteristics of Syrah grape vines of two ages at harvest at the end of the 2019-20 season. Standard errors for each variable \pm are shown in brackets $(n=3)$.

\begin{tabular}{|c|c|c|c|c|c|c|}
\hline $\begin{array}{l}\text { Aged } \\
\text { vine }\end{array}$ & $\begin{array}{l}\text { Bunch } \\
\text { weight } \\
\text { (g) }\end{array}$ & $\begin{array}{l}\text { Yield } \\
\text { per } \\
\text { vine } \\
\text { (kg) }\end{array}$ & $\begin{array}{c}\text { Yield } \\
\text { per ha } \\
\text { (tonne) }\end{array}$ & $\begin{array}{l}\text { Fruit } \\
\text { dry } \\
\text { matter } \\
\text { content } \\
(\%)\end{array}$ & $\begin{array}{l}\text { Calculated } \\
\text { fruit dry } \\
\text { matter } \\
\text { production } \\
\text { per ha } \\
\text { (tonne) }\end{array}$ & $\begin{array}{c}\text { Soluble } \\
\text { solids } \\
\text { content } \\
\text { (SSC) }\end{array}$ \\
\hline Young & $\begin{array}{c}225.3 \\
(6.0)\end{array}$ & 4.1 & 9.6 & $\begin{array}{l}24.7 \\
(0.2)\end{array}$ & $2.4(2.8)$ & $22(0.9)$ \\
\hline Old & $\begin{array}{l}132.5 \\
(12.0)\end{array}$ & 2.9 & 8.1 & $\begin{array}{l}25.4 \\
(0.1)\end{array}$ & $2.1(2.2)$ & $\begin{array}{c}22 \\
(0.05)\end{array}$ \\
\hline
\end{tabular}

Both young and old Syrah showed the same mean SSC results, and indicated that they had reached harvest maturity.

\subsection{Discussion}

\subsubsection{Effect of orchard design and trellis systems on the light environment and leaf area}

Overall, the results here have shown distinct differences among the trellis systems in terms of their light environment and leaf area index. The trends that emerged from this chapter have complimented the soil water content results found in Chapter 2, which help to build a better understanding of what is happening in this soil-plant-atmosphere continuum.

\section{Apple trellis systems}

The vee trellis system intercepted the largest amount of light out of the three systems for the 2019/2020 season, followed by the tall spindle, and lastly the planar canopy. This pattern was also shown in the leaf area index results where the vee had the largest LAI, followed by the tall spindle, and lastly the planar canopy, suggesting that the two variables are closely related as has been shown in literature (O'Connell et al. 2008; Wagenmakers and Callesen 1995). The large LAI of the vee trellis is due to the high tree planting density of that system (5714 trees/ha), which is nearly double that of the tall spindle (2198 trees/ha) and planar (1667 trees/ha), therefore a larger LAl is expected. However, on a per-tree basis, leaf area was highest in the planar trees and tall spindle trees, followed by the vee. High planting density of the vee trees $(0.5 \mathrm{~m}$ 
apart in the row), means they require much heavier pruning regimes to eliminate within canopy shading.

Since the light interception results of the tall spindle and vee system are very similar, yet the vee LAI results are almost two-fold greater, this suggests that a large LAI does not necessarily result in increased light interception, as Palmer (1989), Figure 16.2 has also shown. This is due to inner canopy shading and a smaller proportion of leaf area actually intercepting light. As the trees age in the vee system, if the LAI increases above its current reading of 3 , then canopy light interception might decrease and consequently reduce yield and fruit quality. This might be to the advantage of the planar system, as Breen et al. (2020) has shown that planar 'Royal Gala' and 'Scifresh' their fourth leaf can intercept $54-70 \%$ light interception, which exceeds that of the vee (Breen et al. 2016)

Since the planar canopy is one growth year behind the other two trellis systems, this can explain the lower light interception results. Breen et al.(2020) has shown that the planar canopy light interception can exceed that of the vee system in its fourth year of growth. In addition, Wilson, (2020) showed that planar 'Scifresh' and 'Royal Gala' apples in their fifth leaf had an LAl of 2.6 to 3 which does not exceed the optimum range (Palmer 1989). This suggests that the planar trellis system is better designed to intercept light, and that there is more even light distribution throughout the canopy (Breen et al. 2020).

The largest LAI and light interception results shown by the vee, were reflected in the yield results. The vee system showed the greatest yield per hectare (tonnes/ha), primarily due to the large planting density. However, on a treescale, the vee showed the lowest yield, where the tall spindle had the largest. Despite the vee's LAI result almost exceeding that of the suggested limit, fruit quality in terms of dry matter was not hindered. The planar trees showed the lowest fresh weight yield per hectare, however, this is also due to the planar trees being one growth year behind. Breen et al. (2020) proved that planar yields in their fourth leaf can exceed that of the vee, which overall compliments the light interception and yield relationships found in Wagenmakers (1991). The low fruit maturity found in the planar trees in this study was evident in the SPI results, and that reflected in the fresh weight yield. Dry matter content results 
were more variable in the vee system, which suggests that since DMC is strongly related to light interception (Palmer et al., 2002), that there was less light uniformity within the canopy compared with the planar (which had very small variability $0.09 \mathrm{SE})$.

\section{Grape}

Since both grape sites were of the same variety (Syrah), and grown on the same trellis system (VPS), with similar planting density/vineyard layout, differences in the light environment and leaf area come down to soil type and age of the crop. The young Syrah had a much larger LAI at full canopy, and intercepted a larger amount of light, with little variance between monitored vines, suggesting the same principles apply in grapes as Wagenmakers (1991) has shown in apples. The large LAI in the young Syrah can be explained by the greater vigour that younger vines have on silt-loamy soil. In comparison, the old Syrah block was planted on an old alluvial bed with very rocky soil, which means less readily available water in the soil for the plant compared with the silt-loamy soil, slowing down leaf area expansion. In addition, the old age could be contributing to the low vigour. TCA difference between the start and end of the season proves that the old Syrah did not grow in woody biomass, whereas the young Syrah did.

The fresh fruit weight produced for both the old and young Syrah grapes was different between the crops, where the young Syrah produced almost double the crop load in average fresh weight compared with the old Syrah. Similar to the apples results above, this can be explained by the higher light interception rates found in the young Syrah. However, the dry matter results show the old Syrah had slightly higher DMC results compared with the young Syrah. This suggests higher fruit quality which typically comes with aged vines. Sugar levels for both grapes were not different and suggested that they were at the right maturity when harvested.

Canopy management and alterations occurred in the grapes throughout the season which consisted of shoot tipping, and manual and mechanical leaf removal. All of these management practices removed leaf area and altered the light environment. Unfortunately in this study we were unable to record leaf area and light interception pre- and post- these practices. We would expect that there 
would be changes in LAI and light interception during these periods, which would ideally be accounted for. Limited light interception results (due to data logger issues) made it hard to relate these variables accurately and more readings would be required to accurately conclude.

\subsubsection{Understanding changes in soil water content in relation to light interception and LAI}

Cumulative changes in apple soil water content for the three trellis systems (Section 2.3.3, Figure 22), have shown that during the season there were three evident trends that occurred which could not be explained solely by hydrological answers.

Firstly, from budburst $\left(10^{\text {th }}\right.$ September) until $16^{\text {th }}$ October, the vee system appeared to have a larger change in SWC, followed by the planar and tall spindle which are not different. Since all three sites received the same amount of rainfall, on the same soil type, this suggests that there is a physiological reason for this difference. The LAI results explain this difference, where the vee had the greatest increase in LAI during this period. This suggests that during this period of canopy development it was transpiring more, causing a larger change in SWC. Whereas the tall spindle and planar trees show a lower LAI during this period, resulting in lower rates of crop evapotranspiration.

Secondly, the period following the large rainfall event (October $16^{\text {th }}$ ) until midDecember shows very similar trends to that observed in the light interception results. The vee system intercepted the largest amount of light which suggests that crop evapotranspiration was higher (O'Connell et al. 2008), and explains the change in cumulative SWC. This trend is then followed by the tall spindle, and lastly the planar trees. As explained above, the low light interception for the planar was due to its younger age, hence expected lower evapotranspiration rates.

Lastly, in the period following mid-December, when irrigation was first applied, a different trend emerges which was addressed in Chapter 2, Section 2.3.3, Figure 22. The trends shown in this period are mostly due to drainage events occurring rather than differences in leaf area index or light interception. Based on the first two periods, we would expect the vee site to have the largest change in cumulative SWC due to its larger light interception and LAI, 
compared with the other systems. Because of excess water applied to the vee (which had a particularly high water table as observed on October 16th), we suspect waterlogging occurred causing anaerobic conditions in which the tree has responded by stomatal closure, and therefore less transpiration, explaining the low changes in cumulative SWC. This is also the case for the planar site, where water logging was also observed, and in combination with a younger tree, waterlogging may have caused stomatal closure. In comparison, the tall spindle tree followed the trend expected, where it shows a much steeper increase of changes in cumulative SWC, which can be explained by both high evapotranspiration occurring, as well as drainage from irrigation events. It suggests that the tall spindle was growing in a well-watered environment (a more free draining site) which resulted in higher transpiration rates. When comparing fruit yield and quality results to what was observed in the soil water content results, it appears that the suggested waterlogging in the vee and planar sites did not affect fruit yield and fruit quality which would be consistent with moderate waterlogging (soil was not always anaerobic) occurring later in the season (crop load not affected).

\subsubsection{Conclusion and future research suggestions}

This chapter has identified physiological differences in the three apple trellis systems, and different soil type and aged Syrah vines. In the apples, the vee system showed that it had the highest light interception (54\%), followed by the tall spindle (50\%), and lastly the planar (36\%). However, since the planar system is one leaf year behind the other systems, it is likely that if it were the same age, it would intercept a maximum $56 \%$ which would exceed that of the vee. Leaf area index results showed the same trends to the light interception. Both LAI and light interception results can explain changes in the cumulative soil water content for apples, in relation to evapotranspiration occurring, which builds on the findings from Chapter 2 . The same light interception and LAI results were shown in the two different grape sites, showing that the younger vine, grown on silt-loam soil intercepted more light and had a higher LAI than the old vine grown on stoney soil. Due to a lack of soil water content results, these sites were unable to be interpreted further. 
These first two chapters have provided evidence that evapotranspiration is not identical in different apple trellis systems, and that they are important factor to account for. This was illustrated by the unexpected results in the cumulative change in soil water. To further understand what was causing these changes in soil water content during the season, and differentiate between drainage and crop evapotranspiration, the use of sap flow meters would be a solution. This would allow the transpiration rate of an individual tree to be measured, and therefore differentiate drainage from transpiration. Overall, it has suggested that both light interception and LAI are the best method for estimating crop evapotranspiration, which will be explored in the next chapter where simple water balance modelling is introduced. 


\section{$4 \quad$ Chapter 4: Water balance modelling and estimation of crop evapotranspiration}

Chapters 2 and 3 have identified through field experiments that both light interception and LAl can be used to explain temporal changes in soil water content. Therefore, this suggests that they are also the best proxy for accurately estimating crop evapotranspiration in different apple trellis systems and different aged grapes. This chapter will explore how to incorporate light interception measurements into the estimation of crop evapotranspiration. Further, using a simple water balance approach, we estimate what drainage would have been expected to occur if the crops were grown in "well-watered" conditions. These results further support the hypothesis that the unexpected results found in (Chapter 2, Section 2.3.3, Figure 22) were caused by over irrigation, leading to anaerobic conditions that reduced transpiration in the vee and planar systems, and therefore decreased the changes in SWC.

Overall, this chapter aims to identify ways in which estimated crop evapotranspiration and modelled soil water balance can be improved on. Because of the complexity of the groundwater system shown in Chapter 2, and the inability to differentiate between drainage and crop evapotranspiration in Chapter 3, we were unable to successfully model these environments. However, it has outlined key factors that are important to account for when modelling these systems which will be explored in this chapter.

\subsection{Introduction}

Ongoing uncertainty in both rain fed and irrigation water supply is challenging New Zealand's horticultural industry, as discussed in Chapter 1. Improved irrigation in terms of efficiency is required to overcome these problems, in which modelling is a vital tool for exploring the impact of different management options under these changing conditions. Models are capable of considering the impacts of land use (such as horticulture) on ecosystem services at both a farm and catchment scale. We particularly focus on how our findings could improve horticultural representation in such models that represent crop 
evapotranspiration, as there is a need to better represent the impact of changing canopy structure and canopy evolution.

\subsubsection{Estimating evapotranspiration}

There have been a large number of methods developed over the years to estimate evapotranspiration from different climate variables (for example; Allen et al., 1998; Monteith, 1965; Penman, 1948; Priestley \& Taylor, 1972; Shuttleworth \& Wallace, 1985). Of these the modified FAO-56 PenmanMonteith (hereafter FAO-56 method) equation is the most commonly used in horticulture to estimate crop evapotranspiration (Allen 2004; Kumar, Jat, and Shankar 2012). The FAO-56 standard equation builds on the Penman-Monteith equation (Penman 1948). It estimates evapotranspiration from measured meteorological variables (humidity, air temperature, solar radiation and wind speed), and properties of a hypothetical actively growing green grass 'reference' crop (ETo) (Allen et al., 1998). The reference crop has an assumed height of $0.12 \mathrm{~m}$, a fixed surface resistance of $70 \mathrm{sm}^{-1}$ and an albedo of 0.23 (Allen et al., 1998). Since the reference crop (ETo) is not affected by crop types or any other crop characteristic, the only factors influencing ETo are climate parameters (Allen et al., 1998). Therefore, ETo is generally higher under warmer and windier conditions due to high radiation, air temperature, wind speed and low humidity. ETo (mm day-1) can be calculated using Equation 1.

Equation 1: $\mathrm{ET}_{\mathrm{o}}=\frac{0.408 \Delta\left(R_{\mathrm{n}}-G\right)+\gamma \frac{900}{\mathrm{~T}+273} \mathrm{U}_{2}\left(\mathrm{e}_{\mathrm{s}}-\mathrm{e}_{\mathrm{a}}\right)}{\Delta+\gamma\left(1+0.34 \mathrm{u}_{2}\right)}$

Where $R n$ is net radiation at the crop surface ( $M \mathrm{Jm}^{2}$ day $\left.{ }^{-1}\right), G$ is soil heat flux density $\left(M J m^{2}\right.$ day $\left.{ }^{-1}\right), T$ is mean daily air temperature at $2 m$ height $\left({ }^{\circ} \mathrm{C}\right), u_{2}$ is wind speed at $2 m$ height $\left(m s^{-1}\right), e_{s}$ is saturation vapour pressure $(\mathrm{kPa}), e_{\mathrm{a}}$ is actual vapour pressure ( $\mathrm{kPa}$ ), $e_{\mathrm{s}}-\mathrm{e}_{\mathrm{a}}$ is the saturation vapour pressure deficit $(\mathrm{kPa}), \Delta$ is slope vapour pressure curve $\left(\mathrm{kPa}{ }^{\circ} \mathrm{C}^{1}\right)$, and $\mathrm{Y}$ is psychrometric constant $\left(\mathrm{kPa}{ }^{\circ} \mathrm{C}^{1}\right)$. The parameters of the equation are defined in Chapter 3 of Allen et al. (1998).

The reference ETo estimated by Penman-Monteith can be used to estimate crop-specific evapotranspiration (ETc) through the use of a crop coefficient factor $(\mathrm{Kc})$. Kc values incorporate the different types of crops and their growth stages, where these values can be retrieved from look-up tables (Allen et al. 1998). In the crop coefficient method, ETc is calculated by multiplying ETo by 
Kc. The Kc value incorporates differences in evaporation and transpiration between the crop (e.g., apple) and the reference grass crop.

Allen et al. (1998) has further developed the crop coefficient, to the dual crop coefficient which accounts for the basal crop transpiration: Kcb (eg: apple), and the soil evaporation: $\mathrm{Ke}$. Where $\mathrm{Kc}=\mathrm{Kcb}+\mathrm{Ke}$. Similar to the $\mathrm{Kc}$ value, both Kcb and Ke coefficients can be retrieved from look-up tables (Allen et al. 1998). However, all of the crop coefficient values provided by Allen et al. (1998) are generic and do not account for differences in crop variety, trellis design, tree architecture, orchard design factors, and most importantly, light interception and LAI which has been identified in literature (Goodwin and Whitfield 2004; McClymont et al. 2009; O'Connell et al. 2008). The results from Chapter 2 and 3 clearly show that trellis systems cause differences in LAI and light interception, as well as show differences in soil water content for each trellis system. LAI and light interception were able to describe trends found in the soil water content, suggesting that they are related. Therefore, we cannot assume that the generic values for crop coefficients suggested by Allen et al. (1998) are suitable for these growing systems. These suggestions have been backed up by previous studies on apples (O'Connell et al. 2008) and grapes (McClymont et al. 2009; Williams and Ayars 2005).

The authors have shown that Kcb is directly related to effective area of shade (EAS), which is a daily averaged value of canopy light interception of photosynthetically active radiation (PAR), where measurements were taken at three regular intervals during the day: 09:00, 12:00, 15:00, and averaged. Daily EAS values were estimated using regression analysis of EAS measurements taken throughout the season, separated into two stages of canopy development (budburst to flowering, and flowering to harvest). Studies have shown that crop water use is linearly related to ETo weighted by EAS in 'Pink Lady' apples (O'Connell et al. 2008), 'Thompson Seedless' grape (Williams and Ayars 2005), and peach (Ayars et al. 2003; Goodwin et al.,2006). EAS provides a universal way of accounting for differences in orchard designs and trellis systems, as well as providing an easy variable to measure on-site compared with Allen et al. (1998) crop coefficient values. In addition, this method backs up the findings from this thesis, and better incorporates different trellis systems and their differing light environments and LAI. Therefore, this method will be used to 
estimate ETc for the apple trellis systems if they were in well-watered conditions, and further prove the unexpected results in Chapter 3. As a result of the data technicalities at the young Syrah grape site, only apples will be used as a modelling example in this chapter.

\subsubsection{Water balance scenario}

A simple water balance calculation can be carried out for the apple plots to investigate drainage and crop evapotranspiration effects that were shown in the soil water balance results. The water balance can be estimated by accounting for water flow in and out of the soil profile, as well as the measured temporal variation in soil moisture content in Chapter 2. Water flow into the soil profile is described by rainfall and irrigation. Water flow out of the soil profile is described by drainage and crop evapotranspiration. The soil sward (between grass/weed mixes) is considered part of the reference crop explained above. Overall, these variables cause the flux that we observe in the soil water content results.

A change in soil water content can be described by:

$\Delta S W C=(-v e)$ Drainage $+(-v e)$ Crop evapotranspiration + Irrigation + Rainfall

Since we have field measurements of changes in SWC, irrigation and rainfall, this can be rearranged to calculate drainage and crop evapotranspiration:

Drainage + Crop evapotranspiration $=\Delta S W C+$ Irrigation + Rainfall

\subsection{Methodology}

\subsubsection{Estimating reference evapotranspiration}

The FAO-56 Penman-Monteith equation (Equation 1) was used to estimate reference evapotranspiration (ETo). Variables required to estimate ETo were hourly means of solar radiation $\left(\mathrm{MJ} \mathrm{m}^{-2} \mathrm{day}^{-1}\right)$, air temperature $\left({ }^{\circ} \mathrm{C}\right)$, wind speed at $2 \mathrm{~m}$ above ground level $\left(\mathrm{ms}^{-1}\right)$, and humidity (\%). ETo can be retrieved from NIWA weather stations, which calculates potential evapotranspiration (PET), based on the Penman-Monteith equation, which differs slightly to the FAO-56 Penman-Monteith equation. As outlined in the introduction, the FAO-56 method incorporates the use of a 'reference crop' which provides values that are more consistent with measured crop data worldwide (Allen 2004). Since there are 
weather stations located at both Evenden orchard and Te Awa vineyard, whereas the NIWA climate stations are located further away, the manual calculation using FAO-56 Penman-Monteith equation was carried out using the on-site climate station variables.

All variables were able to be collected from the local climate sites, apart from solar radiation. The NIWA site was used to retrieve solar radiation data for both sites, which was called Maraekakaho Cws (-39.663795, 176.68206).

\subsubsection{Estimating crop evapotranspiration}

As stated in section 1.1, the estimation of crop evapotranspiration will be calculated based on the effective area of shade (EAS) method provided by O'Connell et al. (2008). Unlike the methods provided above, light interception was not recorded at three time periods throughout the day. Instead, light interception was measured in diffuse light at various periods throughout the season. This negates the need for measurements during three periods mentioned above as it removes the sun angle and shade effects.

Firstly, daily effective area of shade (EAS) was estimated using regression analysis of EAS (light interception) measurements taken throughout the season, starting at budbreak (10/09/2019 for vee and tall spindle, and 14/09/2019 for planar). Maximum light interception values were set for all different trellis systems based on findings in Chapter 3 . The best-fit models were used to estimate daily EAS. Linear regression was fitted for the planar system, and a polynomial regression for the vee and tall spindle. Equations and R-squared values can be found in Table 11.

Table 11; Regression relationships to calculate daily effective area of shade $(y)$ from light interception $(x)$ measurements taken throughout the season. The regression equation and $R$-squared values are shown.

\begin{tabular}{|c|c|c|}
\hline & Equation & R-squared value \\
\hline Planar & $y=0.1773 x+10.288$ & 0.90 \\
\hline Vee & $y=-0.002 x^{2}+0.67 x+9.95$ & 0.94 \\
\hline Tall Spindle & $y=-0.002 x^{2}+0.565 x+6.09$ & 0.92 \\
\hline
\end{tabular}


ETo was estimated using the FAO-56 equation described above. Since the results from this research could not single-out crop evapotranspiration and drainage from the changes in soil water content, a new relationship could not be established. Instead, the suggested equation provided by O'Connell et al. (2008) will be used to show what ETc was expected to be under well-irrigated conditions. The equations is shown below:

Apple: $\mathrm{ETc}=1.15 \times \mathrm{EAS} \times \mathrm{ETO}+0.1 \times \mathrm{ETo}\left(\mathrm{O}^{\prime}\right.$ Connell et al. 2008)

This equation was used to incorporate different orchard designs and trellis systems through the use of light interception measurements. However, these equations assume well-watered crops, which in this research is not true. We expect that due to the waterlogging observed in Chapter 2, that actual ETc, particularly of the planar and vee, will be a lot lower than what will be calculated using these equations. By applying these methods to the data, it will help further highlight the unexpected trends found in Chapter 2.

\subsubsection{Methods for a simple water balance}

\section{Water inputs}

Water inputs to the soil profile constitute rainfall and irrigation. Hourly rainfall data $(\mathrm{mm} / \mathrm{hr}$ ) were obtained from climate stations (at Evenden orchard) within $500 \mathrm{~m}$ of the sites for the $2019 / 2020$ monitoring period. Rainfall was assumed to be uniform among plots in all the apple sites. It is important to acknowledge that the meteorological variables automatically-collected can be subject to error. For example, the rainfall data are measured by a tipping bucket rain gauge which can underestimate the amount of rainfall during heavy rain events, as the bucket can sometimes not keep up with the rain volume frequency. And vice versa during small rainfall events where evaporation might occur before the rainfall is recorded.

Irrigation volumes $(\mathrm{mm} / \mathrm{hr}$ ) were combined with rainfall to give a total water input to the soil profile. At Evenden orchard, irrigation volumes were recorded weekly by Fruition Horticulture (Hastings, NZ), a horticulture advisory and irrigation scheduling service. All three trellis systems at Evenden Orchard were run from the same irrigation pump and based off the same schedule recommendations. The saturation point was identified by Fruition as $308 \mathrm{~mm}$, in which the refill 
point is at $148 \mathrm{~mm}$. Irrigation recommendations were based on the emitter rate of $11.7 \mathrm{~L} / \mathrm{plant} / \mathrm{hr}$. The actual emitter rates at all three trellis system sites were $8.3 \mathrm{~L} / \mathrm{hr}$, spaced at $40 \mathrm{~cm}$. The amount of irrigation that each tree received during an irrigation event differed due to the differences in tree spacing, and therefore the number of emitters per tree (Table 12).

Table 12; Showing the number of emitters per plot, and emitter rates for the three different apple trellis systems.

\begin{tabular}{|llccl|}
\hline & $\begin{array}{l}\text { Tree } \\
\text { spacing } \\
(\mathrm{m})\end{array}$ & $\begin{array}{c}\text { \# emitters } \\
\text { per area }\end{array}$ & $\begin{array}{l}\text { Emitter rate } \\
\text { per tree area } \\
(\mathrm{L} / \mathrm{hr})\end{array}$ & $\begin{array}{l}\text { Emitter rate } \\
\text { per tree area } \\
(\mathrm{mm} / \mathrm{hr})\end{array}$ \\
\hline Planar & 3 & 8 & 66.4 & 11.1 \\
\hline Vee (2 trees) & 1 & 3 & 24.9 & 7.1 \\
\hline Tall Spindle & 1.3 & 3 & 24.9 & 5.5 \\
\hline
\end{tabular}

Irrigation events (timing and duration) were the same for all three trellis systems. However, the volume that each tree received differed, as shown in Table 12. Irrigation events were manually identified from December-onwards when there was an increase in SWC that did not correlate with rainfall or nighttime recharge from the groundwater, which typically coincided with midday when SWC reached a critical low point. The number of hours irrigated per week was calculated by dividing the total amount of irrigation by the emitter rate. The hours were then associated with the irrigation events identified. Lastly, the amount of irrigation received per tree system was calculated based on the ratio between the recommended emitter rate by Fruition $(11.7 \mathrm{~mm} / \mathrm{hr})$, and the actual emitter rate calculated for each trellis system (Table 12). The extrapolated data are subject to error and might not account for issues such as blocked drip lines which can overestimate the amount of irrigation applied to a tree, as well as not identifying irrigation events accurately. Hourly recordings of irrigation would be recommended for future work. 


\section{Water outputs}

The relationship that we observe in Chapter 2, Section 2.3.3, Figure 22 of positive cumulative changes in soil water content is a function of both drainage (or groundwater upwelling) and crop evapotranspiration, as described in the equation above. Therefore, to further investigate trends in drainage among the different trellis system sites, and in an attempt to single out drainage, crop evapotranspiration was estimated based on the assumption that the trees were from a well- but not over-watered environment, despite knowing this was unlikely to be the case. In this well-watered scenario, based on the EAS equations above, we would expect the vee system, followed by the tall spindle to have the highest evapotranspiration rate, followed lastly by the planar, because this mirrors differences in light interception. Therefore, in terms of the water balance, we would expect the tall spindle and vee system to have lower drainage volumes as the plant is transpiring more than the planar, in addition to having less irrigation applied per tree. The amount of irrigation applied per tree is greatest in the planar, further supporting its expected higher drainage rate.

\section{$4.3 \quad$ Results}

\subsubsection{Estimated crop evapotranspiration (ETC) adjusted by light interception results}

As expected, when applying the EAS adjusted equations, the differences in ETc followed the same trends as the light interception results. These results assume that the plants are in a well-watered environment (Figure 35). At the apple sites, the planar canopy showed smaller fluctuations and amounts of ETc $(\mathrm{mm})$ over the season than the vee and tall spindle system, due to lower light interception of the younger canopy (Figure 355). The estimated ETc maximum of the tall spindle and vee appears to be double that of the planar canopy. In the first 30 days after budburst (10 September), all three trellis systems had similar ETc, due to the canopy not being fully established. 


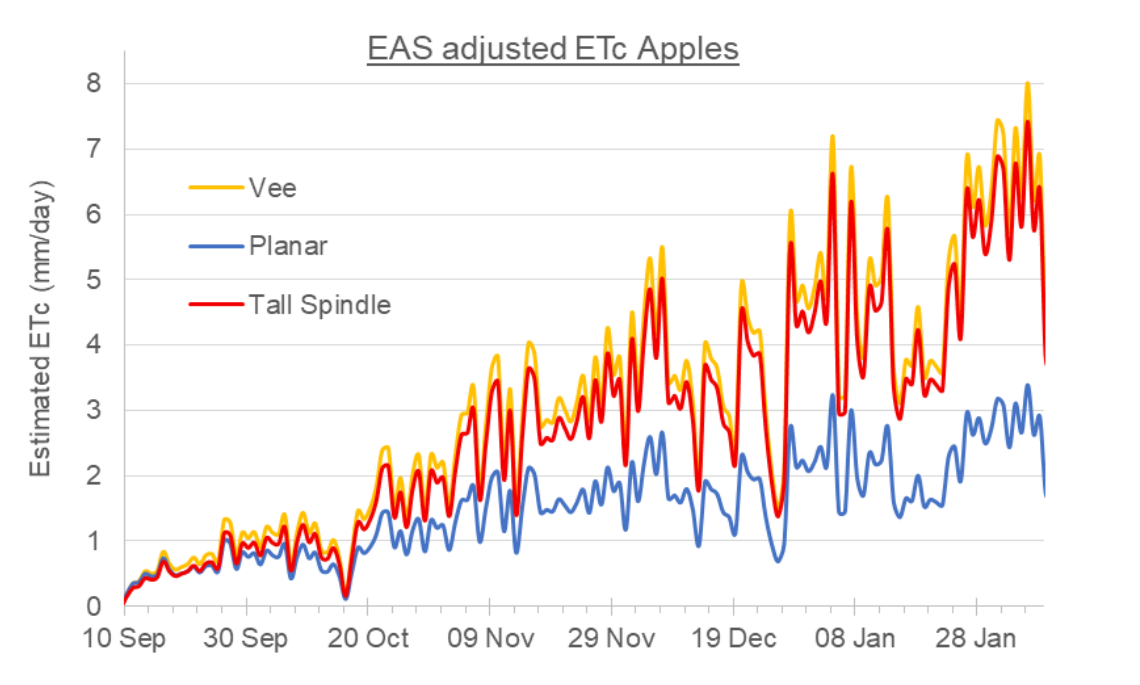

Figure 35; Effective area of shade (EAS) adjusted evapotranspiration for the three apple trellis systems over the season.

\subsubsection{Cumulative seasonal relationships}

The cumulative ETc results (Figure 36) for the apple trellis systems show the trend between each trellis system clearer. The tall spindle and vee system have a similar increasing slope of cumulative ETc, where the tall spindle had a slightly lower cumulative ETc maximum due to lower light interception values. Whereas the planar has a lower cumulative ETc maximum, as the result of a lower gradient.

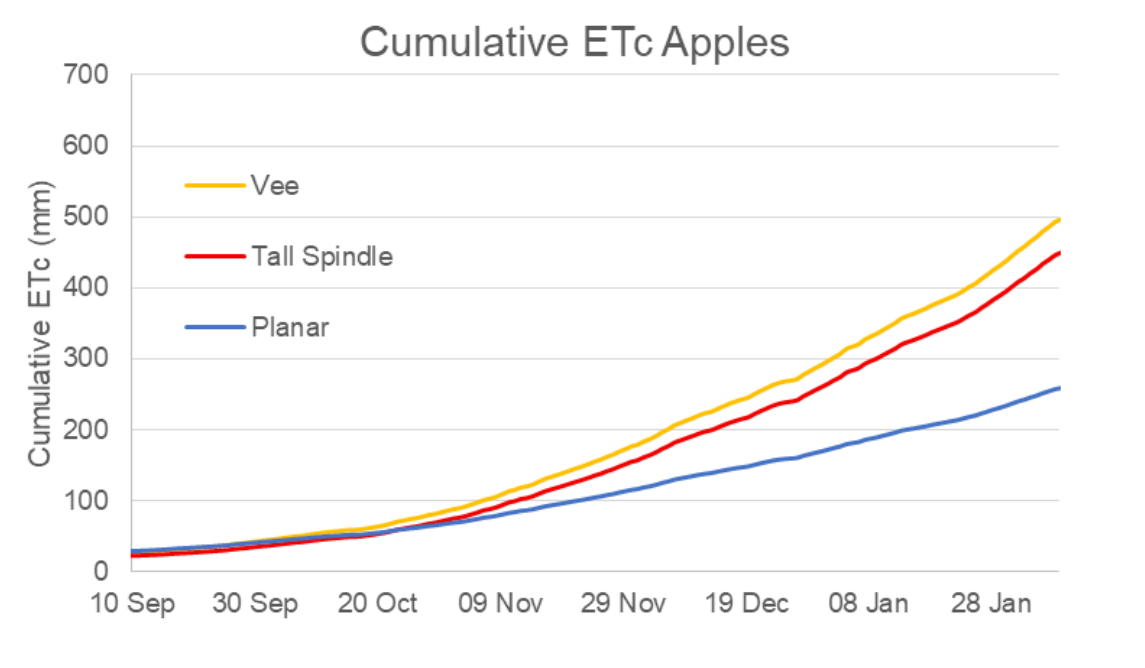

Figure 36; Accumulative crop evapotranspiration for the 2019/2020 season for the three different apple trellis systems.

\subsubsection{Estimated drainage in a well-watered scenario}

The results from this hypothetical water balance scenario indicated that if the crops were in well-watered conditions, then from our SWC results, the drainage 
trends can be predicted (Figure 37). This suggests that the planar system had the largest drainage as a result of the lower ETc rates as calculated in Section 4.3.1. This was followed by the tall spindle, and lastly the vee. The vee has the lowest expected drainage as it was estimated to have the largest ETc rates, meaning that soil water content losses were mostly attributed to transpiration, rather than drainage in this scenario.

Apart from the large rain event on October $16^{\text {th }}$, which is shown in the figure by a near-vertical increase in drainage, the drainage trends of all three trellis systems show similar increases throughout the season. The trends of drainage and ETc showed in Figure 37, and Figure 36, differ to those observed in Chapter 2, Section 2.3.3, Figure 22. This further gives confidence that the crops were most likely sometimes growing in overly-watered environments, which will be explored further in the discussion.

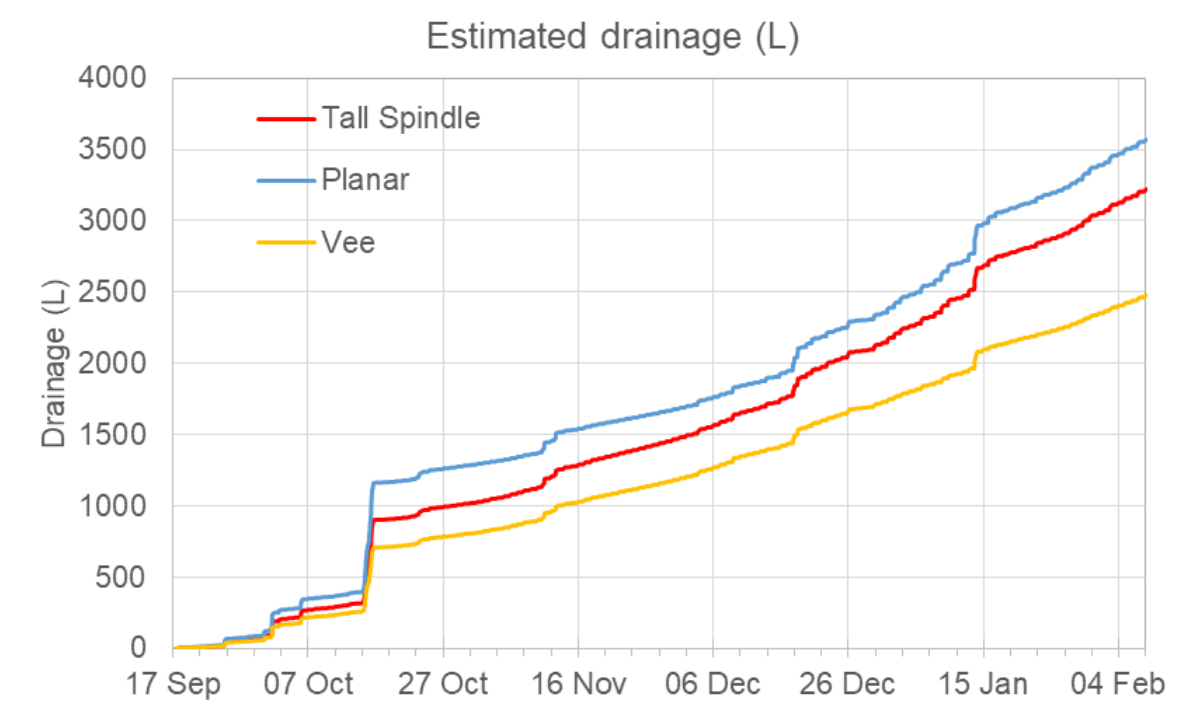

Figure 37: Estimated drainage for three different apple trellis systems based on a water balance scenario.

\subsection{Discussion}

The estimated drainage in Figure 37, and the estimated crop evapotranspiration (Figure 36), suggests that at Evenden orchard, the trees were not grown in a well-watered environment (eg, field capacity). These models were developed to investigate the unexpected trend in cumulative soil water content (Chapter 2 , Section 2.3.3, Figure 22) from mid-December when irrigation was applied. The measured trends of cumulative change in soil water content (accounts for both 
crop evapotranspiration and drainage) in Chapter 2, Section 2.3.3, Figure 22, showed that the tall spindle had the largest change, followed by the vee and planar which were near-identical suggesting that the tall spindle was using more water that vee.

The estimated ETc results (Figure 35) suggest that because of their similar light interception results, the tall spindle and vee trees should have similar evapotranspiration rates, and therefore similar changes in SWC. However, the vee site did not meet this expectation. The tall spindle showed the largest change in SWC which was expected, and can be explained by high transpiration rates due to its high light interception and well-watered environment, as well as drainage. Whereas the vee system showed much lower changes in SWC, which suggests that it was transpiring less than expected (Figure 22). This further backs up data presented in early chapter suggesting that the vee site was over-irrigated, which in combination with its already-high water table, may have caused waterlogging and an anaerobic environment. The vee trees appear to have responded to this anaerobic environment by reducing transpiration, which explains the unexpected trend shown in Figure 22 from December onwards. In addition, the matric potential results in Figure 13 clearly show that the vee site was at saturation the majority of the season.

The planar system has the lowest change in SWC throughout the majority of the season. This follows the same trend as what was expected in the estimated ETc, as the planar system intercepted the lowest amount of light because of its younger age. In addition, as shown in the matric potential results (Figure 13), the soil remained mostly at saturation for the duration of the season. There was no indication from the tree or crop that the stress levels reached were great enough to cause yield or quality depression (as all results were equal), which suggests that the changes in SWC diurnally were sufficient to prevent continual anaerobic conditions. The estimated drainage results suggest that the planar site had the largest drainage due to the amount of water being applied per plant, and the lower ETc rates, which is shown in Figure 37.

Overall, due to the difficulties in differentiating between crop evapotranspiration and drainage when looking at differences in soil water content, we were unable to accurately and confidently model the soil water balance that was proposed in 
the original research question. However, these results have highlighted the complexities in modelling such systems, especially in an environment that we expected, with reason, to be relatively homogenous. It has shown that even within an orchard or vineyard block scale, groundwater and soil environments can be dramatically different over small spatial scales. By applying a simple water balance equation, and estimating what crop evapotranspiration would be in a well-watered environment, we were able to further back up the explanations for the unexpected trends seen in soil water content.

In the future, research on the plant physiological response to water stress points, both deficit and saturation, would be valuable to enable efficient and optimal irrigation scheduling and modelling. When modelling these complex systems in areas with water tables relatively near the surface, it is essential to account for groundwater contributions and broader responses, as this thesis has given evidence that it strongly affects the plant's water balance and functioning in terms of transpiration. 


\section{$5 \quad$ Chapter 5: Final Conclusions}

The development of new innovative horticultural designs and growing systems for apples and grapes is driven by the principle that increased light interception can increase yield returns (Palmer et al., 2002). Increased light interception is achieved by a combination modifications to canopy architecture, keeping LAI within the optimum range (Palmer, 1989), and differing orchard/vineyard designs (changes in row width, canopy architecture etc). There is a lack of knowledge on how these different designs and growing systems affect crop evapotranspiration, and ultimately soil water moisture levels, which in turn influence evapotranspiration. In addition, when modelling the soil water balance in these complex environments, factors such as light interception need to be better incorporated, as this affects photosynthesis, a strong driver of crop evapotranspiration (McClymont et al. 2009; O'Connell et al.,2006; O'Connell et al. 2008). This research aimed to examine the effect of canopy architecture on crop evapotranspiration and water use in Scilate apples and Syrah grapes to provide guidance to improve modelled crop evapotranspiration and better understand the overall soil water balance. The effects of the trellis system (apple), and age and soil type (grape), on light interception and leaf area, were investigate to identify how best to incorporate these factors into soil water balance modelling. Three research objectives were set to achieve the aim above:

- The first objective was to understand how different orchard designs, environments and trellis systems affect the soil water balance and crop evapotranspiration. Three trellis systems: vee, planar and tall spindle which were considered to have homogenous soils were evaluated in Scilate apples, and two differently aged Syrah grapes grown on different soils.

- The second objective was to quantify how orchard designs influence light interception and leaf area, as well as yield and fruit quality in Scilate apples and Syrah grapes.

- The third objective was to understand how modelled crop evapotranspiration and the soil water balance can be improved 
on to account for different orchard designs, environments and trellis systems.

In summary, the research aim and objectives set at the start of this thesis have been met. Through the analysis of light interception, leaf area and leaf area index, fruit yield and quality, it is now understood that these variables differ between different trellis systems in Scilate apples, and different soil types and aged-vines in Syrah grapes. In addition, these variables can be attributed to the differences measured in the soil water content for the trellis systems in apples, and different soil types in grapes. With the exception of the apple vee system, which was shown to be over-irrigated, causing anaerobic conditions that limited transpiration. However, this anaerobic "stress" was not evident in yield, fruit quality or plant appearance as would be expected. Overall, illustrating the complex system that is the soil-plant-atmosphere continuum.

From the results of this thesis, it seems clear the apple vee system intercepted the largest amount of light (54\%), as well as possessing the largest LAI (3.2). Whereas the tall spindle intercepted $50 \%$ of light, followed by the planar site (36\%). The planar system had the lowest light interception, primarily assumed to be because of it being one growth year behind the other systems. Breen et al. (2020), has shown that planar systems in their fourth leaf can intercept $56 \%$, which suggests that the planar system is likely to have exceeded that of the vee if it was the same age. The planar also showed the lowest LAI result (1.3), followed by the tall spindle (1.6). These results were mostly controlled by the planting density of each trellis system, with vee being the highest. This highlights that if the vee system continues to exceed its LAI of 3.2 , then this could impact light interception, yield and fruit quality as a result (Wagenmakers, 1995). In addition to light interception and LAI results, fruit quality in terms of dry matter content did not differ among all three systems. The vee system showed the largest projected fresh weight yield per hectare (141 tonnes/ha), which reflected the light interception and LAI results, followed by the tall spindle (108 tonnes/ha), and lastly the planar (54 tonnes/ha). However, the planar system was limited because of it being a year younger ( $3^{\text {rd }}$ leaf) compared to the other systems (4th leaf). This limitation was evident in all results. 
The trend between high light interception, leaf area and high yields was also shown in the grapes. The young Syrah, planted on silt-loam soil, intercepted the largest amount of light (36\%), had the largest LAI (1.3), and the highest yield per hectare (9.6), whereas the old Syrah had the lowest light interception (22\%), LAI (0.7), and therefore yield (8.1 tonnes/ha).

From the measured matric potential and soil water content results, it is now understood that changes in SWC are occurring as a result of differences in both crop evapotranspiration, and variable soil drainage properties and associated groundwater responses. Despite our best efforts to limit heterogeneity between the apple sites, such as soil type and groundwater, the results made it clear that these heterogeneities did exist. At Evenden orchard, both the vee and planar soils remained mostly at saturation throughout the season due to a high water table and over-irrigated. In addition, cumulative changes in SWC strongly suggest that when irrigation was applied, these saturated conditions were inhibiting plant water uptake (transpiration) in the planar and vee trees, causing unexpected SWC results. These results showed that the planar and vee sites had similar changes in SWC, which is unexpected as the vee system should be much larger as it intercepted $54 \%$ of incoming light compared with $36 \%$ in the planar. The tall spindle site had better-draining soils, in combination with a lower water table as shown by the matric potential results which did not reach saturation, unlike the other sites. In these well-and not over-watered conditions, the tall spindle tree was able to transpire actively for significantly longer periods, resulting in a larger change of SWC compared to the other two systems.

In the period from budburst until mid-December when irrigation was first applied, trends shown in the changes of SWC were similar to the trends shown in light interception and LAI. This suggests that if the vee and planar apple sites were not kept at saturation, then the changes in SWC and crop evapotranspiration would have reflected that shown by the light interception and LAI results, as suggested by O'Connell et al. (2008) and McClymont et al. (2009).

At the grape sites, interpretation of the young Syrah matric potential and SWC results were unfortunately hindered by instrument failure one month into the experiment, which meant that there was insufficient data to warrant a 
discussion. However, the old Syrah SWC results showed large fluxes in SWC due to both rainfall and assumed irrigation events (irrigation was not recorded at this site). Daily evapotranspiration trends were evident by small step-increases in changes of SWC. The old Syrah results were not able to be compared with the young Syrah due to the lack of SWC results. Therefore we were unable to show whether the trends found in light interception and LAI were related to crop evapotranspiration.

Estimations of apple crop evapotranspiration using light interception results based on O'Connell et al. (2008) and McClymont et al. (2009) methods, showed that we would expect the vee and tall spindle to have similar rates of evapotranspiration, in comparison to the planar. These expectations differed to what the changes in soil water content results showed us. When a simple water balance approach was applied to our measured SWC, this further proved that in the vee and planar sites, the trees were not transpiring at expected rates.

This study has clearly identified the differences in apple trellis systems, and age and soil type grapes through light interception, leaf area index, yield, and fruit quality results. Changes in the soil water content can be attributed to both differences in crop evapotranspiration, as well as differences in drainage from saturated, to well-watered environments. Further work in this area will help to better incorporate these complex variables into a more accurate modelled scenario, allowing for more efficient irrigation practices to occur, and therefore, improved plant and environment health.

\subsection{Future directions and recommendations}

- To differentiate the effects that crop evapotranspiration and drainage have on changes in the soil water content, a similar experiment combined with the use of sap flow meters would give a more conclusive understanding of plant transpiration, helping close the water balance to understand drainage and groundwater effects, and clarify when the plants were in overwatered, optimally watered, or under watered conditions.

- To further validate these findings, repeat measurements when the trees have reached full production (particularly the planar) would give a better 
understanding of the trends that we see in evapotranspiration and soil water content currently.

- Treat different canopy/orchard design blocks as different irrigation blocks. 


\section{References}

A.G Aitken, I. J. Warrington. 2020. Fresh Facts New Zealand Horticulture 2019.

Allen, R. 2004. Penman-Monteith Equation. in Encyclopedia of Soils in the Environment.

Allen, Richard G., L. S. Pereira, D. Raes, and M. Smith. 1998. Crop Evapotranspiration: Guidelines for Computing Crop Requirements.

Auzmendi, I., M. Mata, G. Lopez, J. Girona, and J. Marsal. 2011. Intercepted Radiation by Apple Canopy Can Be Used as a Basis for Irrigation Scheduling. Agricultural Water Management.

Ayars, J. E., R. S. Johnson, C. J. Phene, T. J. Trout, D. A. Clark, and R. M. Mead. 2003. Water Use by Drip-Irrigated Late-Season Peaches. Irrigation Science.

Bagstad, Kenneth J., Darius J. Semmens, Sissel Waage, and Robert Winthrop. 2013. A Comparative Assessment of Decision-Support Tools for Ecosystem Services Quantification and Valuation. Ecosystem Services.

Baïram, Emna, Christian leMorvan, Mickaël Delaire, and Gerhard Buck-Sorlin. 2019. Fruit and Leaf Response to Different Source-Sink Ratios in Apple, at the Scale of the Fruit-Bearing Branch. Frontiers in Plant Science.

Barnes, C., T. Tibbitts, J. Sager, G. Deitzer, D. Bubenheim, G. Koerner, and B. Bugbee. 1993. Accuracy of Quantum Sensors Measuring Yield Photon Flux and Photosynthetic Photon Flux. HortScience.

Behboudian, M. H., and T. M. Mills. 2010. Deficit Irrigation in Deciduous Orchards. in Horticultural Reviews.

Bell, J. P. 1987. Neutron Probe Practice. Network.

Bonhomme, R., and P. Chartier. 1972. The Interpretation and Automatic Measurement of Hemispherical Photographs to Obtain Sunlit Foliage Area and Gap Frequency. Israel Journal of Agricultural Research.

Breen, K. C., J. W. Palmer, D. S. Tustin, and D. C. Close. 2016. Artificial Spur Extinction Alters Light Interception by 'Royal Gala' Apple Trees. in Acta Horticulturae.

Breen, K. C., D. S. Tustin, J. W. Palmer, and D. C. Close. 2015. Method of Manipulating Floral Bud Density Affects Fruit Set Responses in Apple. Scientia Horticulturae. 
Breen, K. C., J. M. Wilson, M. J. Oliver, B. M. van Hooijdonk, D. S. Tustin, and G. A. Dayatilake. 2020. Illuminating the Relationship between Canopy Light Relations and Fruit Yield in Apple Planar Cordon Orchard Systems. Acta Horticulturae.

Buttaro, D., Y. Rouphael, C. M. Rivera, G. Colla, and M. Gonnella. 2015. Simple and Accurate Allometric Model for Leaf Area Estimation in Vitis Vinifera L. Genotypes. Photosynthetica.

Campbell, G. S., C. Calissendorff, and J. H. Williams. 1991. Probe for Measuring Soil Specific Heat Using A Heat-Pulse Method. Soil Science Society of America Journal.

Coelho, Eugênio F., Delfran B. Dos Santos, and Carlos A. V. De Azevedo. 2007. Sensor Placement for Soil Water Monitoring in Lemon Irrigated by Micro Sprinklers. International Water and Irrigation.

Cohen, Y., M. Fuchs, and G. C. Green. 1981. Improvement of the Heat Pulse Method for Determining Sap Flow in Trees. Plant, Cell \& Environment.

Cozzolino, Daniel, Wies U. Cynkar, Robert G. Dambergs, Meagan D. Mercurio, and Paul A. Smith. 2008. Measurement of Condensed Tannins and Dry Matter in Red Grape Homogenates Using near Infrared Spectroscopy and Partial Least Squares. Journal of Agricultural and Food Chemistry.

Demirsoy, Hüsnü. 2009. Leaf Area Estimation in Some Species of Fruit Tree by Using Models as a Non-Destructive Method. Fruits.

Doerflinger, Franziska C., William B. Miller, Jacqueline F. Nock, and Christopher B. Watkins. 2015. Relationships between Starch Pattern Indices and Starch Concentrations in Four Apple Cultivars. Postharvest Biology and Technology.

Eftekhari, M., B. Kamkar, and M. Alizadeh. 2011. Prediction of Leaf Area in Some Iranian Table Grape ( Vitis Vinifera L .) Cuttings by a NonDestructive and Simple Method. Science Research Reporter.

Elias, P. 1995. Stomata Density and Size of Apple Trees Growing in Irrigated and Non Irrigated Conditions. Biologia Plantarum 50(1):115-18.

Evert, Ray F., and Susan E. Eichhorn. 2013. Raven Biology of Plants.

Gaydon, A. G. 1967. Handbook of Chemistry and Physics 47th Edition. Physics Bulletin.

Ghosh, S. P. 2016. Internal Structure and Photosynthetic Activity of Different Leaves of Apple. Journal of Horticultural Science. 
Girona, Joan, Jesus del Campo, Merce Mata, Gerardo Lopez, and Jordi Marsal. 2011. A Comparative Study of Apple and Pear Tree Water Consumption Measured with Two Weighing Lysimeters. Irrigation Science.

Goodwin, I., D. Cornwall, and S. R. Green. 2015. Transpiration of Pear Trees and Implications for Irrigation Scheduling. in Acta Horticulturae.

Goodwin, lan, and D. M. Whitfield. 2004. The Relationship between Peach Tree Transpiration and Effective Canopy Cover. Acta Horticulturae 664(Irrigation of Hort. Crops).

Goodwin, lan, Desmond M. Whitfield, and David J. Connor. 2006. Effects of Tree Size on Water Use of Peach (Prunus Persica L. Batsch). Irrigation Science.

Green, S. R., I. Goodwin, and D. Cornwall. 2014. Evaporative Cooling Effects on Tree Transpiration. ISHS Acta Horticulturae 1038: VII(401-406).

Green, S. R., I. Vogeler, B. E. Clothier, T. M. Mills, and C. Van Den Dijssel. 2003. Modelling Water Uptake by a Mature Apple Tree. in Australian Journal of Soil Research.

Green, Steve, and Brent Clothier. 1998. The Root Zone Dynamics of Water Uptake by a Mature Apple Tree. Plant and Soil.

Green, Steve, Keith McNaughton, J. N. Wünsche, and Brent Clothier. 2003. Modeling Light Interception and Transpiration of Apple Tree Canopies. in Agronomy Journal.

Harper, S. 2015. Groundwater Level Changes in the Heretaunga and Ruataniwha Basins from 1994-2014.

HBRC (Hawke's Bay Regional Council). 2019. TANK - Draft Implementation Plan.

Hillel, Daniel. 1998. Environmental Soil Physics: Fundamentals, Applications, and Environmental Considerations.

Hsiao, T. C. 1993. Growth and productivity of crops in reltaion to water status. Acta Horticulturae.

J.E Jackson. 1980. Light Interception and Utilization by Orchard Systems. Pp. 2:208-267 in Horticultural Reviews.

J.W Palmer. 1986. The Measurement of Leaf Area in Apple Trees. The Journal of Horticultural Science 62:5-10. 
Jackson, Bethanna, Timothy Pagella, Fergus Sinclair, Barbara Orellana, Alex Henshaw, Brian Reynolds, Neil Mcintyre, Howard Wheater, and Amy Eycott. 2013. Polyscape: A GIS Mapping Framework Providing Efficient and Spatially Explicit Landscape-Scale Valuation of Multiple Ecosystem Services. Landscape and Urban Planning.

Jackson, J. E., and J. W. Palmer. 1979. A Simple Model of Light Transmission and Interception by Discontinuous Canopies. Annals of Botany.

Jackson, John E. 2011. Light Interception and Utilization by Orchard Systems. in Horticultural Reviews.

Kirkham, M. B. 2014a. Principles of Soil and Plant Water Relations, 2nd Edition.

Kirkham, M. B. 2014b. Principles of Soil and Plant Water Relations: Second Edition.

Kumar, R., M. K. Jat, and V. Shankar. 2012. Methods to Estimate Irrigated Reference Crop Evapotranspiration - A Review. Water Science and Technology.

Lakso, A. N. 1983. Morphological and Physiological Adaptations for Maintaining Photosynthesis under Water Stress in Apple Trees. in Effects of Stress on Photosynthesis.

Lakso, A. N., L. Corelli Grappadelli, J. Wunsche, and T. Robinson. 1997. Understanding Apple Tree Productivity - Balancing Carbohydrate Supply and Demand. Compact Fruit Tree.

Lakso, AN. 1980. Correlations of Fisheye Photography to Canopy Structure, Light Climate, and Biological Responses to Light in Apple Trees. Journal of the American Society for Hoticultural Science.

Lauri, P. E., E. Terouanne, and J. M. Lespinasse. 1997. Relationship between the Early Development of Apple Fruiting Branches and the Regularity of Bearing - An Approach to the Strategies of Various Cultivars. Journal of Horticultural Science and Biotechnology.

Lopez, F. B., and G. F. Barclay. 2017. Plant Anatomy and Physiology. in Pharmacognosy: Fundamentals, Applications and Strategy.

Maggs, D. H., and D. McE. Alexander. 2006. Tests of a Uranyl Oxalate Light Integrator for Use in Fruit Tree Canopies. The Journal of Applied Ecology.

Martínez, Gonzalo, Yakov A. Pachepsky, and Harry Vereecken. 2014. Temporal Stability of Soil Water Content as Affected by Climate and Soil Hydraulic Properties: A Simulation Study. Hydrological Processes. 
McArtney, S., J. W. Palmer, and H. M. Adams. 1996. Crop Loading Studies with 'Royal Gala' and 'Braeburn' Apples: Effect of Time and Level of Hand Thinning. New Zealand Journal of Crop and Horticultural Science.

McCaskill, Malcolm R., Lexie McClymont, lan Goodwin, Steve Green, and Debra L. Partington. 2016. How Hail Netting Reduces Apple Fruit Surface Temperature: A Microclimate and Modelling Study. Agricultural and Forest Meteorology.

McClymont, L., I. Goodwin, D. M. Whitfield, and S. Green. 2009. The Relationship between Grapevine Sap Flow, EToand Effective Area of Shade. Acta Horticulturae.

Miranda, Carlos, and J. Bernardo Royo. 2004. Statistical Model Estimates Potential Yields in ' Golden Delicious ' and 'Royal Gala ' Apples before Bloom. Journal of the American Society for Horticultural Science.

Monteith, J. L. 1965. Light Distribution and Photosynthesis in Field Crops. Annals of Botany.

Novák, Viliam, and Hana Hlaváčiková. 2019. Evaporation. in Theory and Applications of Transport in Porous Media.

O'Connell, M. G., I. Goodwin, and G. M. Dunn. 2006. Towards a Better Understanding of Crop Water Requirement in Orchards: A Case Study from the Goulburn Valley. Australian Journal of Experimental Agriculture.

O'Connell, M. G., I. Goodwin, and A. D. Wheaton. 2008. Response of Pink Lady Apple to Irrigation Estimated from Effective Area of Shade. in Acta Horticulturae.

Palmer, J. W. 1989. Canopy Manipulation for Optimum Utilisation of Light. Wagenmakers, $P$.

Palmer, J. W., D. J. Avery, and S. J. Wertheim. 1992. Effect of Apple Tree Spacing and Summer Pruning on Leaf Area Distribution and Light Interception. Scientia Horticulturae.

Palmer, J. W., and J. E. Jackson. 1977. Seasonal Light Interception and Canopy Development in Hedgerow and Bed System Apple Orchards. The Journal of Applied Ecology.

Palmer, J. W., J. N. Wünsche, M. Meland, and A. Hann. 2002. Annual DryMatter Production by Three Apple Cultivars at Four within-Row Spacings in New Zealand. Journal of Horticultural Science and Biotechnology.

Palmer, John W., F. Roger Harker, D. Stuart Tustin, and Jason Johnston. 2010. 
Fruit Dry Matter Concentration: A New Quality Metric for Apples. Journal of the Science of Food and Agriculture.

Penman, H. L. 1948. Natural Evaporation from Open Water, Hare Soil and Grass. Proceedings of the Royal Society of London. Series A, Mathematical and Physical Sciences.

Philip, J. R. 1969. Theory of Infiltration.

Poni, S., C. Intrieri, and O. Silvestroni. 1994. Interactions of Leaf Age, Fruiting, and Exogenous Cytokinins in Sangiovese Grapevines under Non-Irrigated Conditions. I.Gas Exchange. American Journal of Enology and Viticulture.

Priestley C., and R. Taylor. 1972. On the Assessment of Surface Heat Flux and Evaporation Using Large-Scale Parameters. Monthly Weather Review.

Rakowski, P., and M. Knowling. 2018. Heretaunga Aquifer Groundwater Model Development Report.

Reece, Jane B., Lisa A. Urry, Michael L. Cain, Steven A. Wasserman, Peter V. Minorsky, and Robert B. Jackson. 2010. Campbell Biology.

Reyes, Victor M., Joan Girona, and Jordi Marsal. 2006. Effect of Late Spring Defruiting on Net CO2 Exchange and Leaf Area Development in Apple Tree Canopies. Journal of Horticultural Science and Biotechnology.

Reynolds, Andrew G., and Justine E. Vanden Heuvel. 2009. Influence of Grapevine Training Systems on Vine Growth and Fruit Composition: A Review. American Journal of Enology and Viticulture.

Ritchie, J. T. 1998. Soil Water Balance and Plant Water Stress.

Robinson, T. L., E. J. Seeley, and B. H. Barritt. 1983. Effect of Light Environment and Spur Age on 'Delicious' Apple Fruit Size and Quality. Journal of the American Society for Horticultural Science.

Robinson, Terence L., and Alan N. Lakso. 1991. Bases of Yield and Production Efficiency in Apple Orchard Systems. Journal of the American Society for Horticultural Science.

Sala, Florin, Gicu Gabriel Arsene, Olimpia lordănescu, and Marius Boldea. 2015. Leaf Area Constant Model in Optimizing Foliar Area Measurement in Plants: A Case Study in Apple Tree. Scientia Horticulturae.

Shuttleworth, W. James, and J. S. Wallace. 1985. Evaporation from Sparse Crops- an Energy Combination Theory. The Quarterly Journal of the Royal 
Meteorological Society.

Smart, R. E., N. J. Shaulis, and E. R. Lemon. 1982. The Effect of Concord Vineyard Microclimate on Yield. I. The Effects of Pruning, Training, and Shoot Positioning on Radiation Microclimate. American Journal of Enology and Viticulture.

Smart, R., and M. Robinson. 1991. Sunlight into Wine: A Handbook for Winegrape Canopy Management. Sunlight into Wine: A Handbook for Winegrape Canopy Management.

Smart, Richard E. 1973. Sunlight Interception by Vineyards. American Journal of Enology and Viticulture.

Stats NZ. 2020. Goods and Services Trade by Country: Year Ended June 2019.

Syvertsen, J. P., and L. G. Albrigo. 1980. Seasonal and Diurnal Citrus Leaf and Fruit Water Relations. Botanical Gazette.

Tindal, James A.; Kunkel, James R.; Anderson, Dean E. 1988. Applied Soil Physics: Modeling Water, Solute, and Vapor Movement. Unsaturated Zone. Hydrology for a Scientists and Engineers.

Topp, G. C., and J. L. Davis. 2013. Time-Domain Reflectometry (TDR) and Its Application to Irrigation Scheduling.

Topp, G. C., J. L. Davis, and A. P. Annan. 1980. Electromagnetic Determination of Soil Water Content: Measurements in Coaxial Transmission Lines. Water Resources Research.

Trimble, Stanley, and Melvin Tyree. 2007. Matric Potential. in Encyclopedia of Water Science, Second Edition (Print Version).

Tustin, D. S., G. A. Dayatilake, K. C. Breen, and M. J. Oliver. 2012. Fruit Set Responses to Changes in Floral Bud Load - A New Concept for Crop Load Regulation. in Acta Horticulturae.

Tustin, D. S., and B. M. Van Hooijdonk. 2016. Can Light Interception of Intensive Apple and Pear Orchard Systems Be Increased with New Approaches to Tree Design? in Acta Horticulturae.

Tustin, D. S., B. M. van Hooijdonk, and K. C. Breen. 2018. The Planar Cordon New Planting Systems Concepts to Improve Light Utilisation and Physiological Function to Increase Apple Orchard Yield Potential. Acta Horticulturae. 
Tustin, S., P. Hirst, and I. Warrington. 1988. Influence of Orientation and Position of Fruiting Laterals on Canopy Light Penetration, Yield, and Fruit Quality of 'Granny Smith' Apple. Journal of the American Society for Horticultural Science.

Vollset, S. E., Goren, E., Yuan, C. W., Cao, J., Smith, A. E., Hsiao, T., ... \& Dolgert, A. J. 2020. Fertility, Mortality, Migration, and Population Scenarios for 195 Countries and Territories from 2017 to 2100: A Forecasting Analysis for the Global Burden of Disease Study. The Lancet.

Wagenmakers, P. S., and O. Callesen. 1995. Light Distribution in Apple Orchard Systems in Relation to Production and Fruit Quality. Journal of Horticultural Science.

Walker, Jeffrey P., Garry R. Willgoose, and Jetse D. Kalma. 2004. In Situ Measurement of Soil Moisture: A Comparison of Techniques. Journal of Hydrology.

Warrington, I. J., C. J. Stanley, D. S. Tustin, P. M. Hirst, and W. M. Cashmore. 1996. Light Transmission, Yield Distribution, and Fruit Quality in Six Tree Canopy Forms of 'Granny Smith' Apple. Journal of Tree Fruit Production.

Warrit, B., J. J. Landsberg, and M. R. Thorpe. 1980. Responses of Apple Leaf Stomata to Environmental Factors. Plant, Cell \& Environment.

Williams, L. E., and J. E. Ayars. 2005. Grapevine Water Use and the Crop Coefficient Are Linear Functions of the Shaded Area Measured beneath the Canopy. Agricultural and Forest Meteorology.

Wilson, Jack. 2020. Understanding the Pomology of the Planar Cordon Tree Architecture in Apple. Massey University, Palmerston North.

Wright, Harrison, Douglas Nichols, and Charles Embree. 2006. Evaluating the Accountability of Trunk Size and Canopy Volume Models for Determining Apple Tree Production Potential across Diverse Management Regimes. in Acta Horticulturae.

Wünsche, J. N., and A. N. Lakso. 2000. The Relationship between Leaf Area and Light Interceptor by Spur and Extension Shoot Leaves and Apple Orchard Productivity. HortScience.

Wunsche, J. N., A. N. Lakso, and T. L. Robinson. 1995.Comparison of Four Methods for Estimating Total Light Interception by Apple Trees of Varying Forms. HortScience.

Wünsche, Jens N., and Ian B. Ferguson. 2010. Crop Load Interactions in Apple" in Horticultural Reviews. 
Wünsche, Jens N., Alan N. Lakso, Terence L. Robinson, Fritz Lenz, and Steven S. Denning. 1996. The Bases of Productivity in Apple Production Systems: The Role of Light Interception by Different Shoot Types. Journal of the American Society for Horticultural Science.

Wünsche, Jens N., and John W. Palmer. 1997. Comparison of Non-Destructive Methods of Estimating Leaf Area in Apple Tree Canopies. in Acta Horticulturae.

Zhang, Lu, Glen R. Gr Walker, and Warrick R. Wr Dawes. 2002. Water Balance Modelling: Concepts and Applications. Regional Water and Soil Assessment for Managing Sustainable Agriculture in China and Australia. 